Aus der Klinik für Hämatologie und Medizinische Onkologie

(Komm. Direktor: Prof. Dr. med. G. Wulf)

der Medizinischen Fakultät der Universität Göttingen

\title{
In-ovo-Analysen zur Interaktion von \\ Hodgkin-Lymphomzellen \\ mit Monozyten
}

\author{
INAUGURAL-DISSERTATION \\ zur Erlangung des Doktorgrades \\ der Medizinischen Fakultät der \\ Georg-August-Universität zu Göttingen
}

vorgelegt von

Markus Maulhardt

aus

Nordhausen

Göttingen 2021 
Dekan:

\section{Betreuungsausschuss}

Betreuer/in:

Ko-Betreuer/in:

\section{Prüfungskommission}

Referent/in:

Ko-Referent/in:

Drittreferent/in:

Datum der mündlichen Prüfung:
Prof. Dr. med. W. Brück

Prof. Dr. rer. nat. D. Kube

Prof. Dr. rer. nat. J. Wilting

Prof. Dr. rer. nat. D. Kube

Prof. Dr. rer. nat. H. Reichardt

11.11.2021 
Hiermit erkläre ich, die Dissertation mit dem Titel

"In-ovo-Analysen zur Interaktion von Hodgkin-Lymphomzellen mit Monozyten"

eigenständig angefertigt und keine anderen als die von mir angegebenen Quellen und Hilfsmittel verwendet zu haben.

Göttingen, den 
Die Daten, auf denen die vorliegende Arbeit basiert, wurden teilweise publiziert:

Arlt A, von Bonin F, Rehberg T, Perez-Rubio P, Engelmann JC, Limm K, Reinke S, Dullin C, Sun X, Specht R, Maulhardt M et al. (2020): High CD206 levels in Hodgkin lymphoma-educated macrophages are linked to matrix-remodeling and lymphoma dissemination. Mol On$\operatorname{col} 14,571-589$ 


\section{Inhaltsverzeichnis}

Abbildungsverzeichnis ....................................................................................II

Tabellenverzeichnis .................................................................................. III

Abkürzungsverzeichnis...................................................................................

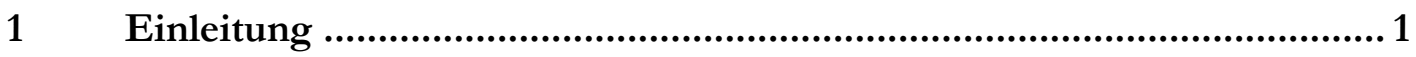

$1.1 \quad$ Einordnung und Biologie des Hodgkin-Lymphoms ..........................................................

1.2 Tumormikromilieu und tumorassoziierte Makrophagen ...................................................6

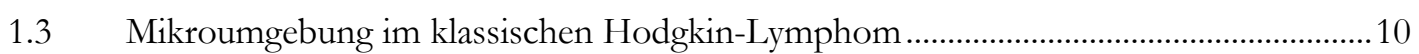

$1.4 \quad$ Klinik und Therapiemodalitäten des Hodgkin-Lymphoms.................................................12

$1.5 \quad$ Vorergebnisse der Arbeitsgruppe …………………………………………………….....14

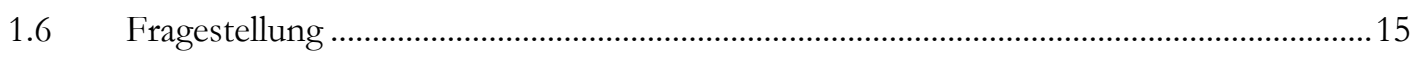

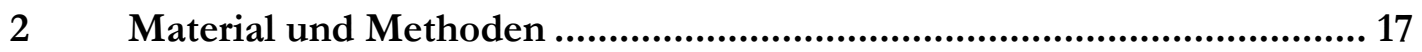

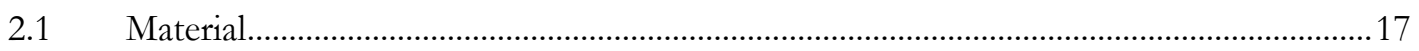

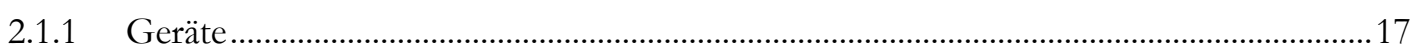

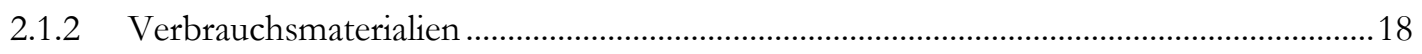

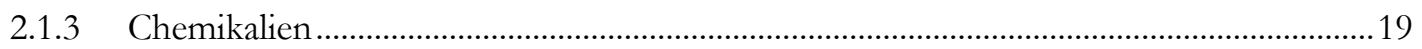

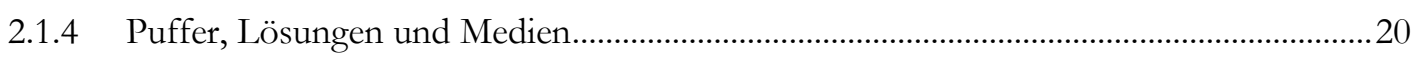

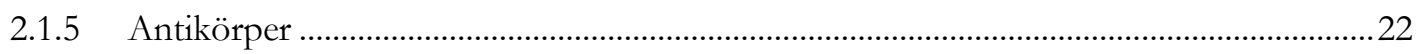

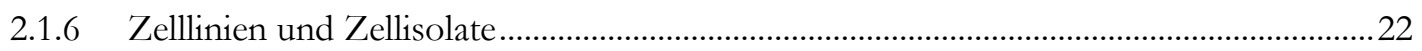

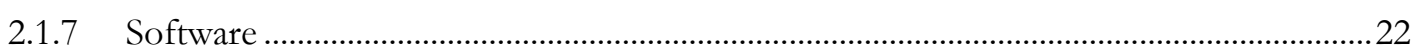

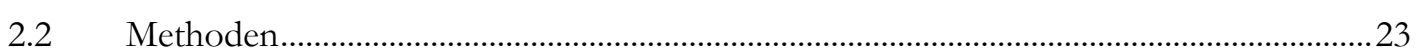

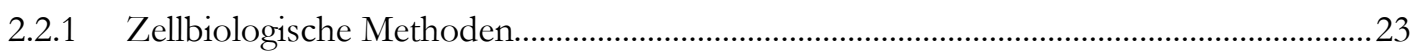

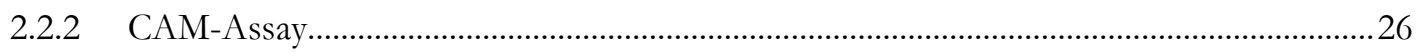

2.2.3 Histologische Aufarbeitung der CAM-Läsionen...........................................................2 28

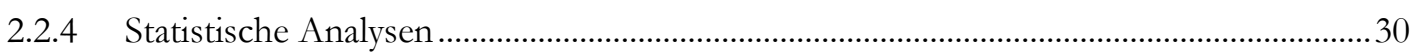

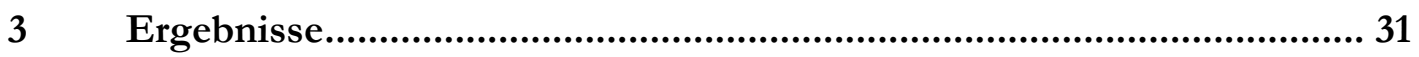

3.1 CD14+_PBMCs als Inokulum im CAM-Assay ............................................................

3.2 Morphologie von Mischtumoren aus HL-Zellen und Monozyten ...................................38

3.3 CD206-Expression nach In-ovo-Ko-Kultur mit CD14+_PBMCs nachweisbar..................51

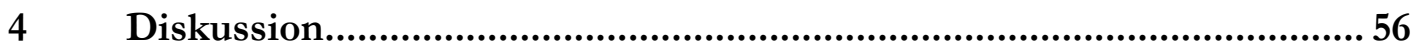

4.1 Ko-Kultur von L-428-HL-Zellen mit CD14+-PBMCs führt zu kleineren Tumoren und verringerter Einblutung im CAM-Assay..........................................................................56

4.2 CD206-Expression in Mischtumoren aus L-428 und CD14+_PBMCs ............................59

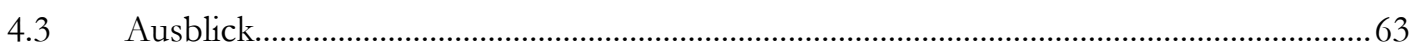

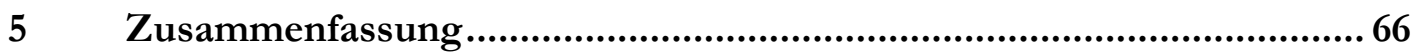

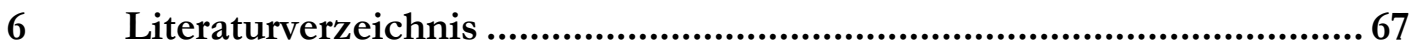




\section{Abbildungsverzeichnis}

Abbildung 1: Anreicherung an CD14+_PBMCs nach MACS.

Abbildung 2: CD14+_PBMCs (Monozyten) bilden blasige und transparente Läsionen nach vier Tagen auf der CAM.

Abbildung 3: Trichrom-Färbung von zwei monozytären CAM-Läsionen. 35

Abbildung 4: Monozyten können die Chorionmembran durchbrechen. 36

Abbildung 5: CD68-Expression in rein monozytärer CAM-Läsion. 37

Abbildung 6: L-428-CD14+_PBMCs-Mischlymphome sind kleiner als L-428-Lymphome auf der CAM.

Abbildung 7: CAM-Lymphome der HL-Zelllinie L-428 sind durch großflächige Einblutungen charakterisiert.

Abbildung 8: Aufsicht-Fotografien repräsentativer Mischtumoren aus HL-Zellen und Monozyten.

Abbildung 9: Morphologie zweier repräsentativer L-428-CAM-Lymphome.

Abbildung 10: Ternäre Kompartimentierung eines CAM-Mischtumors aus L-428-Zellen und $\mathrm{CD} 14^{+}-\mathrm{PBMCs}$

Abbildung 11: Trichrom-gefärbte CAM-Mischtumoren.

Abbildung 12: HL-Zellen und Monozyten bilden kompartimentierte CAM-Tumoren.

Abbildung 13: Ubiquitäre CD30-Expression in L-428-CAM-Lymphomen. 48

Abbildung 14: Peroxidase-Färbung an CAM-Mischtumoren zeigt Verteilung der Zellpopulationen.

Abbildung 15: Lymphomzellen invadieren in den Zwischenraum zwischen Chorion- und Allantoismembran.

Abbildung 16: CD206-Expression von Makrophagen in CAM-Mischtumoren nach vier Tagen.

Abbildung 17: HRS-Zellen und CD206+-Makrophagen an einem Blutgefäß der CAM.

Abbildung 18: CD206-Expression von Zellen in der Basis eines CAM-Mischtumors. 55 


\section{Tabellenverzeichnis}

Tabelle 1: Verwendete Geräte.

Tabelle 2: Verwendete Verbauchsmaterialien.

Tabelle 3: Verwendete Chemikalien.

Tabelle 4: Verwendete Puffer, Lösungen und Medien.

Tabelle 5: Verwendete Antikörper.

Tabelle 6: Verwendete Zelllinien und Zellisolate.

Tabelle 7: Verwendete Software.

Tabelle 8: Peroxidase-Färbung der CAM-Schnittpräparate. 29

Tabelle 9: Übersicht der CAM-Läsionen. 31 


\section{Abkürzungsverzeichnis}

ALCL anaplastic large-cell lymphoma, Anaplastisches großzelliges Lymphom

BL

Burkitt-Lymphom

BSA

bovines Serumalbumin

BZR

B-Zell-Rezeptor

CAM

Chorion-Allantois-Membran

$\mathrm{CD}$ cluster of differentiation, Oberflächenmerkmal auf Zellen

$\mathrm{CD}^{+}$

CD4-positiv

$\mathrm{CD} 8^{+}$

CD8-positiv

CD14+

CD14-positiv

CD206 ${ }^{+}$

CD206-positiv

cHL

klassisches Hodgkin-Lymphom

$\mathrm{CM}$

konditioniertes Medium

$\mathrm{DAB}$

3,3'-Diaminobenzidin

$\mathrm{ddH}_{2} \mathrm{O}$

doppelt destilliertes Wasser

DLBCL diffuse large B-cell lymphoma, Diffuses großzelliges B-Zell-Lymphom

DMSO Dimethylsulfoxid

DNA Desoxyribonukleinsäure

EBV

Epstein-Barr-Virus

EDTA

Ethylendiamintetraacetat

FACS

fluorescence-activated cell sorting

FCS

fetal calf serum, fetales Kälberserum, Zusatzstoff zu Zellkulturmedien

FITC

fluorescein isothiocyanate, Fluoreszeinisothiocyanat

GM-CSF granulocyte macrophage colony-stimulating factor

HEMs

Hodgkin lymphoma-educated macrophages

HL

Hodgkin-Lymphom

HRP

horseradish peroxidase, Meerrettich-Peroxidase

HRS-Zellen Hodgkin-Reed-Sternberg-Zellen

$\operatorname{Ig}$

Immunglobulin

JAK

Januskinasen

MACS

magnetic cell separation

M-CSF

macrophage colony-stimulating factor

MRC1

mannose receptor C-type 1

$\mathrm{NF}-x \mathrm{~B}$

nuclear factor kappa-light-chain-enhancer of activated B-cells 
NK natural killer

NHL

Non-Hodgkin-Lymphom

NLPHL Noduläres Lymphozyten-prädominantes Hodgkin-Lymphom

PD-1 programmed cell death protein 1

PD-L1 programmed death-ligand 1

$\mathrm{P} / \mathrm{S}$ Penicillin/Streptomycin

PBMCs peripheral blood mononuclear cells, mononukleäre Zellen des peripheren Blutes

PBS phosphate-buffered saline, phosphatgepufferte Salzlösung

PFA Paraformaldehyd

RNA ribonucleic acid, Ribonukleinsäure

RPMI-1640 Roswell Park Memorial Institute

RT Raumtemperatur

STAT signal transducers and activators of transcription, Transkriptionsfaktoren

TAMs tumor-associated macrophages

TGF $\beta \quad$ transforming growth factor $\beta$

TME tumor microenvironment

TNF tumor necrosis factor, Tumornekrosefaktor

TBS tris-buffered saline, Tris-gepufferte Salzlösung

WHO World Health Organization 


\section{$1 \quad$ Einleitung}

\subsection{Einordnung und Biologie des Hodgkin-Lymphoms}

Als bösartige Erkrankungen des lymphatischen Systems zählen maligne Lymphome zu den hämatologischen Neoplasien. Sie machen drei bis vier Prozent aller Malignome weltweit aus (Huh 2012). Im biologischen Sinn liegt eine klonale Proliferation lymphoider Zellen vor. Immunologisch gesehen kommt es zum Verharren von Lymphozyten auf verschiedenen Reifungsstufen der Lymphopoese. Klinisch betrachtet kommt es besonders zur Vergrößerung der sekundären lymphatischen Organe wie Lymphknoten oder Milz, gleichwohl auch extralymphatische Organe betroffen sein können. Maligne Lymphome sind eine heterogene Gruppe verschiedenster Tumorentitäten, die sich hinsichtlich ihrer Biologie, Therapie und Prognose unterscheiden. Histologisch werden Hodgkin-Lymphome (HL) von Non-Hodgkin-Lymphomen (NHL) differenziert.

Es war noch nichts über Histopathologie und Molekularbiologie des Krankheitsbildes bekannt, als der britische Mediziner Thomas Hodgkin 1832 die klinischen Charakteristika des später nach ihm benannten Hodgkin-Lymphoms erstmalig als eigenständige Entität beschrieb (Hodgkin 1832). Damals war die Prognose für die Mehrzahl der Betroffenen infaust. Die Weiterentwicklung des multimodalen Therapiekonzepts in den letzten Jahrzehnten hat dazu geführt, dass das Hodgkin-Lymphom heutzutage meistens primär kurabel ist. Deutlich über 80 Prozent der Patient*innen können bei optimaler und risikoadaptierter Behandlung geheilt werden (Borchmann et al. 2012; Ansell 2018). Trotz dieser für Krebserkrankungen außergewöhnlichen Ansprechraten gibt es weiterhin Optimierungsbedarf. Die aktuelle Strategie der Risikostratifizierung beim HL führt dazu, dass ein nicht unerheblicher Teil der Patient*innen entweder über- oder unterbehandelt wird. In beiden Fällen sind die Konsequenzen gravierend (Scott und Steidl 2014). Die Langzeittoxizität der Therapie, beispielsweise in Form von sekundären Neoplasien, steht im Gegensatz zur günstigen Prognose des HodgkinLymphoms (LeMieux et al. 2015; Herold 2016). Daher muss die Toxizität der Radio-Chemotherapie bei gleichzeitigem Erhalt der Effektivität reduziert werden (Franklin et al. 2006; Diefenbach und Steidl 2013; Ansell 2018). Etwa 20 Prozent der Hodgkin-Lymphome sind 
therapierefraktär oder rezidivieren nach initialer kompletter Remission, was mit einer drastisch reduzierten Prognose einhergehen kann. Auch primär disseminierte Fälle stellen eine besondere Herausforderung für die Behandelnden dar (Montanari und Diefenbach 2014).

In der westlichen Welt gehört das Hodgkin-Lymphom mit einer jährlichen Inzidenz von zwei bis drei Neuerkrankungen pro 100.000 Einwohnern zu den häufigsten malignen Lymphomen, wobei das männliche Geschlecht etwas häufiger betroffen ist (Thomas et al. 2002; Küppers et al. 2012). Die Inzidenz in den Industrieländern zeigt eine bimodale Verteilungskurve mit einem ersten Häufigkeitsgipfel in der dritten Lebensdekade und einem zweiten nach dem 50. Lebensjahr (Thomas et al. 2002). Bei Jugendlichen und jungen Erwachsenen ist das Hodgkin-Lymphom die häufigste Tumorerkrankung (Carbone et al. 2015; Mottok und Steidl 2018). Gerade bei diesen jungen Patient*innen mit langer Lebenserwartung stellt die behandlungsassoziierte Langzeittoxizität ein großes Problem dar (Engert 2016; Mottok und Steidl 2018). In Entwicklungsländern tritt das Hodgkin-Lymphom vor allem im Kindesund Jugendalter auf (Thomas et al. 2002).

Bis heute kann die Frage nach der Ätiologie des Hodgkin-Lymphoms nur unzureichend beantwortet werden. $\mathrm{Zu}$ den assoziierten Risikofaktoren zählen eine positive Familienanamnese, Virusinfektionen und verschiedene, jedoch noch nicht näher definierte Immunsuppressionsreaktionen (Glaser und Jarrett 1996). Die stärkste Assoziation zeigt eine Infektion mit dem Epstein-Barr-Virus (EBV). Dieses humane Herpesvirus ist der Erreger der infektiösen Mononukleose und bei entsprechender Anamnese ist das Risiko, an einem HodgkinLymphom zu erkranken, zwei- bis dreifach erhöht (Thomas et al. 2002). Etwa 40 Prozent der HL-Patient*innen in westlichen Ländern und bis zu 90 Prozent in Entwicklungsländern sind mit EBV infiziert (Glaser et al. 1997). Da B-Lymphozyten durch EBV in vitro immortalisiert werden können und in Lymphknotenbiopsien von EBV-positiven Fällen alle maligne transfomierten Zellen im HL das EBV-Genom in sich tragen, liegt der Schluss nahe, dass dem EBV eine bedeutende Rolle im Transformationsprozess des Hodgkin-Lymphoms zukommt (Thomas et al. 2002; Küppers 2009a). Für das onkogene Potenzial des EBV spricht außerdem, dass es auch das Auftreten von NHL wie dem Burkitt-Lymphom (BL) begünstigt und ebenso mit dem Nasopharynxkarzinom assoziiert ist, da EBV neben Lymphozyten auch Epithelzellen besiedeln kann (Brady et al. 2007; Tsao et al. 2017; Edwards et al. 2019). Familienangehörige von HL-Patient*innen haben ein deutlich erhöhtes Risiko, ebenfalls an einem Hodgkin-Lymphom zu erkranken, was eine genetische Determinante in der Krankheitsentstehung demonstriert (Grufferman et al. 1977; Thomas et al. 2002). 
Histopathologisch wird das Hodgkin-Lymphom durch die WHO in fünf Subtypen klassifiziert (Swerdlow et al. 2008). Am häufigsten sind der Subtyp der Nodularsklerose mit einem Anteil von 50 bis 80 Prozent der Erkrankungen sowie der Typ der gemischten Zellularität, welcher bei 20 bis 30 Prozent der Betroffenen nachgewiesen wird (Eberle et al. 2009). Deutlich seltener sind die lymphozytenreichen respektive lymphotzytenarmen Subtypen und der Typ des nodulären Lymphozyten-prädominanten Hodgkin-Lymphoms (NLPHL) (Swerdlow et al. 2008; Eberle et al. 2009). Als klassisches Hodgkin-Lymphom (cHL), das 95 Prozent aller HL-Fälle ausmacht, werden die vier erstgenannten Subtypen dem NLPHL mit seiner divergenten Biologie und Therapie gegenübergestellt (Swerdlow et al. 2008; Eichenauer und Engert 2017). Beim NLPHL werden die Lymphozyten-prädominanten Tumorzellen als LPZellen bezeichnet und exprimieren klassische B-Zell-Marker wie die Oberflächenproteine cluster of differentiation 20 (CD20) oder CD79a, welche von den malignen Zellen im cHL nicht oder nur eingeschränkt exprimiert werden (Schmid et al. 1991; Poppema 2005; Küppers 2009a; Schmitz et al. 2009; Venkataraman et al. 2014; Vardhana und Younes 2016). LP-Zellen leiten sich von antigenselektierten Keimzentrums-B-Zellen ab (Schmitz et al. 2009).

Die Seltenheit der neoplastischen Zellen im Hodgkin-Lymphom macht diese Tumorentität zu einem einzigartigen Sonderfall. Die mikroskopisch sehr großen, mononukleären Hodgkin-Zellen beziehungsweise bi- oder multinukleären Reed-Sternberg-Zellen, meist zusammen als Hodgkin-Reed-Sternberg-Zellen (HRS-Zellen) bezeichnet, machen nur etwa ein Prozent der Tumormasse aus (Thomas et al. 2004). Der Großteil des Mikromilieus im Hodgkin-Lymphom wird von einem dichten und heterogenen Infiltrat aus benignen Immunzellen und Bindegewebszellen gestellt (Küppers et al. 2012). Diese quantitative Dominanz der reaktiven bystander cells ist charakteristisch und macht das Hodgkin-Lymphom zu einer prototypischen Neoplasie, um die Interaktion der Tumorzellen mit ihrer inflammatorischen Mikroumgebung zu untersuchen (Liu und Shipp 2017; Hollander et al. 2018). Zum leukozytären Umgebungsinfiltrat in den cHL-Läsionen zählen T-Lymphozyten, benigne B-Lymphozyten, Makrophagen, Granulozyten, Mastzellen, Plasmazellen und dendritische Zellen. Daneben sind auch Fibroblasten Teil des Mikromilieus (Küppers 2009a; Küppers 2009b; Küppers et al. 2012; Mathas et al. 2016; Hollander et al. 2018; Aldinucci et al. 2019).

Die entarteten HRS-Zellen exprimieren das Transmembranprotein CD30, was eine sichere diagnostische Identifizierung ermöglicht und mittlerweile im Rahmen der targeted therapy auch pharmakologische Relevanz hat (Küppers 2009b; Younes et al. 2010). CD30 gehört zur Superfamilie der Rezeptoren für den tumor necrosis factor (TNF) und führt bei entsprechender Ligandenbindung zu einer Aktivierung des Transkriptionsfaktors nuclear factor kappa-light- 
chain-enhancer of activated B-cells (NF-xB), welcher vielfältige proinflammatorische Zielgene reguliert (Schmitz et al. 2009). Humane CD30-positive B-Zellen stellen eine spezielle Untergruppe mit Verwandtschaft zu HRS-Zellen dar (Weniger et al. 2018). Auch die Zellen im anaplastisch großzelligen Lymphom (ALCL) exprimieren CD30 (Younes et al. 2010). Außerdem exprimieren HRS-Zellen meistens den granulozytären Marker CD15 (Stein et al. 1982; Schmitz et al. 2009).

Reife, naive B-Zellen zirkulieren zwischen Blutbahn und den sekundären lymphatischen Organen. Voraktivierte B-Zellen durchwandern die B-Zell-Follikel der Lymphknoten, in denen sich dann sogenannte Keimzentren ausprägen, und werden zu einer starken Proliferation angeregt. Hier können sie über ihre gereiften Immunglobuline (Ig), auch B-Zell-Rezeptor (BZR) genannt, Antigene erkennen, die beispielsweise von follikulären dendritischen Zellen oder T-Zellen präsentiert werden (Vinuesa et al. 2010; Girard et al. 2012). Bei der Reifung und Selektion der B-Zellen kommt es zu somatischen Hypermutationen in den Genen für die variable Region der Immunglobulin-Rezeptoren, aber auch zum Ig-Klassenwechsel (Hamel et al. 2012). In beiden Prozessen findet ein Doppelstrangbruch der Desoxyribonukleinsäure (DNA) statt. Ziel dieser Keimzentrumsreaktion ist die Affinitätsreifung der B-Zellen, um spezifische Antigene hochselektiv zu erkennen und beispielsweise durch Produktion hochaffiner Antikörper durch ausdifferenzierte Plasmazellen eine möglichst effektive adaptive Immunantwort zu ermöglichen (Hamel et al. 2012). Gelegentlich kann es bei diesen proliferativen und mutagenen Prozessen zur malignen Transformation von B-Zellen kommen. Die meisten NHL entstehen auf diesem Wege ebenfalls aus entarteten KeimzentrumsB-Zellen (Basso und Dalla-Favera 2015).

Küppers et al. (1994) konnten nachweisen, dass HRS-Zellen somatisch mutierte und klonal neu arrangierte Immunglobulin-Gene tragen und so ihre Abstammung aus reifen Keimzentrums-B-Zellen untermauern. Der monoklonale B-Zell-Ursprung konnte bestätigt werden (Hummel et al. 1996). Die klonale Natur der Hodgkin-Lymphomzellen geht mit größeren chromosomalen Aberrationen einher (Inghirami et al. 1994). Außerdem wurde gezeigt, dass klonale HRS-Zellen mit identisch somatisch mutierten und neu arrangierten Genen der schweren Ig-Kette in jeweils verschiedenen Biopsien von Patient*innen mit rezidiviertem cHL nachzuweisen sind, was für Persistenz und Disseminierung einer klonalen Tumorzellpopulation im Hodgkin-Lymphom spricht (Vockerodt et al. 1998).

Die klonale B-Zell-Identität der HRS-Zellen geht allerdings mit einem aberranten Immunphänotyp einher (Küppers et al. 2012; Mathas et al. 2016). Das Genexpressionsmuster normaler B-Zellen ist in HRS-Zellen herunterreguliert, was in diesem Ausmaß unter B-Zell- 
Lymphomen beispiellos ist (Watanabe et al. 2000; Stein et al. 2001; Schwering et al. 2003; Küppers et al. 2012). So werden der BZR und die meisten assoziierten Signalwegskomponenten nicht mehr exprimiert (Kanzler et al. 1996). HRS-Zellen können Gene verschiedener hämatopoetischer Linien ko-exprimieren und solche, die charakteristisch für aktivierte lymphoide Zellen sind, werden von den meisten HRS-Zellen exprimiert (Trümper et al. 1993).

Der weitgehende Verlust des B-Zell-Phänotyps beziehungsweise des BZR-Signalweges würde normalerweise die Apoptose der maligne transformierten B-Zelle bedeuten. HRSZellen sind durch eine deregulierte Aktivierung verschiedener Signalwege wie dem NF- $\varkappa$ Bund JAK (Januskinasen)/STAT (signal transducers and activators of transcription)-Signalweg und anderer Transkriptionsfaktoren charakterisiert (Hinz et al. 2001; Farrell und Jarrett 2011; Küppers et al. 2012). In den 1990iger Jahren ist man beispielsweise davon ausgegangen, dass autokrin sezerniertes Interleukin (IL)-6 für eine aberrante Aktivierung des JAK/STAT-Signalweges verantwortlich sein könnte. So konnte eine konstitutive Aktivierung von STAT3 in mehreren HL-Zelllinien nachgewiesen werden, die unter anderem zur Aktivierung von basic leucine zipper transcriptional factor ATF-like 3 (BATF3) führen kann (Kube et al. 2001; Lollies et al. 2018). Die aberrante Aktivierung des JAK/STAT-Signalweges kann aber nach neuerem Wissensstand auch auf Aberrationen bei JAK2 oder Mutationen in suppressor of cytokine signaling 1 (SOCS1)-Genen zurückgeführt werden. Dies hat auch dazu geführt, dass neben STAT3 auch konstitutiv aktiviertes STAT5 sowie STAT6, beide über eine Aktivierung durch Zytokine wie beispielsweise IL-21 oder IL-13, beschrieben werden konnten (Skinnider et al. 2001; Skinnider et al. 2002a; Skinnider und Mak 2002a; Lamprecht et al. 2008; Scheeren et al. 2008). Diese Aktivierungen sind durch genetische Läsionen und durch die Interaktion der HRS-Zellen mit den Zellen ihrer Mikroumgebung bedingt (Küppers et al. 2012). Durch Mutationen verursacht sind die HRS-Zellen immun für Apoptose-Signale des Keimzentrums (Schattner und Friedman 1996; Re et al. 2000; Holtick et al. 2005; Küppers et al. 2012). Mit dieser Apoptose-Resistenz erfüllen sie eine weitere Kerneigenschaft von Krebszellen (Hanahan und Weinberg 2000).

Im cHL konnte eine 9p24.1-Amplifikation beschrieben werden. Hierdurch werden das JAK2-Gen und die in seiner Nachbarschaft befindlichen Gene, wie z.B. programmed deathligand 1 (PD-L1) oder PD-L2, amplifiziert. Es entsteht also ein Amplikon und durch das vermehrte Vorhandensein von JAK2 resultiert eine regulatorische Schleife, die zu einer vermehrten Expression von PD-L1 respektive PD-L2 führt (Green et al. 2010). Dies ist die molekulare Grundlage dafür, dass beim cHL die Immuncheckpoint-Therapien sehr erfolgreich weiterentwickelt werden konnten (Armand et al. 2016; Younes et al. 2016). 
Durch Manipulation der Mikroumgebung kann sich der maligne Phänotyp der HRS-Zellen voll ausprägen und die Tumorzellen können sich einer effektiven Immunabwehr entziehen (Aldinucci et al. 2010; Aldinucci et al. 2016). Verschiedene Studien haben gezeigt, dass das Mikromilieu im Hodgkin-Lymphom ein vielversprechender therapeutischer Angriffspunkt ist. Dies könnte zur Entwicklung neuer Therapie-Strategien führen, die auch die reaktiven Umgebungszellen inkludieren werden (Steidl et al. 2011). So scheinen Makrophagen im cHL beispielsweise negativ mit Therapieansprechen und Prognose zu korrelieren (Steidl et al. 2010).

\subsection{Tumormikromilieu und tumorassoziierte Makrophagen}

Das Verständnis von Krebs als systemische Erkrankung hat in den letzten zwei Jahrzehnten dazu geführt, nicht nur die malignen Zellen selbst, sondern auch das sie umgebende Mikromilieu genauer zu betrachten. Benigne, aber funktionsuntüchtige Umgebungszellen bilden einen komplexen reaktiven Hintergrund, der Kanzerogenese, Tumorwachstum und Progress der Erkrankung unterstützt. Zusammen mit der extrazellulären Matrix und löslichen Faktoren wird diese Mikroumgebung als tumor microenvironment (TME) bezeichnet (Egeblad et al. 2010). Das TME trägt aktiv dazu bei, den Tumorzellen ein optimales Milieu zu bieten (Wang et al. 2017). Zur zellulären Komponente des TME gehört ein diverses Immunzellinfiltrat aus T- und B-Zellen, Granulozyten, Mastzellen und Makrophagen (Kerkar und Restifo 2012). Ihre physiologische Funktion der Tumorbekämpfung können diese Immunzellen allerdings nicht mehr ausüben. Sie sind so manipuliert, dass sie die Tumorzellen aktiv unterstützen, indem sie Immunantworten unterdrücken oder Wachstumsfaktoren sezernieren (Albini et al. 2015; Pauken und Wherry 2015).

Als Teil des angeborenen Immunsystems sind Makrophagen durch ihre Fähigkeit zur Phagozytose charakterisiert (Cavaillon 2011). Makrophagen sind in allen Geweben verbreitet und spielen eine Rolle in der Regulation von Immunreaktionen und Gewebehomöostase. Sie leiten sich von myeloiden Vorläuferzellen, den Monozyten, ab. Diese verlassen die Blutbahn und können sich im Zielgewebe in entsprechende Makrophagen differenzieren (Varol et al. 2009). Außerdem konnte gezeigt werden, dass sessile Makrophagen auch zur Selbstregeneration befähigt sind und dass die Kolonisierung des Körpers mit Makrophagen während der Embryogenese keine Monozyten erfordert (Aziz et al. 2009; Schulz et al. 2012). Im Rahmen von Infektionen können jedoch neue Makrophagen rekrutiert werden, die sich aus Monozyten aus dem Knochenmark ableiten. CD14 ist ein humanes Protein, das von Monozyten und 
Makrophagen exprimiert wird und sowohl in einer membrangebundenen als auch einer löslichen Form existiert (Pugin et al. 1994). Als Ko-Rezeptor des Toll-like-Rezeptors 4 (TLR4) ist das Glycosylphosphatidylinositol (GPI)-verankerte CD14 im Verbund mit myeloid differentiation factor 2 (MD-2) an der durch Lipopolysaccharide (LPS) gramnegativer Bakterien ausgelösten Reaktion des angeborenen Immunsystems beteiligt, die schließlich zur Translokation von NF- $x$ B in den Zellkern führt (Jiang et al. 2000).

Die große Plastizität und Reaktionsfähigkeit von Makrophagen ermöglicht es ihnen, ihren Phänotyp den Umgebungsbedingungen spezifisch und dynamisch anzupassen (Varol et al. 2015). Anhand ihres Aktivierungszustandes können diese heterogenen Immunzellen grob in zwei gegensätzliche Kategorien eingeteilt werden. Klassisch aktivierte M1-Makrophagen fördern Immunreaktionen beispielsweise bei bakteriellen Geschehen, wohingegen alternativ aktivierte M2-Makrophagen immunsuppressiv und fördernd für Wundheilung und Angiogenese wirken (Mills et al. 2000; Gordon 2003; Mantovani et al. 2017). Die Benennung erfolgt anhand des von diesen aktivierten Makrophagen induzierten Zytokinmusters in T-Helferzellen. So werden vermehrt $\mathrm{T}_{\mathrm{H}} 1$ - oder $\mathrm{T}_{\mathrm{H}} 2$-Zytokine produziert, die ihrerseits verstärkt Makrophagen entweder in M1-Richtung oder zum M2-Phänotyp hin aktivieren. Die beiden Makrophagen-Aktivierungszustände unterscheiden sich nicht nur in ihren Funktionen, sondern auch in der Expression von Rezeptoren und ihrer Zytokin- und Chemokinproduktion (Aldinucci et al. 2019). Die Polarisierung zu M2-Makrophagen aus Monozyten kann durch macrophage colony-stimulating factor (M-CSF), IL-4, IL-10, IL-13, transforming growth factor (TGF) $\beta$, Glukokortikoide und Vitamin $\mathrm{D}_{3}$ induziert werden. In diesem Prozess können Monozyten beziehungsweise Makrophagen unter anderem IL-10, TGF $\beta$, chemokine (C-C Motif) ligand (CCL)17, CCL18 und CCL22 sekretieren, aber auch an der Zelloberfläche Aktivierungsmoleküle wie zum Beispiel CD163, CD206 oder PD-L1 exponieren und die Expression der Indolamin-2,3-Dioxygenase (IDO) und von pSTAT3/6 steigern (Murray et al. 2014; Mantovani et al. 2017). Lipopolysaccharide, Interferon (IFN)- $\gamma$ und granulocyte-macrophage colony-stimulating factor (GM-CSF) polarisieren Makrophagen zum M1-Phänotyp, was die Sekretion von IL-1 $\beta$, TNF- $\alpha$, IL-12, IL-18, IL-23 und chemokine (C-C Motif) receptor (CCR)7 induziert und die Expression von CD40, CD68, CD80 und CD86 verstärkt (Murray et al. 2014; Mantovani et al. 2017). In der Aufarbeitung von Tumorproben dient die immunhistochemische Färbung von CD163 und CD206 als Nachweis für die Existenz von M2-Makrophagen. Das M1-M2-Dogma der Makrophagen-Aktivierung wird den vielfältigen Aktivierungsspektren der Makrophagen jedoch nicht mehr gerecht. Eine starre Dichotomie mit rein opponierenden Aktivierungszuständen liegt nur selten vor (Mosser und Edwards 2008; Kiss et al. 2018). Vor allem innerhalb der M2-Makrophagen-Population werden aktuell in Abhängigkeit vom 
Zytokin-Expressionsmuster der Gewebe, in die die Monozyten migrieren, unterschiedliche M2-Subgruppen beschrieben (Sica und Mantovani 2012; Sousa und Määttä 2016). Durch die Identifizierung von tumor-associated macrophages (TAMs), die sehr häufig zu den M2-ähnlichen Makrophagen gezählt werden, ist die Diversität der M2-Subpopulationen gestiegen und die fortschreitende Analyse von Makrophagen mittels single cell next-generation sequencing (NGS) wird hier in der nahen Zukunft weitere Überraschungen bringen.

TAMs sind Makrophagen, die innerhalb von oder nahe an Neoplasien zu finden sind. TAMs ähneln M2-Makrophagen und können in histologischen Schnittpräparaten von Tumoren anhand des erwähnten Makrophagenmarkers CD163 und des Aktivierungsmarkers CD206 detektiert werden (Heusinkveld und van der Burg 2011; Zhang et al. 2012). Molekularbiologische Methoden zeigen aber eine große Heterogenität in diesen M2-ähnlichen tumorassoziierten Makrophagen mit Phänotypen, die vom bimodalen Modell der M1-M2-Achse nicht abgebildet werden (Chevrier et al. 2017; Lavin et al. 2017). Als Bestandteil des TME erhalten tumorassoziierte Makrophagen in letzter Zeit verstärkte Aufmerksamkeit (Mantovani und Sica 2010; Twum et al. 2017). Sie sind an verschiedenen Aspekten von Tumorprogression beteiligt, beispielsweise über eine aberrante Zytokinexpression, die Umgestaltung der Tumormatrix, Angiogenese und Therapieresistenz (Mantovani et al. 2002; Mantovani und Sica 2010; Mantovani et al. 2017). TAMs sind in die Pathogenese von verschiedenen Lymphomen verwickelt, darunter auch das Hodgkin-Lymphom. Außerdem scheinen sie eine Rolle in der Krankheitsentstehung von indolenten NHL wie der chronisch lymphatischen Leukämie oder dem follikulären Lymphom und auch bei aggressiven NHL wie dem BL und dem diffuse large B-cell lymphoma (DLBCL) zu spielen (Lenz et al. 2008; Steidl et al. 2010; Steidl et al. 2011; Kridel et al. 2015b; Kridel et al. 2015a; Pham et al. 2018; Verdière et al. 2018). Auch wenn T-Zellen die dominierenden Umgebungszellen im Mikromilieu des cHL darstellen, sind Makrophagen ein integraler Bestandteil des TME (Steidl et al. 2010; Scott und Steidl 2014). Das Wissen über die Funktionen, Interaktionen und die Regulation von TAMs im HodgkinLymphom ist aber immer noch limitiert (Mantovani et al. 2002; Steidl et al. 2010; Martinez und Gordon 2014).

Tudor et al. (2014) fanden heraus, dass von HRS-Zellen konditioniertes Medium (CM) die Expression von CD163 und CD206 in vitro in Monozyten aus dem peripheren Blut hochreguliert. Inflammatorische M1-Makrophagen wurden durch Stimulation von Monozyten mit GM-CSF generiert und immunregulatorische M2-Makrophagen durch Monozyten-Behandlung mit M-CSF. HRS-Zellen waren nicht in der Lage, M1-GM-CSF-Makrophagen in M2M-CSF-Makrophagen zu repolarisieren (Tudor et al. 2014). Kürzlich konnte ebenso gezeigt 
werden, dass HRS-Zellen Monozyten in immunsuppressive M2-TAMs programmieren können (Casagrande et al. 2019). Die Behandlung der humanen Monozyten mit CM der Hodgkin-Zelllinien L-1236 und L-428 erhöhte die Expression von CD206, PD-L1 und IDO (Casagrande et al. 2019). Verschiedene Untersuchungen haben gezeigt, dass eine hohe Anzahl an infiltrierenden TAMs (Koh et al. 2014; Tudor et al. 2014), die vor allem von zirkulierenden Monozyten abgeleitet sind (Crane et al. 2016), und eine hohe absolute Monozytenzahl im peripheren Blut mit einer schlechten Prognose im cHL korrelieren (Steidl et al. 2010; Gotti et al. 2017; Aldinucci et al. 2019).

Der Mannose-Rezeptor CD206 ist das Genprodukt des mannose receptor C-type 1 (MRC1)Gens und wird von Makrophagen, dendritischen Zellen und Endothelzellen exprimiert (Martinez-Pomares 2012). Verschiedene exogene und endogene Liganden sind beschrieben, welche Funktionen des Rezeptors in Entzündung, Immuntoleranz und Homöostase implizieren. Für die Clathrin-abhängige Endozytose der Substrate müssen die Rezeptoren multimerisieren (Howard und Isacke 2002; Martinez-Pomares et al. 2006; Martinez-Pomares 2012). Nach Internalisierung ins frühe Endosom wird CD206 freigesetzt und kann zur Plasmamembran zurück transportiert werden (Howard und Isacke 2002; Taylor et al. 2005). CD206 besteht aus fünf Elementen: eine kurze C-terminale zytoplasmatische Domäne, eine Transmembranregion, acht bis zehn C-type lectin-like domains (CTLDs), eine Fibronectin Typ IIDomäne (FNII) und eine N-terminale Cystein-reiche Domäne (CR) (Taylor et al. 2005). Die drei extrazellulären Domänen binden an spezifische Substrate. Die CTLDs binden terminale Mannose, Fucose und N-Acetylglucosamin, während die FNII-Domäne Kollagene als endogene Liganden binden kann, was eine Rolle in der Umstrukturierung der extrazellulären Matrix suggeriert. Die CR-Domäne bindet sulfatierte Galactose und sulfatiertes N-Acetylgalactosamin (Fiete et al. 1998; Martinez-Pomares et al. 2006). Klinische Relevanz hat CD206 als Aktivierungsmarker für M2-aktivierte TAMs in der Mikroumgebung von Tumoren. Zur Aufgabe von CD206 gehört auch die Phagozytose von bakteriellen Pathogenen wie Mycobacterium tuberculosis und Pilzen wie Candida albicans (Lee et al. 2003). Über CD206 könnte daher eine gesteigerte Beseitigung von Pathogenen erreicht werden (Lee et al. 2003). Aus den vielfältigen möglichen Liganden und Wirkmechanismen von CD206 aus In-vitro-Untersuchungen ergibt sich bisher aber noch kein einheitliches Bild. Die klinische Relevanz von CD206 muss weiter evaluiert werden. 


\subsection{Mikroumgebung im klassischen Hodgkin-Lymphom}

Auch wenn HRS-Zellen nur eine kleine Fraktion der Tumormasse in cHL-Läsionen präsentieren, erschaffen sie durch die aktive Umgestaltung ihrer Mikroumgebung ein aggressives Malignom (Mottok und Steidl 2018). Die Wechselwirkungen zwischen den benignen Leukozyten und den HRS-Zellen stehen in Zusammenhang mit Tumorprogression und der Fähigkeit der Tumorzellen, einer adäquaten Immunantwort zu entgehen (Hollander et al. 2018). HRS-Zellen selbst zeigen nur eine geringe Proliferationskapazität. Sie sekretieren aber Zytokine und Chemokine, um so das heterogene Immuninfiltrat zu rekrutieren und zu manipulieren und das eigene Überleben in einem günstigen Milieu zu sichern (Re et al. 2005; Aldinucci et al. 2010; Küppers et al. 2012; Aldinucci et al. 2016). Analog zu ihrem aberranten Immunphänotyp ist auch das Zytokinexpressionsmuster der HRS-Zellen dereguliert und nicht eindeutig einer Zellreihe zuordenbar. $\mathrm{T}_{\mathrm{H}} 2$-Zytokine (IL-2, IL-5, IL-6, IL-9, IL-10, IL13) werden ebenso wie $T_{H} 1$-Zytokine (IL-12, Interferon- $\gamma /$ INF- $\gamma$ ) sowie IL-1, TGF $\beta$, IL-7, IL-8 und B cell activating factor (BAFF) von HRS-Zellen exprimiert (Skinnider und Mak 2002; Aldinucci et al. 2016). Die Rolle des IL-13 im cHL ist besonders gut beschrieben (Skinnider et al. 2002b).

Die Lymphomzellen können T-Effektorzellen und natural killer (NK)-Zellen in immunsuppressive bystander cells umprogrammieren (Aldinucci et al. 2019). Die größte Zellpopulation im TME des Hodgkin-Lymphoms wird von polyklonalen CD4-positiven (CD4 ${ }^{+}$)-T-Helferzellen gestellt (Poppema et al. 1998). Im mikroskopischen Schnittpräparat sind diese T-Lymphozyten rosettenförmig um die HRS-Zellen gruppiert (Steidl et al. 2011; Liu et al. 2014). Sie interagieren mit den malignen Zellen beispielsweise über die CD40-CD40-Ligand-Bindung (Carbone et al. 1995) und schützen die HRS-Zellen vor zytotoxischen CD8-positiven $\left(\mathrm{CD}^{+}\right)$-T-Zellen und NK-Zellen (Mottok und Steidl 2018), deren Anzahl herunterreguliert ist (Hollander et al. 2018). HRS-Zellen locken $\mathrm{T}_{\mathrm{H}} 2$-Helferzellen und regulatorische T-Zellen durch Sekretion der Chemokine CCL5, CCL17 und CCL22 an (Küppers 2009b). Regulatorische T-Zellen schützen HRS-Zellen vor einer durch zytotoxische T-Zellen eingeleiteten Apoptose (Marshall et al. 2004; Gandhi et al. 2006). Eosinophile Granulozyten werden von den Tumorzellen durch IL-5, IL-9, CCL5, CCL28 und GM-CSF in das inflammatorische TME des Hodgkin-Lymphoms rekrutiert (Küppers 2009b). Außerdem sekretieren HRS-Zellen und regulatorische T-Zellen das immunsuppressive Zytokin IL-10, um die Funktion der

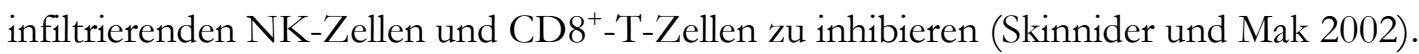

Ein direkter Mechanismus der HRS-Zellen, um CD8 ${ }^{+}-$T-Lymphozyten zu hemmen, ist die verstärkte Expression von PD-L1. Durch Bindung an das programmed cell death protein 1 (PD- 
1) der T-Effektorzellen werden diese in ihrer Funktion inhibiert. HRS-Zellen haben genetische Aberrationen im Genlocus für CD274 (PD-L1), was zu einer verstärkten Expression des Proteins führt (Green et al. 2010; Roemer et al. 2016b). Außerdem exprimieren TAMs in den cHL-Läsionen ebenfalls PD-L1 und können so die sie umgebenden CD8+-T-Zellen und NK-Zellen in ihrer zytotoxischen Aktivität einschränken (Carey et al. 2017; Vari et al. 2018). Die PD-L1-positiven-TAMs bilden dabei eine immunprotektive Nische und umgeben die malignen HRS-Zellen. Diese besondere Topologie, die sich in der räumlichen Nähe von PD-L1-exprimierenden benignen und malignen Zellen ausdrückt, verstärkt vermutlich den Einfluss des PD-1-Signals im cHL (Carey et al. 2017; Liu und Shipp 2017). Neben PD-L1 werden weitere inhibitorische Liganden wie B7-H4 von tumorassoziierten Makrophagen exponiert und sie sekretieren immunsuppressive Mediatoren wie IL-10 (Kryczek et al. 2006). TAMs können durch die Sekretion von CCL17 und CCL22 auch regulatorische T-Zellen rekrutieren, welche ihrerseits zytotoxische T-Zellen hemmen (Kryczek et al. 2006).

Weiterhin konnte eine hohe Anzahl an infiltrierenden TAMs ein kürzeres Überleben nach Chemotherapie vorhersagen (Tan et al. 2012), auch wenn andere Studien keine Assoziation mit der Quantität an TAMs beobachten, sondern eher den Makrophagen-Phänotyp als ausschlaggebend nahelegen (Aldinucci et al. 2019). Das von HRS-Zellen sekretierte CCL5 rekrutiert Makrophagen und Mastzellen chemotaktisch und IL-8 lockt neutrophile Granulozyten an (Skinnider und Mak 2002; Fischer et al. 2003). Zirkulierende Monozyten werden von HRS-Zellen durch CCL2 rekrutiert (Luciani et al.1998).

Typisch für Krebszellen ist auch die Herunterregulierung von major histocompatibility complex I (MHC I) durch HRS-Zellen (Reichel et al. 2015; Roemer et al. 2016a). Normalerweise würden NK-Zellen dies erkennen und Apoptose in Tumorzellen einleiten. Durch eine Vielzahl von Mechanismen können HRS-Zellen allerdings eine quantitative und qualitative NK-ZellDefizienz im Hodgkin-Lymphom induzieren (Chiu et al. 2018). Die nicht neoplastischen Zellen im reaktiven Hintergrund des Immuninfiltrates zeigen also keine physiologische Tumorbekämpfung mehr. Immunsuppression im Hodgkin-Lymphom wird nicht nur durch die HRS-Zellen selbst mediiert, sondern auch an CD4 ${ }^{+}-$T-Lymphozyten, regulatorische T-Zellen, Mastzellen und Makrophagen abgetreten. Klinische Studien legen nahe, dass CD4 ${ }^{+}$- und regulatorische T-Zellen mit einer schlechteren Prognose assoziiert sind, wohingegen $\mathrm{CD}^{+}{ }_{-}$ T-Zellen mit einer besseren Prognose vergesellschaftet zu sein scheinen (Koreishi et al. 2010; Alonso-Álvarez et al. 2017; Hollander et al. 2018). Mastzellen und Makrophagen dagegen scheinen eher mit einer schlechteren Prognose zu korrelieren (Glimelius et al. 2005; Canioni et al. 2009; Guo et al. 2016). Außerdem korreliert die Makrophagen-Last im TME des Hodg- 
kin-Lymphoms mit der Anzahl an regulatorischen T-Zellen, was eine gegenseitige Rekrutierung der Umgebungszellen nahe legt (Barros et al. 2012; Barros et al. 2015).

\subsection{Klinik und Therapiemodalitäten des Hodgkin-Lymphoms}

Zum Diagnosezeitpunkt besteht bei den meisten Patient*innen mit Hodgkin-Lymphom eine indolente supradiaphragmale Lymphadenopathie. Am häufigsten finden sich die Lymphknotenkonglomerate im zervikalen und mediastinalen Bereich. Auch supraklavikulär und axillär manifestiert sich das HL über dem Zwerchfell. Etwa ein Drittel bis 40 Prozent der Betroffenen entwickeln systemische Symptome wie anderweitig nicht erklärbares Fieber, starken Nachtschweiß und ungewollten Gewichtsverlust, was als sogenannte B-Symptomatik zusammengefasst wird (Küppers et al. 2012; Ansell 2018). Weitere häufige Begleiterscheinungen sind ein chronischer Pruritus und allgemeines Schwächegefühl. Gleichwohl sich das Hodgkin-Lymphom in der Regel lymphogen über benachbarte Lymphknotenstationen ausbreitet, ist auch eine hämatogene Aussaat möglich (Guermazi et al. 2001; Ansell 2018). Bei Milzbefall kann eine Splenomegalie resultieren. Die häufigsten extranodalen Manifestationsorte sind Leber, Lunge und Knochenmark (Ansell 2018). Extralymphatische Manifestationen sind beim Hodgkin-Lymphom wesentlicher seltener als bei den NHL (Guermazi et al. 2001). Laborchemisch kann eine unspezifische Erhöhung von Entzündungsparametern sowie der Lactatdehydrogenase (LDH) imponieren. Im Blutbild findet sich häufig als Zusatzbefund eine absolute Lymphozytopenie und gelegentlich eine Eosinophilie (Herold 2016).

Die Verdachtsdiagnose, die sich in der Regel aus Anamnese und körperlicher Untersuchung ergibt, muss stets histologisch gesichert werden. Dies erfordert eine Lymphknotenexstirpation, da der diagnostische Wert einer zytologischen Feinnadelaspiration unzureichend für die Beurteilung der Lymphknotenarchitektur ist (Ansell 2018). Der immunhistochemische Nachweis der CD30-positiven HRS-Zellen in der Mikroskopie im Verbund mit dem typischen reaktiven zellulären Infiltrat bestätigt die Diagnose (Ansell 2018). Im Rahmen des klinischen Stagings wird bildgeberisch die Ausbreitung des Hodgkin-Lymphoms beurteilt. Dafür kommt neben einem Röntgen-Thorax eine Computertomographie mit Kontrastmittel für Hals, Thorax und Abdomen infrage. Suspekte Herde können ferner mittels Abdomensonographie identifiziert werden. Zudem wird meist eine Knochenmarkpunktion durchgeführt, um eine Infiltration der Markräume auszuschließen (Franco et al. 2004; Herold 2016). Mit erfolgter initialer Ausbreitungsdiagnostik werden die HL-Patient*innen anhand der AnnArbor-Klassifikation in vier Krankheitsstadien eingeordnet (Carbone et al. 1971; Canellos et 
al. 2014), welche wiederum risikostratifiziert drei Prognosegruppen zugeordnet werden (Engert et al. 2010).

Der Therapieansatz ist unabhängig vom Stadium beim cHL kurativ. Frühe und intermediäre Stadien werden mit einer kombinierten Radio-Chemotherapie behandelt. Das ABVDSchema (Akronym für die eingesetzten Chemotherapeutika Adriamycin/Doxorubicin, Bleomycin, Vinblastin, Dacarbazin) wird dabei mit einer involved site radiation therapy (ISRT), also einer lokalen Bestrahlung der initial befallenen Lymphknoten, kombiniert. Fortgeschrittene Stadien werden für gewöhnlich nur mit einer Hochdosis-Chemotherapie therapiert. Häufig kommt hierbei das BEACOPP-Regime zum Einsatz (beinhaltet die Zytostatika Bleomycin, Etoposid, Doxorubicin, Cyclophosphamid, Vincristin, Procarbazin und Prednison) (Engert 2016; Ansell 2018). Trotz der guten Heilungschancen sprechen etwa fünf bis zehn Prozent der HL-Patient*innen nicht auf die initiale Therapie an und bleiben therapierefraktär. 10 bis 30 Prozent der Betroffenen rezidivieren nach initialer kompletter Remission (Hoppe et al. 2017). Für diese Patient*innen besteht die Standardtherapie derzeit aus einer Salvage-Hochdosis-Chemotherapie gefolgt von einer autologen Stammzelltransplantation, was bei 50 Prozent der Patient*innen zu einer dauerhaften Remission führt (Schmitz et al. 2002; Montanari und Diefenbach 2014; von Tresckow und Moskowitz 2016; Hoppe et al. 2017).

Die Aufdeckung der komplexen Wechselwirkungen zwischen HRS-Zellen und den umgebenden benignen Immunzellen im TME der cHL-Läsionen bietet Möglichkeiten für neue therapeutische Interventionen. Im Rahmen der targeted therapy sollen nicht nur die HRS-Zellen selektiver attackiert werden, sondern auch das Mikromilieu im Hodgkin-Lymphom wird in Zukunft stärker in den Fokus rücken. Dem immunsuppressiven Umprogrammieren von normalen Zellen soll entgegengewirkt und neue pharmakologische Optionen getestet werden (Carbone et al. 2015; Roma-Rodrigues et al. 2019). So könnten Therapieresistenz überwunden und die Langzeitnebenwirkungen von aggressiven Polychemotherapien wie BEACOPP vermindert werden. Schon heute gibt es vielversprechende klinische Daten aus der Rezidivtherapie des Hodgkin-Lymphoms mit selektiven Agenzien und akzeptabler Toxizität, welche die konventionellen Therapieansätze erweitern. Brentuximab-Vedotin ist ein AntikörperWirkstoff-Konjugat mit dem Zielantigen CD30 auf den HRS-Zellen, das auf diesem Wege einen Mitosehemmstoff selektiv in den Tumorzellen anreichert und so die Apoptose dieser induziert. Das Immunkonjugat ist auch für die Behandlung des therapieresistenten und rezidivierten ALCL zugelassen (Younes et al. 2010). Mit den Immuncheckpoint-Inhibitoren Pembrolizumab und Nivolumab, die beide an PD-1 binden, gibt es weitere monoklonale 
Antikörper für die Behandlung des therapierefraktären und rezidivierenden klassischen Hodgkin-Lymphoms bei vorbehandelten Patient*innen im Rahmen von Studien (Ansell et al. 2015; Armand et al. 2016; Vassilakopoulos et al. 2019).

Weitere Forschung an der engen Interaktion zwischen HRS-Zellen und ihrer inflammatorischen Mikroumgebung soll in Zukunft also eine selektivere und nebenwirkungsärmere Behandlung in allen Stadien des Hodgkin-Lymphoms ermöglichen und bei Therapierefraktärität oder im Rezidiv bessere Perspektiven bieten. Nach wie vor kann die Hälfte der Patient*innen mit rezidiviertem Hodgkin-Lymphom nicht geheilt werden (Montanari und Diefenbach 2014). Zweit-Malignome wie akute Leukämien oder solide Tumoren, die mit einer Latenz von Jahrzehnten auftreten können, vermindern die langfristige Prognose und stehen im Kontrast zu den guten Heilungschancen der Primärerkrankung. Hinzu kommen weitere schwerwiegende Therapiefolgen wie Kardio- und Pulmotoxizität, Infertilität und Fatigue, welche Lebenserwartung und Lebensqualität der Betroffenen einschränken (Franklin et al. 2006; Küppers et al. 2012; Amin et al. 2020). Die Hauptaufgabe wird in Zukunft darin bestehen, die neuen Erkenntnisse über die Mikroumgebung des cHL in der Klinik zu implementieren. Eine neue Risikostratifizierung beim Hodgkin-Lymphom und die Etablierung besserer Prognosefaktoren könnten es möglich machen, weniger toxische Behandlungen zu etablieren und nicht nur die HRS-Zellen selbst zu attackieren, sondern auch deren Interaktionen mit dem TME und die Umprogrammierung von immunsuppressiven Zellen zu adressieren (Aldinucci et al. 2019).

\subsection{Vorergebnisse der Arbeitsgruppe}

In der Arbeitsgruppe (AG) wird schon seit Längerem in Zusammenarbeit mit anderen Forschungsgruppen mit dem In-ovo-Modell der Chorion-Allantois-Membran (CAM) und Lymphomen gearbeitet. Der CAM-Assay ist ein anerkanntes In-vivo-Xenograft-Modell in der experimentellen Onkologie (Ribatti 2014). So konnten Becker et al. (2012) und Klingenberg et al. (2014) das CAM-Modell für Analysen mit Lymphomzellen weiterentwickeln und auch erste Hinweise auf die Lymphomdisseminierung gewinnen. Hierbei wurde der CAM-Assay zunächst zur Untersuchung des Burkitt-Lymphoms eingesetzt (Becker et al. 2012; Klingenberg et al. 2014).

Früh haben wir in der AG auch zunächst durch Dr. N. Schoof und später in den Analysen der Dres. A. Arlt und M. Harenberg mit Zelllinien des cHL auf der CAM gearbeitet (Arlt 2018; Harenberg 2019). In den Arbeiten von Dr. A. Arlt und R. Specht wurde zum Beispiel die Frage untersucht, wie sich L-428-Lymphome in ovo verändern und disseminieren, wenn 
sie in Anwesenheit von Lymphom-assoziierten Makrophagen auf die CAM appliziert werden. Hierbei konnten die Kolleg*innen zeigen, dass L-428-Lymphomzellen, die gemeinsam mit durch HL-CM ausdifferenzierten M2-ähnlichen Makrophagen auf der CAM gewachsen sind, verstärkt lymphogen disseminierten.

Wir konnten auch beobachten, dass Tumorgröße und Gefäßzerstörung im Verbund mit TAMs im Vergleich zu reinen CAM-Lymphomen vermindert waren (Arlt et al. 2020). Überraschend war jedoch, dass die in vitro von Dr. A.Arlt beschriebenen Unterschiede von Makrophagen, die mit M-CSF oder HL-CM behandelt wurden, vor allem bezüglich der CD206Expression auf der CAM nicht mehr eindeutig dargestellt werden konnten (Taylor et al. 2005; Arlt et al. 2020).

Die Hypothese, die daraus abgeleitet wurde, beinhaltet die Frage, ob auf der CAM die L-428Zellen weiterhin Differenzierungsfaktoren für Makrophagen sezernieren und so die M-CSFdifferenzierten Makrophagen weiter in Richtung Hodgkin lymphoma-educated macrophages (HEMs) polarisieren können, also in ovo nach Ko-Applikation von Lymphomzellen und Makrophagen letztendlich kaum noch Unterschiede zwischen beiden Makrophagen-Populationen sichtbar werden.

\subsection{Fragestellung}

Ausgehend von dem Befund, dass Makrophagen beim klassischen Hodgkin-Lymphom prognostischen Wert haben können, wurde in der AG ein In-ovo-Modell etabliert, um Interaktionen zwischen Makrophagen und HRS-Zellen zu untersuchen. In den bisherigen Untersuchungen wurden vordifferenzierte Makrophagen mit Lymphomzellen zusammen auf die CAM appliziert.

Die Fragestellung, die wir im Rahmen dieser Arbeit beantworten wollen, beinhaltet folgende Aspekte:

1. Führt eine Inokulation von undifferenzierten Monozyten, also von CD14-positiven $\left(\mathrm{CD} 14^{+}\right)$peripheral blood mononuclear cells (PBMCs), zusammen mit Hodgkin-Lymphomzellen auf die CAM zu vergleichbaren Tumoren wie die Ko-Applikation von HEMs mit HL-Zellen?

2. Ist in diesen ko-kultivierten CAM-Lymphomen aus HRS-Zellen und Monozyten eine Aktivierung respektive Differenzierung der CD14+_PBMCs hin zu HEMs nachweisbar? 
Zur Beantwortung der Fragen sollte die Hodgkin-Zelllinie L-428 verwendet werden. CD14 ${ }^{+}$ PBMCs sollten aus Vollblutkonserven von Blutspender*innen isoliert und Monozyten mittels magnetischer Zellsortierung angereichert werden. Die entstehenden CAM-Lymphome sollten dann morphologisch und durch immunhistochemische Analysen weiter charakterisiert werden. Die immunhistochemische Färbung von CD30 war hier für die Darstellung der HL-Zellen und CD68 und CD206 zur Beschreibung der Makrophagen in ovo vorgesehen.

Die vorliegende Arbeit soll somit ein besseres Verständnis für die Wechselwirkungen von Tumorzellen im cHL mit Monozyten bieten und längerfristig auch Zusatzinformationen erarbeiten, um über selektive Therapiemöglichkeiten zu diskutieren, die sowohl Lymphomzellen als auch TAMs adressieren könnten. 


\section{$2 \quad$ Material und Methoden}

Im folgenden Materialteil (Kapitel 2.1) sind alle regelmäßig verwendeten Geräte, Substanzen und Softwares mit deren Herstellern aufgeführt.

Der Methodenteil (Kapitel 2.2) gliedert sich in zellbiologische Methoden (Kapitel 2.2.1), CAM-Assay (Kapitel 2.2.2), histologische Aufarbeitung der CAM-Läsionen (Kapitel 2.2.3) und statistische Analysen (Kapitel 2.2.4).

\subsection{Material}

\subsubsection{Geräte}

Tabelle 1: Verwendete Geräte.

\begin{tabular}{|c|c|}
\hline Gerät & Hersteller \\
\hline Accu Jet & Brand GmbH \& Co. KG, Wertheim, Deutschland \\
\hline BSS 300 GTFS Brutgerät & Grumbach Brutgeräte GmbH, Asslar, Deutschland \\
\hline Centrifuge 5424 & Eppendorf, Hamburg, Deutschland \\
\hline Dampfgarer SIGG Vapeur & SIGG AG, Frauenfeld, Schweiz \\
\hline Dremel Parkside PMGS 12 B2 & Lidl Stiftung \& Co. KG, Neckarsulm, Deutschland \\
\hline FACSCanto II Durchflusszytometer & BD Biosciences, Franklin Lakes, NJ, USA \\
\hline Glimmer-Sägeblatt $0,4 \mathrm{~mm}$ & Seipp GmbH, Langgöns, Deutschland \\
\hline Heraeus Multifuge 3 L-R & Thermo Fisher Scientific Inc., Waltham, MA, USA \\
\hline HERAfreeze, $-80^{\circ} \mathrm{C}$ Freezer & Thermo Fisher Scientific Inc., Waltham, MA, USA \\
\hline Ikamag RCT Magnetrührer/Heizplatte & $\begin{array}{l}\text { IKA-Werke GmbH \& Co. KG, } \\
\text { Staufen, Deutschland }\end{array}$ \\
\hline Infinite F50 & Tecan Group Ltd., Männedorf, Schweiz \\
\hline Inkubator Cytoperm & Thermo Fisher Scientific Inc., Waltham, MA, USA \\
\hline Inverses Durchlichtmikroskop Telaval 31 & Carl Zeiss Microscopy GmbH, Jena, Deutschland \\
\hline Leica DM5000 B & Leica Microsystems GmbH, Wetzlar, Deutschland \\
\hline Leica HI1210 Wasserbad & Leica Microsystems GmbH, Wetzlar, Deutschland \\
\hline Leica M125 & Leica Microsystems GmbH, Wetzlar, Deutschland \\
\hline Leica RM2245 & Leica Microsystems GmbH, Wetzlar, Deutschland \\
\hline Leica S6E & Leica Microsystems GmbH, Wetzlar, Deutschland \\
\hline Leica TP 1020 Gewebeeinbettautomat & Leica Microsystems GmbH, Wetzlar, Deutschland \\
\hline MACS MultiStand & Miltenyi Biotec, Bergisch Gladbach, Deutschland \\
\hline Microcentrifuge 5415 & Eppendorf, Hamburg, Deutschland \\
\hline Microflow Laminar Downflow Workstation & Bioquell Ltd., Andover, Großbritannien \\
\hline Microm HM 355 S & $\begin{array}{l}\text { Microm International GmbH, } \\
\text { Walldorf, Deutschland }\end{array}$ \\
\hline Motic SMZ-161 Stereomikroskop & Motic Inc., Xiamen, VR China \\
\hline
\end{tabular}




\begin{tabular}{|l|l|}
\hline Gerät & Hersteller \\
\hline Neubauer-Zählkammer & $\begin{array}{l}\text { LO Laboroptik GmbH, } \\
\text { Friedrichsdorf, Deutschland }\end{array}$ \\
\hline Pinzette Dumont & Sigma, Osterode, Deutschland \\
\hline Pipetboy acu & Integra Biosciences AG, Fernwald, Deutschland \\
\hline QuadroMACS Separator & Miltenyi Biotec, Bergisch Gladbach, Deutschland \\
\hline Sanyo Ultra Low -152 ${ }^{\circ}$ C Freezer & Panasonic Healthcare Co. Ltd., Tokio, Japan \\
\hline Schott KL 1600 LED & Schott AG, Mainz, Deutschland \\
\hline Schüttelapparat 3005 mit Kreisbewegung & $\begin{array}{l}\text { GFL Gesellschaft für Labortechnik mbH, } \\
\text { Burgwedel, Deutschland }\end{array}$ \\
\hline Shandon Citadel 2000 Tissue Processor & Thermo Fisher Scientific Inc., Waltham, MA, USA \\
\hline Shandon Histocentre & Thermo Fisher Scientific Inc., Waltham, MA, USA \\
\hline Tischzentrifuge 1-15k & $\begin{array}{l}\text { Sigma Laborzentrifugen GmbH, } \\
\text { Osterode, Deutschland }\end{array}$ \\
\hline Varistain 24-4 Automatic Slide Stainer & Thermo Fisher Scientific Inc., Waltham, MA, USA \\
\hline Vortex Genie 2 & Schütt Labortechnik, Göttingen, Deutschland \\
\hline Waage L2200S & Sartorius AG, Göttingen, Deutschland \\
\hline Wasserbad & Köttermann Uetze/Hänigsen, Deutschland \\
\hline Zeiss Axiocam MRm & Carl Zeiss Microscopy GmbH, Jena, Deutschland \\
\hline Zeiss Imager.Z1 & Carl Zeiss Microscopy GmbH, Jena, Deutschland \\
\hline
\end{tabular}

\subsubsection{Verbrauchsmaterialien}

Tabelle 2: Verwendete Verbauchsmaterialien.

\begin{tabular}{|l|l|}
\hline Verbrauchsmaterial & Hersteller \\
\hline 96-Well-Platte, 12 Well-Platte & Sarstedt AG Co., Nümbrecht, Deutschland \\
\hline Cellstar Tissue Culture Dishes & $\begin{array}{l}\text { Greiner Bio-One International GmbH, } \\
\text { Kremsmünster, Österreich }\end{array}$ \\
\hline Deckgläser & Menzel, Braunschweig, Deutschland \\
\hline Einbettformen aus Metall & Carl Roth GmbH, Karlsruhe, Deutschland \\
\hline Falcon Röhrchen $(15 \mathrm{ml}, 50 \mathrm{ml})$ & Sarstedt AG Co., Nümbrecht, Deutschland \\
\hline Filter Tips $(10 \mu 1,100 \mu \mathrm{l}, 1000 \mu \mathrm{l})$ & Sarstedt AG Co., Nümbrecht, Deutschland \\
\hline Filtropur S 0,45 & Sarstedt AG Co., Nümbrecht, Deutschland \\
\hline Kryoröhrchen/Einfriergefäße & $\begin{array}{l}\text { Greiner Bio-One International GmbH, } \\
\text { Kremsmünster, Österreich }\end{array}$ \\
\hline Leukosilk & BSN medical, Hamburg, Deutschland \\
\hline MACS LS Column & Miltenyi Biotec, Bergisch Gladbach, Deutschland \\
\hline Nunc Petrischale & Thermo Fisher Scientific Inc., Waltham, MA, USA \\
\hline Objektträger SuperFrost & Thermo Fisher Scientific Inc., Waltham, MA, USA \\
\hline Pasteur-Plast Pipetten, steril & Brand GmbH \& Co. KG, Wertheim, Deutschland \\
\hline Perfusor Syringe $50 \mathrm{ml}$ & Braun, Melsungen, Deutschland \\
\hline Reaktionsgefäße $(0,5 \mathrm{ml}, 1,5 \mathrm{ml}, 2 \mathrm{ml})$ & Eppendorf, Hamburg, Deutschland \\
\hline Rotilabo-Einbettkassetten & Carl Roth GmbH, Karlsruhe, Deutschland \\
\hline
\end{tabular}




\begin{tabular}{|l|l|}
\hline Verbrauchsmaterial & Hersteller \\
\hline Serologische Pipetten $(5 \mathrm{ml}, 10 \mathrm{ml}, 25 \mathrm{ml})$ & Sarstedt AG Co., Nümbrecht, Deutschland \\
\hline $\begin{array}{l}\text { Specific Pathogen Free Eggs, Hühnereier frei von } \\
\text { spezifischen Pathogenen }\end{array}$ & $\begin{array}{l}\text { Valo BioMedia GmbH, } \\
\text { Osterholz-Scharmbeck, Deutschland }\end{array}$ \\
\hline $\begin{array}{l}\text { Zellkulturflaschen mit Belüftungskappe } \\
\left(25 \mathrm{~cm}^{2}, 75 \mathrm{~cm}^{2}, 175 \mathrm{~cm}^{2}\right) \text { für Suspensionszellen }\end{array}$ & Sarstedt AG Co., Nümbrecht, Deutschland \\
\hline
\end{tabular}

\subsubsection{Chemikalien}

Tabelle 3: Verwendete Chemikalien.

\begin{tabular}{|c|c|}
\hline Chemikalien & Hersteller \\
\hline BD Matrigel Matrix, Growth Factor Reduced & BD Biosciences, Franklin Lakes, NJ, USA \\
\hline Biocoll Separating Solution & Biochrom GmbH, Berlin, Deutschland \\
\hline Bovines Serumalbumin (BSA) & Carl Roth GmbH, Karlsruhe, Deutschland \\
\hline Calciumchlorid $\left(\mathrm{CaCl}_{2}\right)$ & Merck KGaA, Darmstadt, Deutschland \\
\hline DAB (3,3'-Diaminobenzidin) Chromogen & Nordic Biosite, Täby, Schweden \\
\hline DAB Detect (DAB Substrate Puffer) & Nordic Biosite, Täby, Schweden \\
\hline Dimethylsulfoxid (DMSO) & Sigma-Aldrich Corporation, St. Louis, MO, USA \\
\hline DPX-Eindeckmedium für Histologie & Sigma-Aldrich Corporation, St. Louis, MO, USA \\
\hline Eisen(III)-chlorid-Hexahydrat & AppliChem GmbH, Darmstadt, Deutschland \\
\hline Essigsäure $100 \%$ (Eisessig) & Merck KGaA, Darmstadt, Deutschland \\
\hline Ethanol $99 \%$ & J.T. Baker, Center Valley, PA, USA \\
\hline Ethanol $96 \%$ & $\begin{array}{l}\text { Chemsolute, Th. Geyer GmbH \& Co. KG, } \\
\text { Renningen, Deutschland }\end{array}$ \\
\hline Ethylendiamintetraacetat (EDTA) & Merck KGaA, Darmstadt, Deutschland \\
\hline Fetales Kälberserum (FCS) & $\begin{array}{l}\text { Biochrom, Merck, Millipore, } \\
\text { Darmstadt, Deutschland }\end{array}$ \\
\hline Fluoromount $\mathrm{G}$ & Thermo Fisher Scientific Inc., Waltham, MA, USA \\
\hline Formaldehyd & Sigma-Aldrich Corporation, St. Louis, MO, USA \\
\hline Formaldehyd-Lösung $37 \%$ & Merck KGaA, Darmstadt, Deutschland \\
\hline Goat-Serum $10 \mathrm{ml}$ & Sigma-Aldrich Corporation, St. Louis, MO, USA \\
\hline Hämalaunlösung sauer nach Mayer & Carl Roth GmbH, Karlsruhe, Deutschland \\
\hline Hämatoxylin & Merck KGaA, Darmstadt, Deutschland \\
\hline Isopropanol & J.T. Baker, Center Valley, PA, USA \\
\hline Kaliumchlorid $(\mathrm{KaCl})$ & Merck KGaA, Darmstadt, Deutschland \\
\hline Kollagen Typ I, 5 mg/ml & Trevigen Inc., Gaithersburg, MD, USA \\
\hline Lichtgrün SF gelblich & Merck KGaA, Darmstadt, Deutschland \\
\hline Mayers Hämalaun Lösung & Merck KGaA, Darmstadt, Deutschland \\
\hline Natriumchlorid $(\mathrm{NaCl})$ & Merck KGaA, Darmstadt, Deutschland \\
\hline Orange $\mathrm{G}$ & Sigma-Aldrich Corporation, St. Louis, MO, USA \\
\hline Paraformaldehyd & Carl Roth GmbH, Karlsruhe, Deutschland \\
\hline Paraplast Plus (Paraffin) & Sigma-Aldrich Corporation, St. Louis, MO, USA \\
\hline
\end{tabular}




\begin{tabular}{|l|l|}
\hline Chemikalien & Hersteller \\
\hline Penicillin/Streptomycin (P/S) & Lonza Group Ltd., Basel, Schweiz \\
\hline Perdrogen Wasserstoffperoxid $\left(\mathrm{H}_{2} \mathrm{O}_{2}\right)$ & Sigma-Aldrich Corporation, St. Louis, MO, USA \\
\hline Phosphatgepufferte Salzlösung (PBS) & PAN-Biotech GmbH, Aidenbach, Deutschland \\
\hline Pikrinsäure & Merck KGaA, Darmstadt, Deutschland \\
\hline Ponceau S & Merck KGaA, Darmstadt, Deutschland \\
\hline Roti-Histokitt II & Carl Roth GmbH, Karlsruhe, Deutschland \\
\hline RPMI-1640 mit L-Glutamin & Lonza Group Ltd., Basel, Schweiz \\
\hline Salzsäure (HCl) rauchend 37 \% & Carl Roth GmbH, Karlsruhe, Deutschland \\
\hline Säurefuchsin & Merck KGaA, Darmstadt, Deutschland \\
\hline Tris-gepufferte Salzlösung (TBS) & Carl Roth GmbH, Karlsruhe, Deutschland \\
\hline Triton X 100 & Carl Roth GmbH, Karlsruhe, Deutschland \\
\hline Trypanblau 0,4 \% in PBS & Sigma-Aldrich Corporation, St. Louis, MO, USA \\
\hline Wolframatophosphorsäure-Hydrat & Merck KGaA, Darmstadt, Deutschland \\
\hline Xylol & Sigma-Aldrich Corporation, St. Louis, MO, USA \\
\hline
\end{tabular}

\subsubsection{Puffer, Lösungen und Medien}

Tabelle 4: Verwendete Puffer, Lösungen und Medien.

\begin{tabular}{|c|c|}
\hline Puffer / Lösung / Ansatz & Zutaten \\
\hline $1 \%$ Eisessig & $1 \mathrm{ml}$ Eisessig in $100 \mathrm{ml}$ Aquadest \\
\hline $2 \%$ Goat-Serum & $100 \mu \mathrm{l}$ Goat-Serum in $5 \mathrm{ml}$ PBS \\
\hline $4 \%$ Paraformaldehyd & $4 \%$ PFA in PBS \\
\hline Antikörperlösung & $\begin{array}{l}1 \times \text { TBS } \\
1 \% \text { BSA } \\
0,5 \% \text { Triton } \times 100\end{array}$ \\
\hline Blockierlösung & $\begin{array}{l}5 \% \text { Goat-Serum } \\
1 \% \text { BSA } \\
0,2 \% \text { Triton x } 100 \text { in PBS }\end{array}$ \\
\hline Bouin-Fixanz (wässriges Bouin) & $\begin{array}{l}150 \mathrm{ml} \text { Formaldehyd } 37 \% \\
50 \mathrm{ml} \text { Pikrinsäure } \\
10 \mathrm{ml} \text { Essigsäure } 100 \%\end{array}$ \\
\hline Einfriermedium & $\begin{array}{l}90 \%(\mathrm{v} / \mathrm{v}) \mathrm{FCS} \\
10 \%(\mathrm{v} / \mathrm{v}) \mathrm{DMSO}\end{array}$ \\
\hline Eisenhämatoxylin nach Weigert (Lösung A) & $\begin{array}{l}96 \% \text { Ethanol } \\
1 \%(\mathrm{w} / \mathrm{v}) \text { Hämatoxylin }\end{array}$ \\
\hline Eisenhämatoxylin nach Weigert (Lösung B) & $\begin{array}{l}\text { 17,9 mM Eisen(III)-chlorid } \\
2,5 \%(\mathrm{w} / \mathrm{v}) \text { Salzsäure }\end{array}$ \\
\hline FACS-Puffer & $\begin{array}{l}\text { PBS } \\
10 \%(v / v) \text { humanes AB-Serum }\end{array}$ \\
\hline
\end{tabular}




\begin{tabular}{|c|c|}
\hline Puffer / Lösung / Ansatz & Zutaten \\
\hline Lichtgrün & $\begin{array}{l}1,35 \mathrm{~g} \text { Lichtgrün } \\
900 \mathrm{ml} \text { Aquadest } \\
1,8 \mathrm{ml} \text { Eisessig }\end{array}$ \\
\hline Lockelösung & $\begin{array}{l}\text { 152,45 } \mathrm{mM} \mathrm{NaCl} \\
5,64 \mathrm{mM} \mathrm{KCl} \\
2,14 \mathrm{mM} \mathrm{CaCl} 2\end{array}$ \\
\hline MACS-Puffer & $\begin{array}{l}\text { PBS } \\
0.5 \%(\mathrm{w} / \mathrm{v}) \mathrm{BSA} \\
1 \mathrm{mM} \text { EDTA }\end{array}$ \\
\hline Mayer's Hämalaun-Lösung & $\begin{array}{l}1 \mathrm{~g} \text { Hämalaun } \\
1000 \mathrm{ml} \text { ddH2O } \\
0,2 \mathrm{~g} \text { NaJO3 } \\
50 \mathrm{~g} \text { Kalialaun } \\
50 \mathrm{~g} \text { Chloraldydrat } \\
1 \mathrm{~g} \text { Zitronensäure }\end{array}$ \\
\hline PBS/EDTA & $\begin{array}{l}\text { PBS } \\
1 \mathrm{mM} \text { EDTA }\end{array}$ \\
\hline Phosphorwolframsäure + Orange $G$ & $\begin{array}{l}36 \mathrm{~g} \text { Phosphorwolframsäure } \\
18 \mathrm{~g} \text { Orange G } \\
900 \mathrm{ml} \text { Aquadest }\end{array}$ \\
\hline Säurefuchsin-Lösung & $\begin{array}{l}\text { 0,6 g Ponceau S } \\
0,3 \mathrm{~g} \text { Säurefuchsin } \\
900 \mathrm{ml} \text { Aquadest } \\
1,8 \mathrm{ml} \text { Eisessig }\end{array}$ \\
\hline TE-Puffer & $\begin{array}{l}10 \text { mM Tris-base, } \mathrm{pH} 9 \\
1 \text { mM EDTA }\end{array}$ \\
\hline Trypanblau-Lösung & $\begin{array}{l}\text { PBS } \\
0,4 \%(w / v) \text { Trypanblau }\end{array}$ \\
\hline Zellkulturmedium (für HL-Zelllinie) & $\begin{array}{l}\text { RPMI-1640 mit } 4 \mathrm{mM} \text { L-Glutamin } \\
10 \% \text { FCS } \\
1 \% \mathrm{P} / \mathrm{S}\end{array}$ \\
\hline
\end{tabular}




\subsubsection{Antikörper}

Tabelle 5: Verwendete Antikörper.

\begin{tabular}{|l|l|l|}
\hline Antikörper & Klon & Hersteller \\
\hline mouse anti-CD30 & Ber-H2 & Dako, Agilent, Santa Clara, CA, USA \\
\hline mouse anti-CD68 & KP1 & Dako, Agilent, Santa Clara, CA, USA \\
\hline mouse anti-CD206 & D-1 & Santa Cruz Biotechnology Inc., Dallas, TX, USA \\
\hline goat anti-mouse HRP & polyklonal & Dako, Agilent, Santa Clara, CA, USA \\
\hline mouse anti-CD14 FITC & M5E2 & BD Biosciences, Franklin Lakes, NJ, USA \\
\hline CD14-microbeads, human & $\begin{array}{l}\text { Katalog-Nr.: } \\
130-050-201\end{array}$ & Miltenyi Biotec, Bergisch Gladbach, Deutschland \\
\hline
\end{tabular}

\subsubsection{Zelllinien und Zellisolate}

Tabelle 6: Verwendete Zelllinien und Zellisolate.

\begin{tabular}{|l|l|}
\hline Zelllinie / Zellisolate & Referenz \\
\hline L-428 & (Schaadt et al. 1979) \\
\hline Humane Vollblutkonserven & Freundlicherweise überlassen vom \\
von anonymen Spender*innen & Blutspendedienst der Universitätsmedizin \\
zur Monozyten-Isolierung & Göttingen, Abteilung Transfusionsmedizin \\
\hline
\end{tabular}

\subsubsection{Software}

Tabelle 7: Verwendete Software.

\begin{tabular}{|l|l|}
\hline Software & Hersteller \\
\hline FACS Diva Version 6.1.3 & BD Biosciences, Franklin Lakes, NJ, USA \\
\hline GraphPad Prism 7.04 for Windows & Graph Pad Software Inc., San Diego, CA, USA \\
\hline ImageJ 1.48v & $\begin{array}{l}\text { Wayne Rasband, National Institutes of Health, } \\
\text { Bethesda, MD, USA }\end{array}$ \\
\hline Leica Application Suite 3.8.0 & Leica Microsystems, Wetzlar, Deutschland \\
\hline Microsoft Office 2016 (Word, PowerPoint, Excel) & Microsoft, Redmont, WA, USA \\
\hline Zeiss Axiovision 4.6.3 & Carl Zeiss Microscopy GmbH, Jena, Deutschland \\
\hline
\end{tabular}




\subsection{Methoden}

\subsubsection{Zellbiologische Methoden}

\subsubsection{Hodgkin-Lymphom-Zelllinie}

Die in der vorliegenden Arbeit verwendete Zelllinie L-428 wurde 1978 aus dem malignen Pleuraerguss einer 37-jährigen Patientin mit histologisch gesichertem Hodgkin-Lymphom vom nodulär-sklerosierenden Typ (Stadium IVb) gewonnen und immortalisiert (Schaadt et al. 1979). Die gewonnenen HRS-Zellen wurden zur Etablierung einer in Suspension wachsenden und EBV-negativen In-vitro-Langzeit-Zellkultur verwendet.

Alle zwei Tage wurden die Zellen in frischem RPMI-1640-Medium aufgenommen und in einer Konzentration von $5 \cdot 10^{5} / \mathrm{ml}$ kultiviert, um danach für weitere $48 \mathrm{~h}$ in Zellkulturflaschen mit Belüftungskappe im Brutschrank bei $37{ }^{\circ} \mathrm{C}, 5 \% \mathrm{CO}_{2}$ und $95 \%$ Luftfeuchtigkeit inkubiert zu werden. Zur Verwendung in den Versuchen mussten die HRS-Zellen eine Viabilität von mindestens $90 \%$ zeigen.

Die Arbeitsgruppe erhielt ihren L-428-Stock für experimentelle Studien 1992 von Prof. V. Diehl aus Köln. Die L-428-Zelllinie ist auch bei der Deutschen Sammlung von Mikroorganismen und Zellkulturen (DSMZ) in Braunschweig erhältlich und wurde regelmäßig durch Immunglobulin-Sequenzanalysen und die DSMZ überprüft.

\subsubsection{Zellzahl- und Viabilitätsbestimmung}

Um Zellzahl und -viabilität zu ermitteln, wurden die Lymphomzellen gründlich resuspendiert. Nach Entnahme eines $20 \mu$ l-Aliquots aus der Zellsuspension wurde dieses im Verhältnis von 1:1 mit 0,4 \%iger Trypanblau-Lösung auf einer Mikrotiterplatte vermengt. Abgestorbene Zellen wurden so dunkelblau gefärbt und konnten durchlichtmikroskopisch als solche identifiziert werden. Zur Definition der Konzentration viabler Zellen mittels NeubauerZählkammer wurde die folgende Formel herangezogen: Zellen $/ \mathrm{ml}=(\Sigma$ der gezählten Zellen in allen vier Quadranten / 4) $2 \cdot 10^{4}$. Anschließend konnte die Gesamtzellzahl mittels Multiplikation der errechneten Zellkonzentration pro Mililiter mit dem Gesamtvolumen der jeweiligen Zellsuspension erhoben werden. Konsekutiv ließ sich die Viabilität bestimmen: Viabilität $[\%]=($ Anzahl der lebendigen Zellen / Anzahl aller ausgezählten Zellen $) \cdot 100$.

\subsubsection{Kultivierung und Kryokonservierung der Lymphomzellen}

Elf Tage vor den Beimpfungsexperimenten auf der CAM wurden die bei $-150{ }^{\circ} \mathrm{C}$ in Einfriermedium aufbewahrten L-428-Zellen in Kultur genommen. Zu diesem Zweck wurden die 
HRS-Zellen rasch im Wasserbad bei $37^{\circ} \mathrm{C}$ aufgetaut und umgehend mit $9 \mathrm{ml}$ vorgewärmten RPMI-Medium vermengt. Nach Entnahme eines Aliquots zur Festlegung von Zellzahl und -viabilität konnte die restliche Zellsuspension bei Raumtemperatur (RT) für 5 min und $120 \mathrm{~g}$ zentrifugiert werden. Der Überstand wurde unter Zuhilfenahme einer Absaugpumpe mit einer Pasteurpipette entfernt und das generierte Zellpellet in einer Konzentration von $5 \cdot 10^{5}$ Zellen $/ \mathrm{ml}$ in frischem Kulturmedium aufgenommen und für $48 \mathrm{~h}$ bei $37{ }^{\circ} \mathrm{C}$ und $5 \%$ $\mathrm{CO}_{2}$ inkubiert.

Für die Langzeitaufbewahrung bei $-150{ }^{\circ} \mathrm{C}$ wurde ein Stock der L-428-Lymphomzellen in Einfriermedium (10\% DMSO und 90 \% FCS) kryokonserviert. Pro Kryoröhrchen wurde ein Pellet von $5 \cdot 10^{6}$ HRS-Zellen in $1 \mathrm{ml}$ Einfriermedium resuspendiert und bis zum Eichstrich aufgenommen. Um Gefrierschäden zu vermeiden, wurden die Zellen sukzessive mit einer Rate von $-1{ }^{\circ} \mathrm{C} / \mathrm{min}$ heruntergekühlt und dafür die Kryotubes in Isopropanol-Gefrierboxen bei $-80^{\circ} \mathrm{C}$ für $24 \mathrm{~h}$ zwischengelagert, um ab dem Folgetag bei $-150{ }^{\circ} \mathrm{C}$ aufbewahrt zu werden.

\subsubsection{Monozyten-Anreicherung mittels MACS}

An den Versuchstagen wurden jeweils die Vollblutkonserven zweier gesunder Spender*innen aufgearbeitet, freundlicherweise zur Verfügung gestellt vom Blutspendedienst der Abteilung Transfusionsmedizin der Universitätsmedizin Göttingen (Ethikvotum 16/5/18An). Die PBMCs, also mononukleäre Zellen des peripheren Blutes, wurden aus frischen buffy coats (Leukozytenfilmen) der Vollblutkonserven gewonnen (Menck et al. 2014).

Zur Verringerung der Erythrozytenzahl wurden die Proben zunächst im Verhältnis 1:1 mit PBS/EDTA verdünnt und für $20 \mathrm{~min}$ bei $1350 \mathrm{~g}$ zentrifugiert. Die weißliche Interphase wurde abgenommen und auf jeweils $30 \mathrm{ml}$ mit PBS/EDTA aufgefüllt. Um die Leukozyten weiter anzureichern, wurden sie mittels Dichtegradientenzentrifugation (Biocoll separating solution) ausgearbeitet. Die beschichteten Biocoll-Lösungen wurden für 30 min bei $400 \mathrm{~g}$ zentrifugiert. Leukozyten, die sich zwischen Plasma- und Erythrozytenphase befanden, wurden entnommen und in PBS gewaschen. Hierbei wurden auch die Thrombozyten weiter depletiert. Anschließend wurde die Zellzahl bestimmt.

Mittels Dichtegradientenzentrifugation über Biocoll separating solution (Biochrom $\mathrm{GmbH}$, Berlin, Deutschland) wurden, wie zuvor beschrieben, CD14+-Monozyten aus PBMCs durch das magnetic cell separation (MACS)-Verfahren isoliert. MACS ist ein Verfahren zur Fraktionie- 
rung einzelner Zellpopulationen aus Zellgemischen anhand selektiv exprimierter Oberflächenmarker. Dazu wurden anti-CD14-microbeads (Miltenyi Biotec, Bergisch Gladbach, Deutschland) analog zu den Instruktionen des Herstellers verwendet.

Kurz zusammengefasst wurden zu den PBMCs in der erforderlichen Zellzahl $\left(1 \cdot 10^{7}\right.$ Zellen / $20 \mu 1$ microbeads) die CD14-microbeads hinzugefügt und die Zellsuspension wurde durch vorsichtiges Schwenken vermischt und für 15 min im Kühlschrank bei $4{ }^{\circ} \mathrm{C}$ inkubiert. Danach wurden die Zellen gewaschen und von überschüssigen microbeads befreit. Nach einem zweiten Waschschritt wurden die Zellen in MACS-Puffer resuspendiert und auf die Vorfilter und LS column im QuadroMACS Separator aufgetragen. Der Durchfluss wurde zunächst aufgefangen. Es folgten drei Waschschritte mit MACS-Puffer. Danach wurde die Säule vom Separator entfernt und auf einem adäquaten Auffang-Falcon platziert. Mit 3 ml MACS-Puffer wurden die an die magnetischen Partikel gebundenen Zellen eluiert, indem der Stempel fest in die Säule gedrückt wurde. Die Zellen wurden in PBS gewaschen und nun konnte die Zellzahl bestimmt werden. Ein weiteres Aliquot wurde zur Verifizierung der CD14-Reinheit entnommen. Die Reinheit der CD14 ${ }^{+}$-Zellen wurde anschließend per Durchflusszytometrie (fluorescence-activated cell sorting, FACS) quantifiziert. Zellen mit einer Reinheit von $\geq 95 \%$ bezogen auf CD14 wurden für die CAM-Analysen eingesetzt.

\subsubsection{Durchflusszytometrie}

Um die Reinheit der $\mathrm{CD}_{14}{ }^{+}$-Zellen in der resultierenden Zellsuspension zu quantifizieren, wurden $100 \mu \mathrm{l}$ Zellsuspension mit einem Fluoreszeinisothiocyanat (FITC)-markierten CD14-Antikörper gefärbt und in einem FACSCanto II Durchflusszytometer mit FACS Diva Software analysiert. Wenn der Anteil an $\mathrm{CD} 14^{+}$-Monozyten $95 \%$ und mehr betrug, wurden die Zellen für die CAM-Versuche verwendet.

Mit Hilfe der Durchflusszytometrie lassen sich Zellen auf physikalische und biochemische Eigenschaften anhand ihrer Größe, Struktur, Granularität und exprimierter Oberflächenmarker untersuchen. Bei der durchflusszytometrischen Analyse mittels FACS werden Einzelzellen durch fluoreszierende Markierung sortiert und anhand des reflektierten Lichts detektiert. Dabei werden die Zellen einzeln durch eine Flusskammer an einem Laserstrahl vorbeigeführt. Aufgrund morphologischer Charakteristika wird bei Kreuzung des Laserstrahls ein Streulicht generiert, das an zwei Stellen detektiert wird. Das Vorwärtsstreulicht (forward angle light scatter, Ablenkwinkel $1^{\circ}$ bis $10^{\circ}$ ) als Maß der Zellgröße wird in Richtung des ursprünglichen Laserstrahls gemessen, während das Seitwärtsstreulicht (side angle light scatter) im $90^{\circ}$ Winkel zur initialen Richtung des Laserstrahls bestimmt wird und auch mit der zellulären Granularität korreliert. 
Die mononukleären Zellen wurden in einem Rundboden-Röhrchen zentrifugiert und mit einer Konzentration von $10^{7} / \mathrm{ml}$ in FACS-Puffer aufgenommen. Der FITC-konjugierte CD14-Antikörper (BD Biosciences, Franklin Lakes, NJ, USA) markierte nun mittels direkter Immunfluoreszenz die CD14 ${ }^{+}$-Zellfraktion. Die Zellen wurden für 20 min auf Eis gefärbt und dann durch Zugabe von $500 \mu 12 \%$ BSA in PBS gewaschen. Der Überstand wurde nach Zentrifugation für 5 min bei $400 \mathrm{~g}$ verworfen. Nach einem weiteren Waschschritt mit PBS wurden die Zellen in $300 \mu \mathrm{l}$ PBS resuspendiert. Die Datenerhebung erfolgte an einem FACSCanto II Durchflusszytometer unter Verwendung der FACSDiva Software (BD Biosciences, Franklin Lakes, NJ, USA). Nach gating auf viable Zellen wurden Dubletten exkludiert, indem die Breite gegen den Bereich des Seitwärtsstreulichtes geplottet wurde. Ungefärbte Zellen wurden genutzt, um die Laserleistung zu justieren. Für jede Probe wurden Daten von 5000 bis 10.000 Einzelzellen erhoben. Die mittleren Fluoreszenzintensitäten wurden mit der FACSDiva Software berechnet. Mittlere Fluoreszenzintensitäts-Verhältnisse wurden erhalten, indem die mittlere Fluoreszenzintensität des Antikörpers durch die Isotypen-Kontrolle dividiert wurde. Die immunphänotypisch charakterisierten Zellen konnten dann in einem dot plot dargestellt werden und so die CD14-Anreicherung durch das vorausgegangene MACS-Verfahren visualisiert werden (vgl. Abbildung 1).

\subsubsection{CAM-Assay}

Krebserkrankungen können unter Verwendung von experimentellen In-vivo-Xenograft-Modellen veranschaulicht werden. Dazu werden humane Tumorzellen immuninkompetenten Tieren injiziert (Khanna und Hunter 2005). Der CAM-Assay erlaubt es, das Disseminierungspotenzial von malignen Zellen solider oder disseminierter Neoplasien, wie im vorliegenden Fall des cHL, in ovo zu untersuchen. So können Tumorbildung und -progress im Hühnchen-Modell betrachtet werden. Hierzu wurde die CAM befruchteter, pathogenfreier Eier der Spezies Haushuhn (Gallus gallus domesticus) von der Rasse Weißes Leghorn steril freigelegt. Dies ermöglichte die Applikation von in vitro kultivierten Lymphomzellen mit oder ohne Monozyten auf die Membran. Nach vier Tagen Inkubationszeit wurden die generierten CAM-Läsionen extrahiert, vermessen und anschließend histologisch aufgearbeitet.

Die Entwicklung eines Hühnerembryos dauert 21 Tage bis zum Zeitpunkt des Schlüpfens (Ribatti 2010). Die Chorion-Allantois-Membran dient der Sauerstoff- und Nährstoffversorgung des Embryos und ist selten dicker als $100 \mu \mathrm{m}$ (Deryugina und Quigley 2008). Zwischen Tag fünf und sechs der Embryonalentwicklung entsteht die CAM durch Fusion von Chorion (Zottenhaut) und Allantois (embryonale Harnblase) (Melkonian et al. 2002). Etwa nach zehn 
Tagen ist die CAM vollständig vaskularisiert, was das Anwachsen von Tumorzellen fördert (Armstrong et al. 1982; Deryugina und Quigley 2008).

Die befruchteten Hühnereier wurden vier Tage bei $37^{\circ} \mathrm{C}$ und $80 \%$ relativer Luftfeuchtigkeit bebrütet und dabei regelmäßig alle 40 min gewendet. Am vierten Tag der Embryonalentwicklung wurde nach behutsamer Desinfektion der äußersten Eischale ein etwa $0,75 \mathrm{~cm}^{2}$ großes rechteckiges Fenster oberhalb des Dotters mit einem Dremel geschaffen. Die Luftblase des Eis wurde angestochen. Folglich sank der Dotter mit der CAM innerhalb des Eis ab. Die Eier mit der nun freiliegenden CAM wurden mit Leukosilk-Fixierpflaster wieder verschlossen und für weitere sieben Tage im Brutschrank inkubiert.

An Tag elf der Embryonalentwicklung des Huhns zeichnet sich das Gefäßmuster der CAM deutlich ab und die Vaskularisierung ist praktisch abgeschlossen (Ausprunk et al. 1974). Nun konnte die freigelegte CAM in definierten Regionen mit Lymphomzellen beziehungsweise Monozyten beimpft werden. Die Inokulation der CAM mit humanen Zellen erfolgte in drei verschiedenen Bedingungen: Monozyten allein, L-428-Zellen allein und Ko-Kulturen aus Lymphomzellen und Monozyten gesunder Spender*innen. Die Monozyten wurden an den Versuchstagen, wie in Kapitel 2.2.1.4 beschrieben, aus frischen Vollblutkonserven isoliert. Die L-428-Zellen waren elf Tage vorab aufgetaut, kultiviert und alle $48 \mathrm{~h}$ expandiert worden. Am Vortag der CAM-Versuche wurden die Hodgkin-Lymphomzellen nochmals frisch auf eine Konzentration von $5 \cdot 10^{5} / \mathrm{ml}$ eingestellt. Am Versuchstag wurden die L-428-Zellen für 5 min bei $120 \mathrm{~g}$ und RT zentrifugiert, der Überstand verworfen und das Zellpellet mit je 2 $\mathrm{ml}$ PBS in Reaktionsgefäße mit Rundboden aufgenommen. Nach nochmaliger Zentrifugation und Absaugen des Überstandes wurden die L-428-Zellen mit Matrigel vermengt. Die rein monozytären Zellpellets und die Ko-Kultur-Zellpellets aus Lymphomzellen und Monozyten wurden für $7 \mathrm{~min}$ bei $300 \mathrm{~g}$ abzentrifugiert und danach in das Matrigel aufgenommen. Das Matrigel wird aus murinen Engelbreth-Holm-Swarm-Sarkomen gewonnen. Diese Mischung aus verschiedenen Komponenten der extrazellulären Matrix ermöglicht es den Lymphomzellen, in Form eines soliden Tumors auf der CAM anzuwachsen. Die humanen Zellen wurden jeweils in $20 \mu \mathrm{l}$ Matrigel gelöst. Für die Tumorkontrollen wurden pro CAM $2 \cdot 10^{6}$ L-428-Zellen pipettiert. Rein monozytäre Läsionen wurden jeweils mit $1 \cdot 10^{6} \mathrm{CD} 14^{+}$PBMCs pro Ei generiert und für die Ko-Kulturen jeweils $2 \cdot 10^{6} \mathrm{HRS}-Z e l l e n$ zusammen mit $1 \cdot 10^{6}$ Monozyten auf die CAM inokuliert. Die Beimpfung der CAM erfolgte so, dass die Zellen weder ganz nah an größeren Gefäßen noch weitab von jeglichen Gefäßen pipettiert wurden. Nach erfolgter Inokulation wurden die Eier wiederum mit Leukosilk verschlossen und für weitere vier Tage bebrütet. 
Am fünfzehnten Tag der aviären Embryogenese wurden die generierten CAM-Läsionen extrahiert. Dazu wurde das Loch in der Eischale vergrößert und die angewachsenen Tumoren mitsamt umgebender CAM großzügig per Federschere ausgeschnitten. Die Tumoren wurden in PBS gewaschen, lichtmikroskopisch untersucht, fotografiert und vermessen. Ein $1 \mathrm{~cm}$ Maß wurde mit fotografiert. Die Proben wurden dann über Nacht in $4 \%$ Paraformaldehyd (PFA) fixiert.

Mit Hilfe des Programms ImageJ wurden aus den Lichtbild-Aufnahmen der CAM-Läsionen deren Flächen bestimmt. Die Tumorgrenzen wurden unter Nutzung des Polygon Tools umfahren. Fotografien eines vordefinierten $1 \mathrm{~cm}-\mathrm{Ma}$ es wurden zur Skalierung genutzt und so konnte die Fläche des umfahrenen Bereiches berechnet werden.

\subsubsection{Histologische Aufarbeitung der CAM-Läsionen}

Am Tag nach der Ernte der CAM-Läsionen wurden die Proben aus dem 4 \% PFA in 60 \% Ethanol für $3 \mathrm{~h}$ überführt und anschließend maschinell entwässert. Dabei durchliefen die Proben eine aufsteigende Ethanolreihe (70 \% für 3 h, $80 \%$ für 1 h, $90 \%$ für 1 h, $96 \%$ für $1 \mathrm{~h}, 99 \%$ für $2 \mathrm{~h}$ ) und wurden nachfolgend für 1,5 h in Isopropanol belassen. Einer dreimaligen Inkubation in Xylol (30 min, 45 min, 45 min) folgend härteten die Tumoren zuerst für 30 min und anschließend für $7 \mathrm{~h}$ bei $60^{\circ} \mathrm{C}$ in Paraplast Plus aus. Abhängig vom Durchmesser wurden die Tumoren mit einem Skalpell halbiert. So konnten Tumorquerschnitte ohne langes Trimmen am Mikrotom generiert werden. Schließlich wurden die Tumorhälften in Metallschalen in heißem Paraffin eingebettet und kühlten über Nacht aus. Nachfolgend wurden die Paraffinblöcke mit den sich darin befindlichen Tumoren mit dem Mikrotom geschnitten. Die Schnittdicke betrug dabei zwischen $5 \mu \mathrm{m}$ und $6 \mu \mathrm{m}$. Die angefertigten Schnitte wurden in einem Wasserbad auf Objektträger überführt und trockneten anschließend für $24 \mathrm{~h}$ bei $42{ }^{\circ} \mathrm{C}$ im Wärmeschrank.

Die Schnittpräparate wurden mit einer Masson-Trichrom-Färbung behandelt, um eine morphologische Beurteilung der Läsionen zu ermöglichen. Zunächst wurden die Gewebeschnitte entparaffiniert. Zur maschinellen Entparaffinierung wurden die Tumorschnitte zweimal in Xylol belassen ( $3 \mathrm{~min}, 2 \mathrm{~min}$ ), um hiernach eine absteigende Ethanolreihe zu durchlaufen (99\% für 2 min, $96 \%$ für 2 min, $80 \%$ für 2 min, $60 \%$ für 2 min) und in destilliertem Wasser gewaschen zu werden (2 min). Um die Nuklei der Zellen zu färben, wurden die Objektträger zunächst für 3 min in Eisenhämatoxylin nach Weigert gebracht und anschließend in fließendem Leitungswasser gewaschen (9 min). Nach Inkubation in Säurefuchsin-Lösung (5 min) zur Färbung des Zytoplasmas wurden die Tumorschnitte in $1 \%$ 
Eisessig (1 min) und Phosphorwolframsäure mit Orange G getaucht (1 min). Daraufhin wurden die Objektträger in $1 \%$ Eisessig $(1 \mathrm{~min})$ und in Lichtgrün für 5 min überführt. Zuletzt wurden die Tumorschnitte in $1 \%$ Eisessig ( $3 \mathrm{~min}$ ) belassen und es schloss sich eine zweimalige Entparaffinierung der gefärbten Schnitte in absolutem Alkohol (1 min, 2 min) und in Xylol (5 min) an. Die Trichrom-Schnitte wurden abschließend mit DPX-Eindeckmedium und Deckgläschen versehen und über Nacht getrocknet, um schließlich lichtmikroskopisch befundet und fotografiert zu werden.

Für die immunhistochemische Charakterisierung der CAM-Präparate bezüglich einer Expression von CD30, CD68 oder CD206 wurde sich der horseradish peroxidase (HRP, Meerrettich-Peroxidase) als Reporterenzym bedient. Für die HRP-Reaktion wurden die Tumorschnitte auf SuperFrost Ultra Plus Objektträger gebracht. Zur Entparaffinierung wurden die Schnitte dreimal für je 3 min in Xylol gebracht und durchliefen im Anschluss eine absteigende Ethanolreihe (99\% für zweimal $3 \mathrm{~min}, 96 \%$ für $3 \mathrm{~min}, 80 \%$ für $3 \mathrm{~min}, 70 \%$ für 3 min) und wurden in doppelt destilliertem Wasser $\left(\mathrm{ddH}_{2} \mathrm{O}\right)$ gewaschen. Zur Antigendemaskierung wurden die Objektträger für $20 \mathrm{~min}$ in verdampfenden TE-Puffer inkubiert. Zur Inhibition der endogenen Peroxidase wurden die Tumorschnitte für 15 min bei RT in einer Küvette mit $1 \% \mathrm{H}_{2} \mathrm{O}_{2}$ in PBS inkubiert. Die sich anschließenden Färbeschritte können der Tabelle 8 entnommen werden.

Tabelle 8: Peroxidase-Färbung der CAM-Schnittpräparate.

\begin{tabular}{|l|l|l|}
\hline Zeit & Temperatur & Lösung \\
\hline $5 \mathrm{~min}$ & RT & $\mathrm{ddH}_{2} \mathrm{O}$ \\
\hline $1 \mathrm{~min}$ & RT & PBS \\
\hline $30 \mathrm{~min}$ & RT in feuchter Kammer & $2 \%$ Goat-Serum in PBS \\
\hline $1 \mathrm{~min}$ & RT & PBS \\
\hline $16 \mathrm{~h}$ & $4^{\circ} \mathrm{C}$ in feuchter Kammer & CD30 / CD68 / CD206 in $2 \%$ Goat-Serum in PBS \\
\hline $1 \mathrm{~min}$ & RT & PBS \\
\hline $1 \mathrm{~h}$ & RT in feuchter Kammer & Goat anti-mouse HRP in $2 \%$ Goat-Serum in PBS \\
\hline $1 \mathrm{~min}$ & RT & PBS \\
\hline
\end{tabular}

Der primäre CD206-Antikörper wurde 1:50 in 2\% Goat-Serum in PBS diluiert. Der Sekundärantikörper (goat anti-mouse HRP) wurde stets 1:100 in 2\% Goat-Serum in PBS verdünnt. Für die Entwicklung der Antikörper-markierten Tumorquerschnitte wurde als Substrat der HRP jeweils $50 \mu \mathrm{l}$ DAB Chromogen in DAB Detect (1:100) für 1 min auf die Schnittpräparate pipettiert. Die Substratkonversion führte zu einem wasserunlöslichen braunen Endprodukt, was während der Färbung der Schnitte mikroskopisch kontrolliert wurde. Bei Sichtbar- 
werden einer intensiven Braunfärbung wurden die Objektträger in Leitungswasser abgestoppt. Schließlich konnten die Nuklei angefärbt werden, indem die Objektträger für 2 min in Hämalaun platziert wurden.

\subsubsection{Statistische Analysen}

Die Ergebnisse der Versuche wurden dargestellt als Mittelwert \pm Standardabweichung (SD) der angegebenen Anzahl an biologischen Replikaten. Der nicht parametrische Mann-Whitney-U-Test wurde zur Analyse der nicht normalverteilten Flächen von L-428- respektive CAM-Mischtumoren verwendet. Die drei verschiedenen Bedingungen auf der CAM wurden mit einem one-way-analysis of variance (ANOVA) mit anschließender Bonferroni-Methode untersucht. Das Signifikanzniveau lag bei $* \mathrm{p}<0,05,{ }^{* *} \mathrm{p}<0.01,{ }^{* * *} \mathrm{p}<0,001$. Für alle statistischen Analysen wurde GraphPad Prism 7.04 verwendet. 


\section{Ergebnisse}

\subsection{CD14 ${ }^{+}$-PBMCs als Inokulum im CAM-Assay}

Wir wollten untersuchen, inwieweit im Xenograft-Modell der Chorion-Allantois-Membran des Hühnereis die L-428-Zellen weiterhin makrophagozytäre Differenzierungsfaktoren sezernieren und somit Monozyten in Richtung HEMs polarisieren können. In Abbildung 1 ist dargestellt, dass die CD14-Anreicherung zu über $95 \%$ Reinheit der CD14+-PBMCs geführt hat und entsprechend für die In-ovo-Analysen genutzt werden konnte. Diese Reinheit wurde in allen Analysen erreicht und entsprechende CD14+ ${ }^{+}$PBMCs eingesetzt.

In den Untersuchungen wurden $2 \cdot 10^{6}$ L-428-Lymphomzellen zusammen mit $1 \cdot 10^{6}$ CD14 ${ }^{+}$-PBMCs in Matrigel vermischt und jeweils $20 \mu$ der Mischung auf die CAM inokuliert. Zum Vergleich wurden entweder nur $2 \cdot 10^{6} \mathrm{~L}-428$-Zellen oder nur $1 \cdot 10^{6} \mathrm{CD} 14^{+}$PBMCs auf die CAM einer vergleichbaren Anzahl von Eiern appliziert. Die Eier wurden dann, wie in Kapitel 2.2.2 beschrieben, für weitere vier Tage (96 h) inkubiert. Die resultierenden CAM-Läsionen wurden geerntet, indem mit einer Federschere großzügig um den Bereich der Applikationsstelle ausgeschnitten wurde.

Es wurden fünf unabhängige Runden mit insgesamt 150 Eiern durchgeführt. Dies ist in Tabelle 9 zusammengefasst. Hierbei wurden die extrahierten Läsionen für jeden CAM-Assay bewertet und die Fläche einer Läsion beziehungsweise eines CAM-Lymphoms bei Sichtbarkeit im Binokular berechnet. Insgesamt wurden in fünf In-ovo-Versuchsreihen 42 Eier mit Monozyten von neun verschiedenen Donor*innen beimpft. Von den 42 befruchteten Eiern konnten 29 von sechs unterschiedlichen Spender*innen ausgewertet werden. 13 Hühnerembryonen waren zum Erntezeitpunkt abgestorben (Auswertungsquote 69 \%). Die geernteten Kontroll-Läsionen hatten eine durchschnittliche Fläche von $0,11 \mathrm{~cm}^{2}(\operatorname{vgl}$. Tabelle 9). Dabei variierte die Größe teils erheblich.

Tabelle 9: Übersicht der CAM-Läsionen. Die Tabelle zeigt eine Zusammenfassung aller extrahierten CAMLäsionen in drei verschiedenen Bedingungen in fünf Replikaten und deren durchschnittliche Flächen in $\mathrm{cm}^{2}$.

\begin{tabular}{|c|c|c|c|c|}
\hline Inokulum & $\begin{array}{c}\text { Anzahl } \\
\text { Eier }\end{array}$ & $\begin{array}{c}\text { Extrahierte Läsionen } \\
\text { pro CAM-Assay }\end{array}$ & $\begin{array}{c}\text { Auswertungs- } \\
\text { quote [\%] }\end{array}$ & $\begin{array}{l}\text { Mittelwert der } \\
\text { Flächen }\left[\mathrm{cm}^{2}\right]\end{array}$ \\
\hline $\mathrm{CD}_{14}^{+}-\mathrm{PBMCs}$ & 42 & 0/10/13/0/6 [29] & 69 & 0,11 \\
\hline L-428 & 52 & $5 / 5 / 14 / 14 / 6 \quad[44]$ & 84,6 & 0,21 \\
\hline $\begin{array}{l}\mathrm{L}-428+ \\
\text { CD14+_PBMCs }\end{array}$ & 56 & 0/10/23/7/14 [54] & 96,4 & 0,113 \\
\hline
\end{tabular}



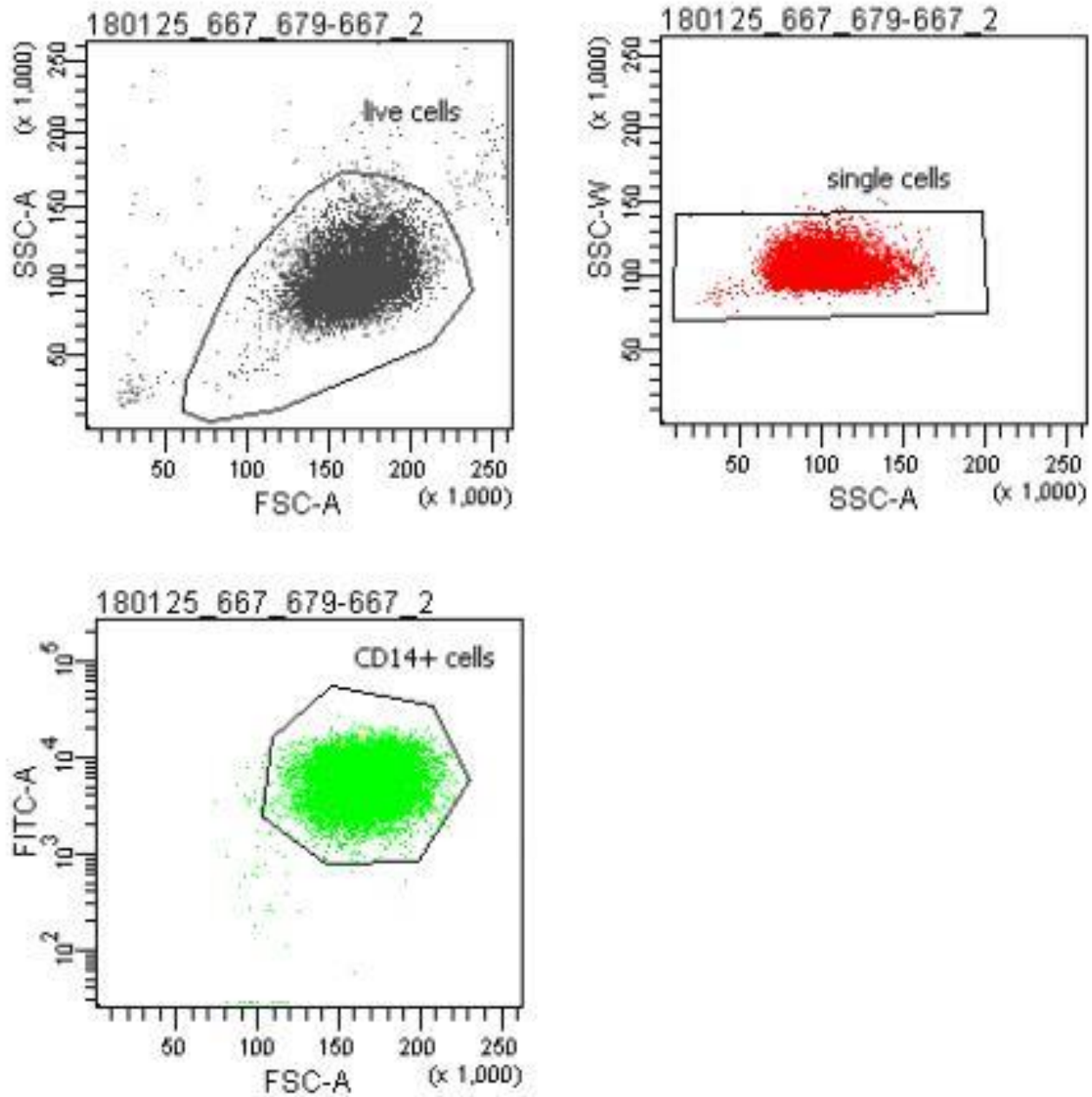

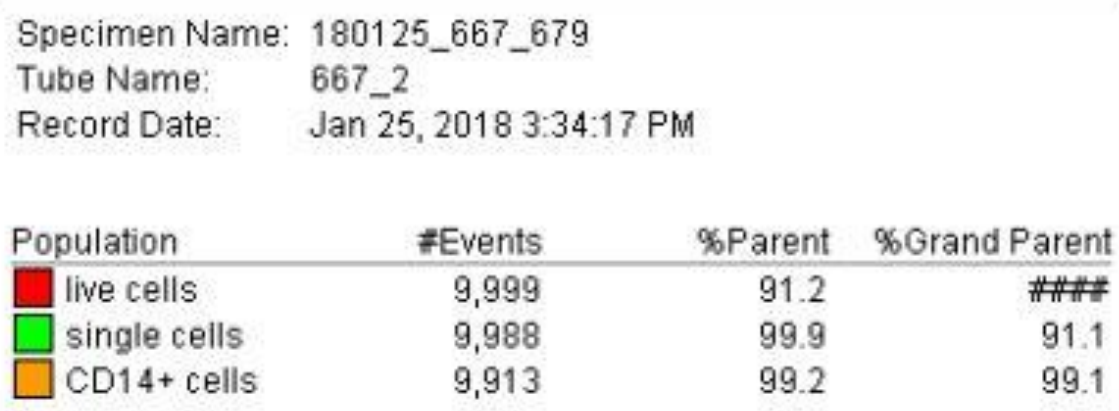

Abbildung 1: Anreicherung an CD14+_PBMCs nach MACS. Dargestellt sind die dot plots von sidescatter (SSCA) und forward-scatter (FSC). Mittels Durchflusszytometrie wurde die CD14-Reinheit der PBMCs verifiziert. Für eine Verwendung in den CAM-Experimenten musste diese bei mindestens $95 \%$ liegen. 
In Abbildung 2 sind die Aufsicht-Fotografien von exemplarischen monozytären Läsionen von vier verschiedenen Spender*innen zu sehen. Die Beimpfung der CAM mit unbehandelten Monozyten führte zum Teil zu makroskopisch blasigen und transparenten Läsionen, die bei der Extraktion mit größter Vorsicht zu handhaben und zum Teil nur schwer zu identifizieren waren. Auch bei Nähe zu größeren Blutgefäßen der Chorion-Allantois-Membran zeigten die monozytären Läsionen keine Einblutungen. Die darunterliegenden Blutgefäße der CAM waren angesichts der Transparenz der Beimpfungsstelle meistens sehr gut erkennbar.

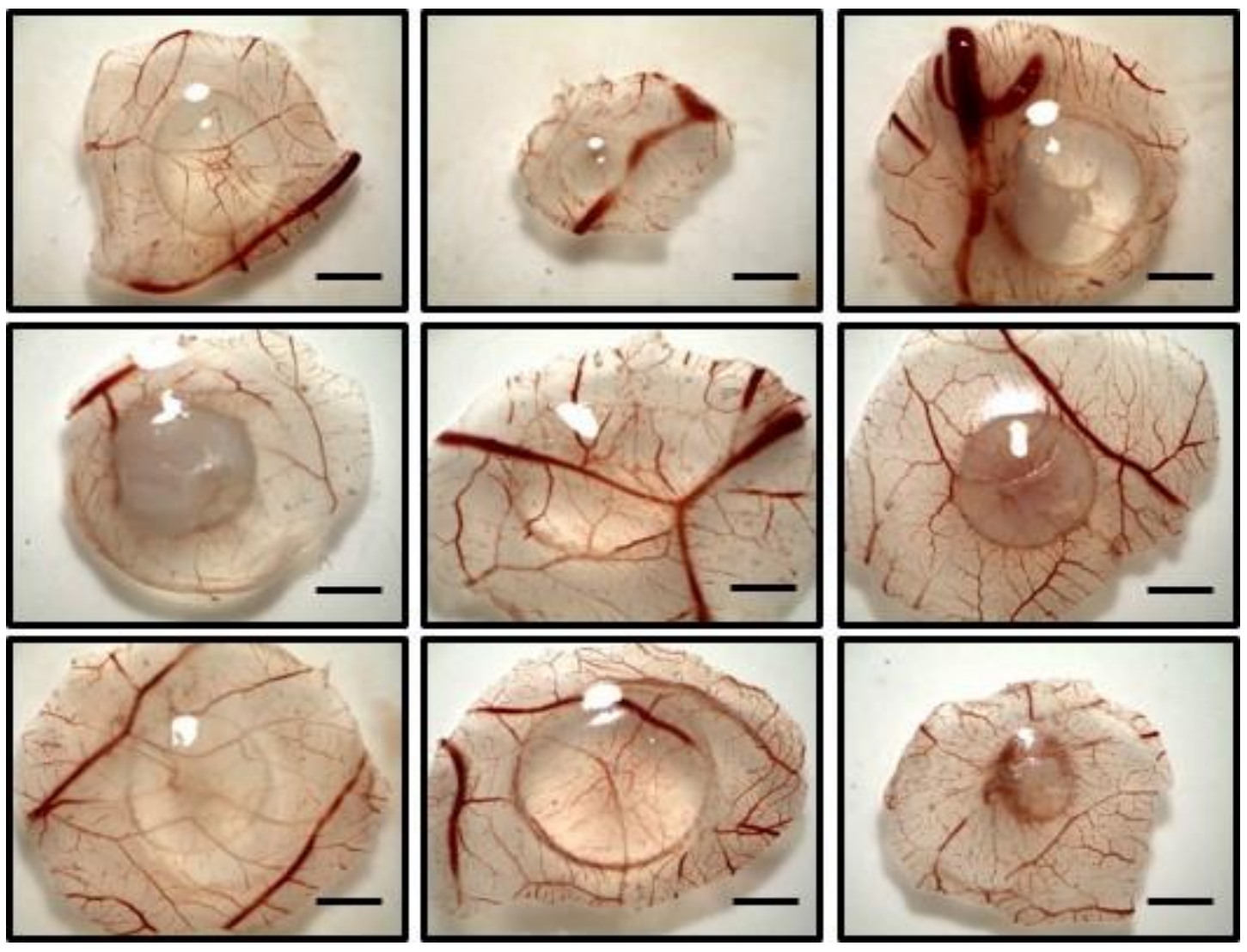

Abbildung 2: CD14+-PBMCs (Monozyten) bilden blasige und transparente Läsionen nach vier Tagen auf der CAM. Zu sehen sind auflichtmikroskopische Aufnahmen von neun verschiedenen CAM-Läsionen, die durch Inokulation von jeweils $1 \cdot 10^{6}$ CD $14^{+}$-PBMCs von vier verschiedenen Spender*innen generiert wurden. Die vaskularisierte CAM scheint durch die transparenten Beimpfungsstellen durch. Die Größe der extrahierten Areale variierte erheblich. Die Maßstabsleiste umfasst $2 \mathrm{~mm}$ (schwarzer Balken).

Die extrahierten monozytären Läsionen wurden für eine histologische Charakterisierung mittels Trichrom-Färbung aufgearbeitet. Mit der hier genutzten Masson-Trichrom-Färbung können kollagene Bindegewebsfasern bläulich-grün dargestellt werden. Da wir das Tumorstroma der CAM-Läsionen und den möglichen Abbau von Bindegewebsstrukturen darstellen wollten, wurde diese Färbung einer Hämatoxylin-Eosin-Färbung vorgezogen. 
In Abbildung 3 sind zwei monozytäre Läsionen mit Übersichtsaufnahmen und histologischem Schnittpräparat in steigender Vergrößerung abgebildet. Die Monozyten der beiden Exemplare stammen von dem*der gleichen Spender*in und verdeutlichen in der mikroskopischen Detailansicht die intraindividuelle morphologische Variabilität bei der Applikation von benignen myeloiden Zellen ohne Tumorzellen auf die CAM. Die CD14-Reinheit bei diesem Zellisolat lag bei 99,2\%. Die linke Läsion (Abbildung 3A) hat eine Fläche von 0,093 $\mathrm{cm}^{2}$ und ist damit deutlich größer als die rechts dargestellte Läsion (Abbildung 3B) mit ihrer Fläche von $0,051 \mathrm{~cm}^{2}$. Dennoch hat das Inokulum jeweils eine vergleichbare Form in der Aufsicht. Bei genauerer Betrachtung zeigt die Trichrom-Färbung, dass die Kollagen-Verteilung (grün) zwischen den beiden Läsionen nicht vergleichbar ist (Abbildung 3E-H). In der linksseitigen Läsion findet sich eine grünliche Schicht aus extrazellulärer Matrix beziehungsweise Matrigel oben in der Läsion (Abbildung 3E+G), wohingegen sich bei der Läsion auf der rechten Seite vermehrtes Bindegewebe vor allem um die CAM-Gefäße findet (Abbildung $3 \mathrm{H}+\mathrm{J})$. In Abbildung $3 \mathrm{~F}$ sieht es so aus, als hätte sich eine neue Chorionmembran über die CD14+-PBMCs gebildet. Eine solche war in der Läsion auf der linken Seite eventuell auch vorhanden, könnte aber durch die präparatorische Manipulation und die gegebene Fragilität der Proben nicht mehr nachweisbar sein. Die myeloiden Zellen sind relativ gleichmäßig in den Läsionen verteilt. Teilweise findet sich eine Spindelform bei diesen Zellen, was für einen Differenzierungsprozess vom Monozyten hin zum gewebeständigen Makrophagen in der CAM in einem Zeitraum von vier Tagen spricht. Die Monozyten respektive Makrophagen sind um die Blutgefäße herum zahlreich vertreten (Abbildung 3I-J).

Als ergänzende Darstellung finden sich in Abbildung 4 zwei exemplarische monozytäre Läsionen von $\mathrm{CD} 14^{+}$-PBMCs, die aus dem Blut von einem*einer weiteren unabhängigen Spender*in isoliert wurden. Die CD14-Reinheit beim verwendeten Zellisolat lag hier bei $97 \%$. Die hier gezeigten Präparate unterscheiden sich von den in Abbildung 3 dargestellten Läsionen insofern, als dass sie in der Aufsicht transparenter wirken (Abbildung 4A-B). In der 12,5und 50-fachen Vergrößerung der Trichrom-gefärbten Gewebeschnitte (Abbildung 4C-F) erkennt man unterschiedliche Kollagenstrukturen. In der linksseitigen CAM-Läsion erscheint das Bindegewebe regulär, wohingegen rechtsseitig die CD14+-PBMCs-getriebene Degradierung zu einem anderen Muster führte. In beiden Fällen war kaum noch Kollagen nachweisbar. Während bei der linken Läsion eine grünliche Schicht über den Blutgefäßen der CAM auffiel, in der sich ebenfalls myeloide Zellen fanden (Abbildung 4G), stellte sich die Verteilung der extrazellulären Matrix in der rechten Läsion homogener dar, wie in $4 \mathrm{H}$ zu sehen ist. 
In der 200-fachen Vergrößerung in 4I-J sind jeweils neben den Hühner-Erythrozyten Monozyten beziehungsweise Makrophagen mit gleichförmigen Verteilungsmuster zu sehen. An Stellen ohne genügend Matrix fehlen die myeloiden Zellen.
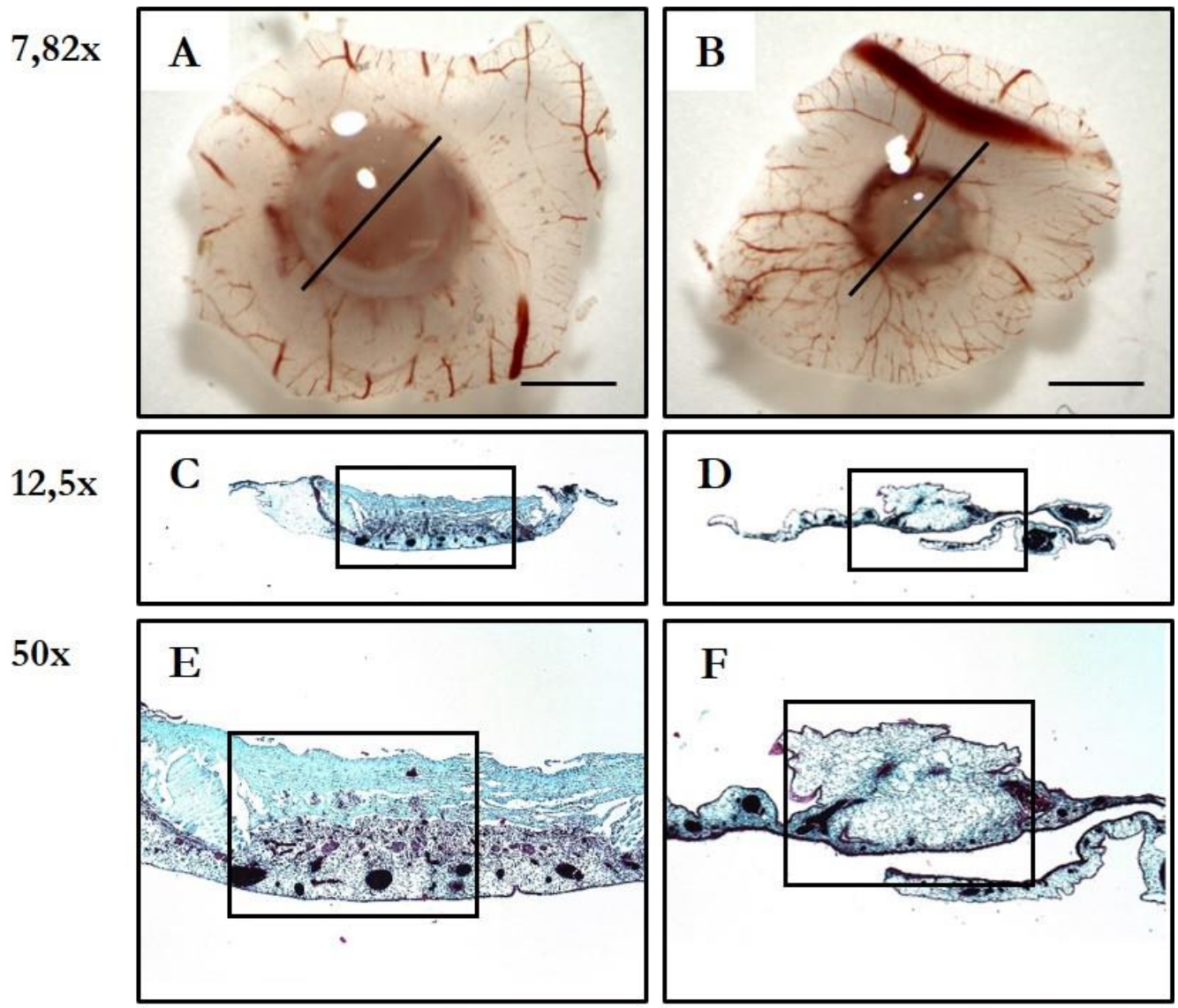

$100 x$
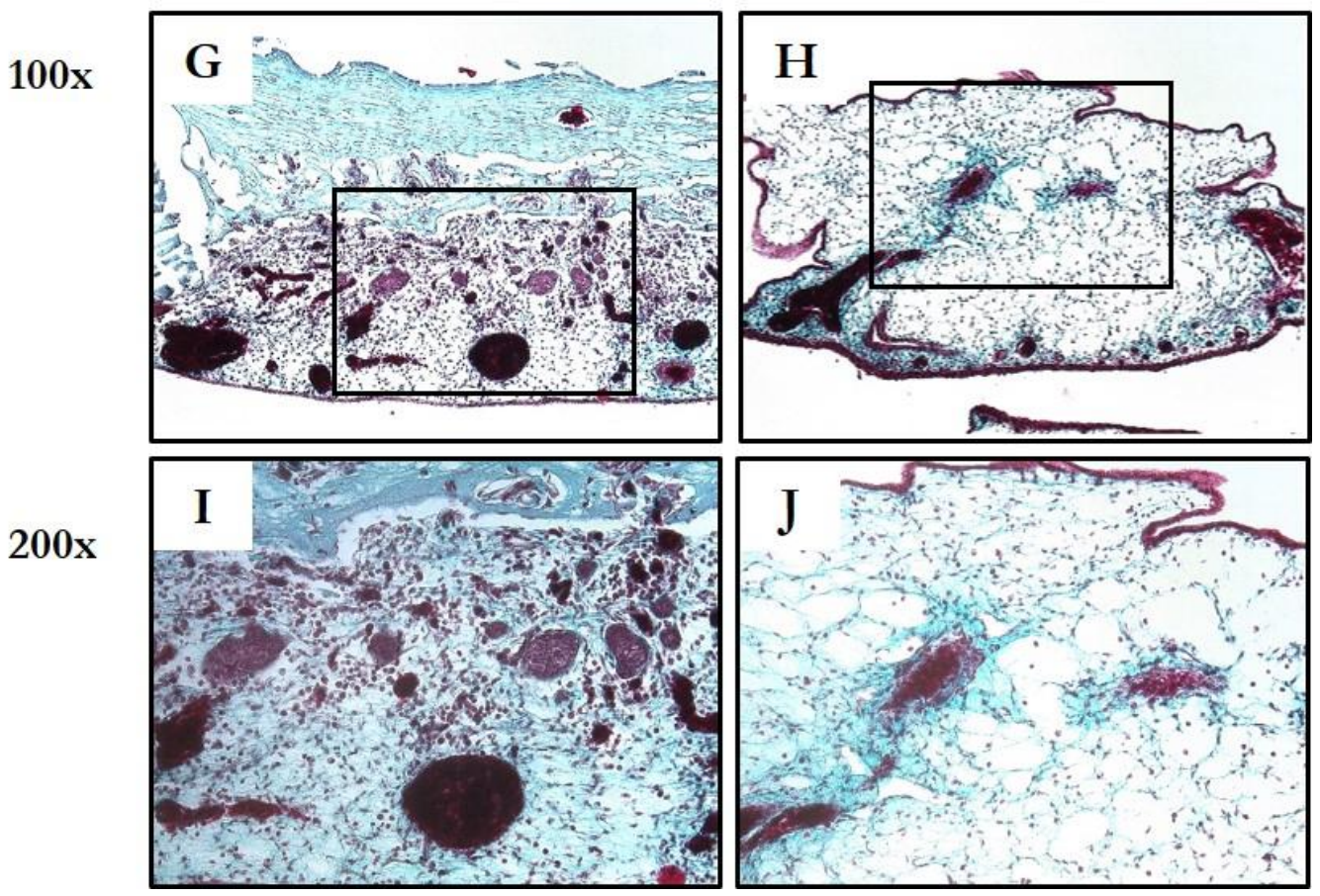

Abbildung 3: Trichrom-Färbung von zwei monozytären CAM-Läsionen. Es zeigen sich unterschiedliche Veränderungen der CAM. Die Ebene des histologischen Schnittes ist in A und B mit einer schwarzen Linie 
markiert und die Maßstabslinie entspricht $2 \mathrm{~mm}$ (schwarzer Balken). Die Übersicht in C und D zeigt die unterschiedliche Morphologie der beiden Läsionen. In den weiteren Vergrößerungen (E-J) erkennt man eine ubiquitäre Verteilung der myeloiden Zellen in den Läsionen, verstärkt finden sie sich um die Blutgefäße der CAM.
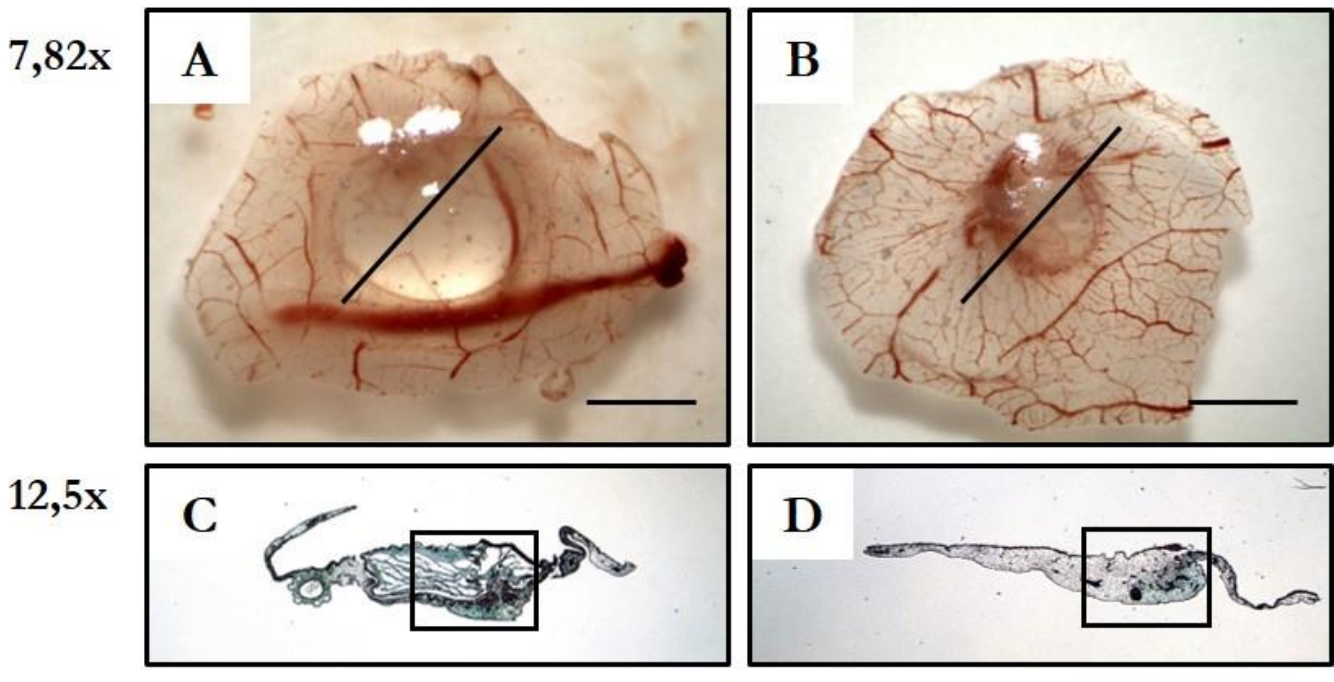

50x
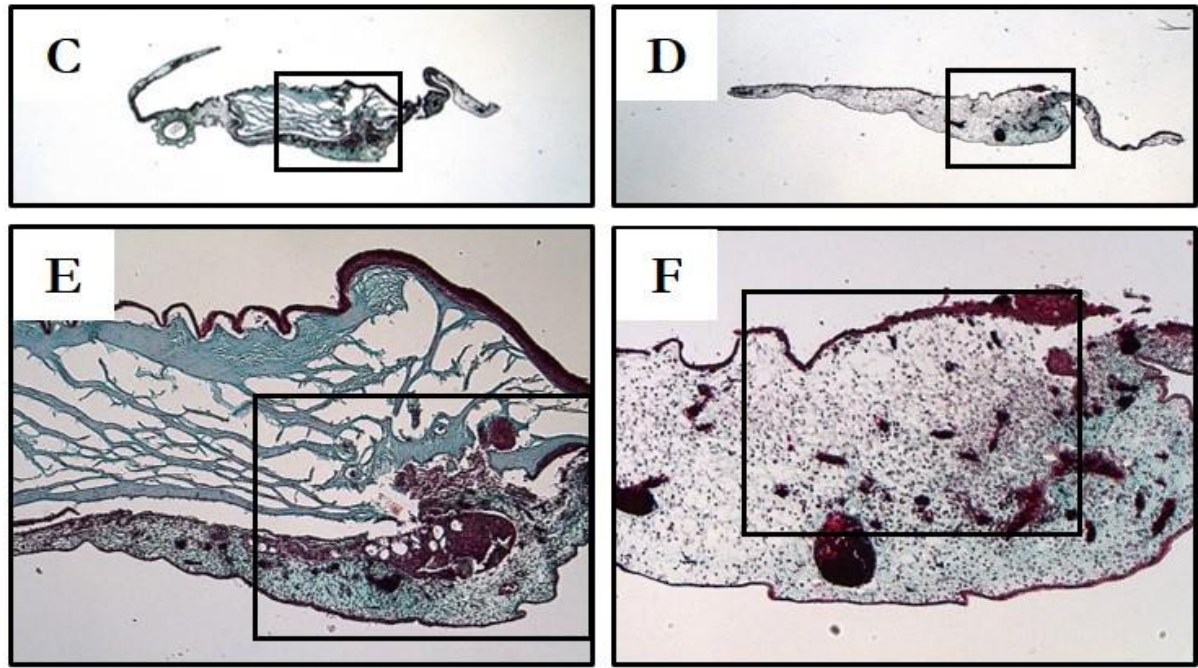

100x
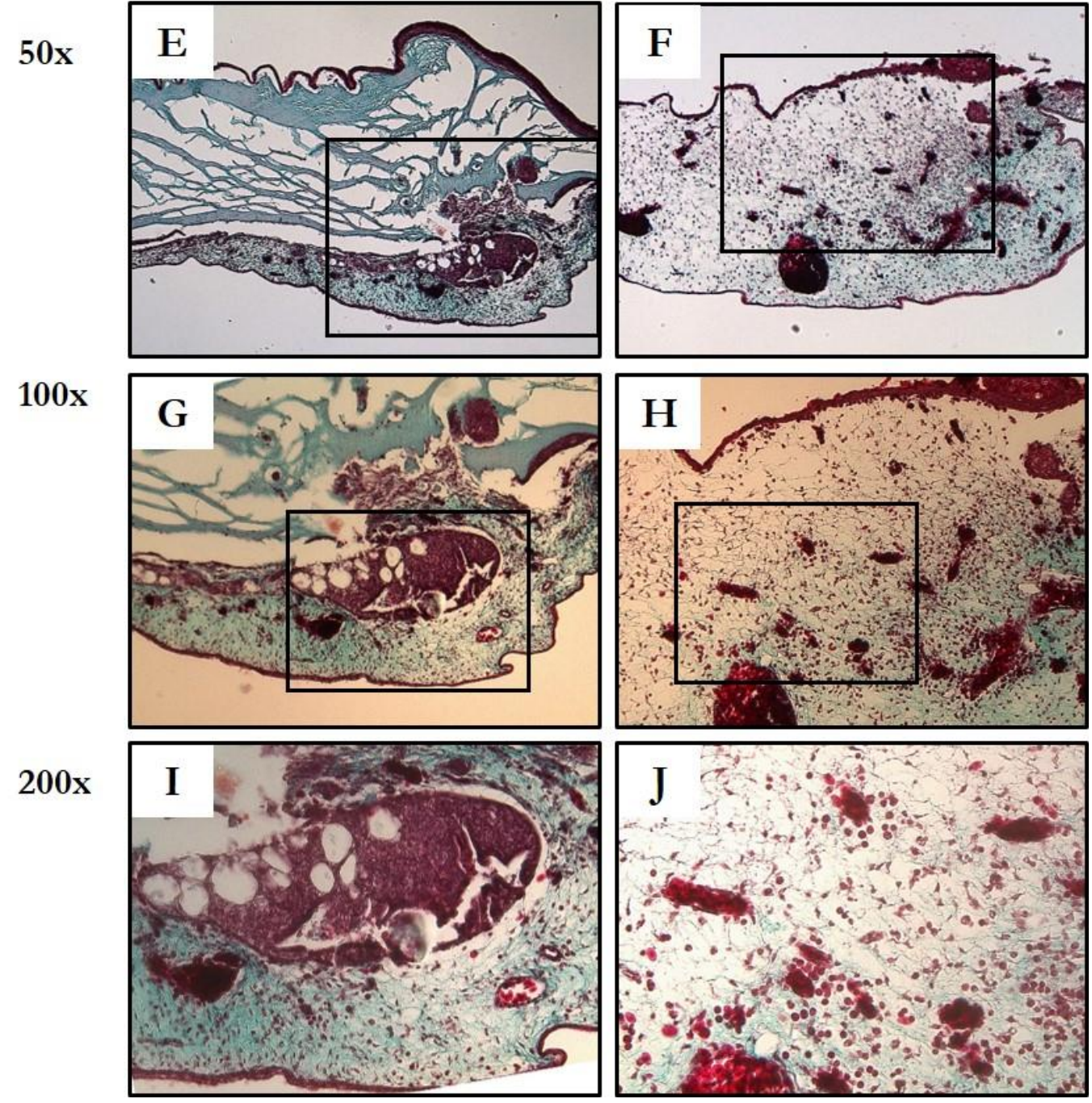

Abbildung 4: Monozyten können die Chorionmembran durchbrechen. CD14+_PBMCs sind in der Lage, die Chorionmembran zu durchbrechen und in das Bindegewebe zwischen Chorion- und Allantoismembran einzudringen. Auch diese beiden exemplarischen Beimpfungsstellen, auf die CD14+-PBMCs pipettiert wurden, 
wurden mit Monozyten von dem*der jeweils gleichen Spender*in generiert. Zu sehen ist eine Trichrom-Färbung mit aufsteigender Vergrößerung. Die Ebene des histologischen Schnittes ist in A und B mit einer schwarzen diagonalen Linie markiert und der schwarze horizontale Balken entspricht einem Maßstab von $2 \mathrm{~mm}$. Die schwarz umrandeten Areale sind jeweils darunter vergrößert dargestellt. In 50-facher Vergrößerung wird die unterschiedliche Manifestation des applizierten Matrigels deutlich (E-F). Wohl fixationsbedingt finden sich dabei in der linken Läsion größere Lücken, wohingegen die Matrix rechtsseitig homogener erscheint.

Um sicher zu verifizieren, dass es sich bei den Zellen in der Trichrom-Färbung um myeloide Zellen handelte, wurden die Läsionen auch einer immunhistochemischen Färbung zugeführt und dabei ein Antikörper, der das Antigen CD68 detektierte, eingesetzt. Im Zuge der HRPReaktion wurde das CD68-Antigen, das sowohl von Monozyten als auch Makrophagen exprimiert wird, farblich sichtbar gemacht.
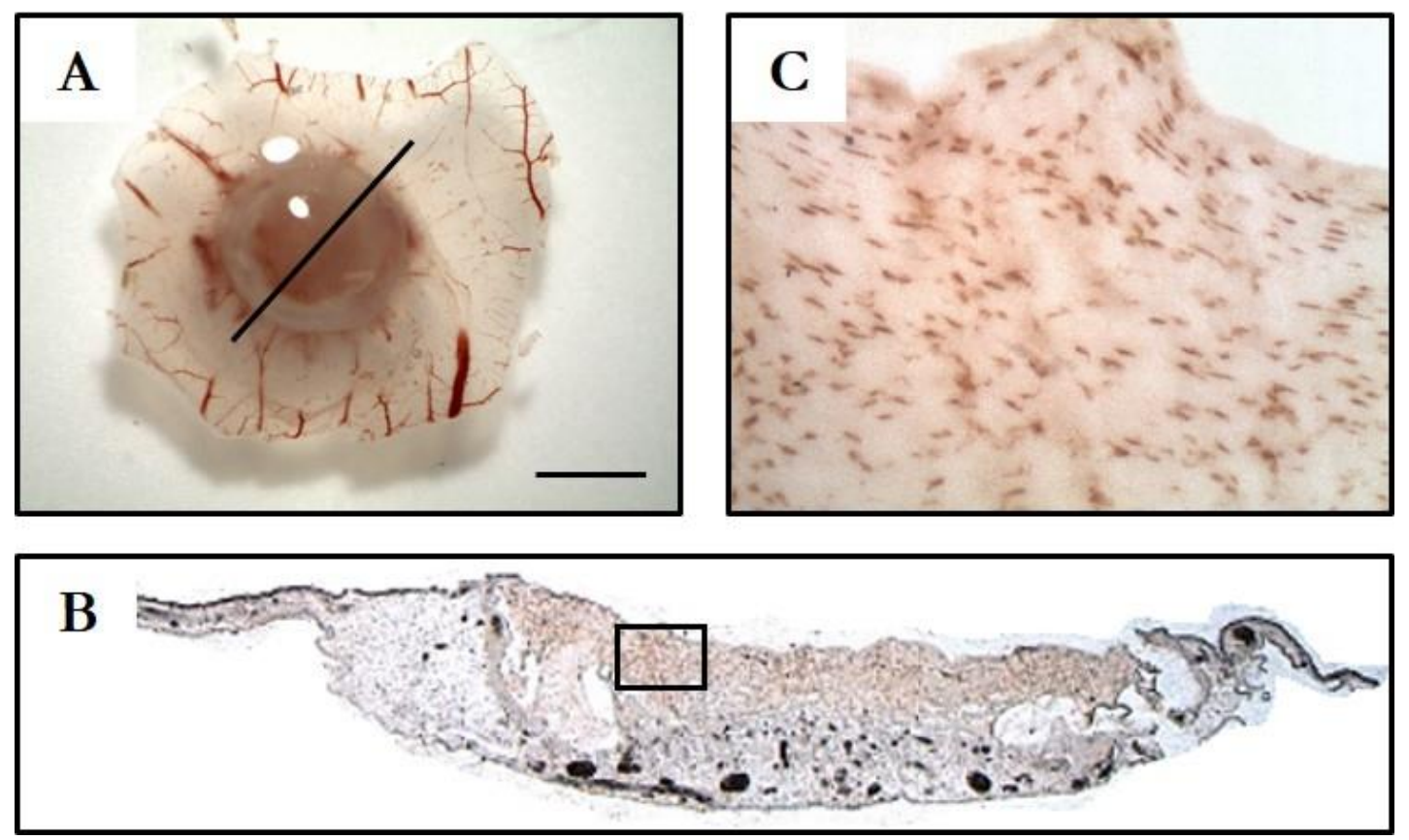

Abbildung 5: CD68-Expression in rein monozytärer CAM-Läsion. Zu sehen ist eine Peroxidase-Färbung mit CD68. Es handelt sich um die monozytäre Läsion auf der linken Seite in Abbildung 3. A. Auflichtmikroskopische Aufnahme mit der Ebene des histologischen Schnittes (schwarze diagonale Linie) in 7,82-facher Vergrößerung. Die Maßstabsleiste umfasst $2 \mathrm{~mm}$ (schwarzer horizontaler Balken). B. 12,5-fache Vergrößerung der Läsion. Der schwarz umrandete Bereich ist in C 400-fach vergrößert dargestellt. Die Monozyten beziehungsweise Makrophagen sind ubiquitär in der CAM-Läsion zu finden, besonders dicht in der Matrix im oberen Bereich. C. Die myeloiden Zellen exprimieren CD68 und sind in diesem Ausschnitt im oberen Bereich der Läsion, eingebettet in Matrigel, zu sehen.

Wie in Abbildung 5 zu sehen, konnte mit der HRP-Reaktion die CD68-Expression und damit die Existenz der myeloiden Zellen in den extrahierten CAM-Bereichen bestätigt werden. Die CD14+-PBMCs, welche auf der CAM zum Teil vier Tage überleben konnten und auch 
teilweise in der Lage waren, die Chorionmembran zu überwinden, waren positiv für CD68. Dies kann als Hinweis auf eine mögliche spontane Differenzierung gewertet werden, gleichwohl die spindelförmigen Zellen besonders dicht im Matrigel an der Oberseite zu finden waren, wie in Abbildung 5C zu erkennen ist.

Zusammenfassend kann festgestellt werden, dass unter den hier genutzten experimentellen Bedingungen CD14+-PBMCs CAM-Läsionen bilden können, die jedoch sehr fragil sind. In ausgewählten Fällen konnten diese Läsionen jedoch histologisch charakterisiert werden. Sie zeigen in unterschiedlichem Maße eine Bindegewebszerstörung und exprimieren den Monozyten- respektive Makrophagenmarker CD68. Betrachten wir nun die L-428-CAM-Lymphome und In-ovo-Ko-Kulturen aus Hodgkin-Lymphomzellen und CD14+-PBMCs.

\subsection{Morphologie von Mischtumoren aus HL-Zellen und Monozyten}

Insgesamt konnten 54 von 56 im Folgenden als „Mischtumoren“ bezeichnete Ko-KulturLäsionen auf der CAM etabliert und im Vergleich zu L-428-Lymphomen untersucht werden (Auswertungsquote von 96,4 \%; vgl. Tabelle 9). Die PBMCs stammten dabei von acht unabhängigen Spender*innen. Insgesamt wurden 44 L-428-Lymphome geerntet, welche im Durchschnitt 0,21 $\mathrm{cm}^{2}$ groß waren (vgl. Tabelle 9 und Abbildung 6). Die extrahierten Mischtumoren aus L-428-Tumorzellen und CD14+-PBMCs hatten eine durchschnittliche Fläche von $0,113 \mathrm{~cm}^{2}$. Damit waren die Mischtumoren signifikant kleiner als L-428-Lymphome auf der CAM, wie in Abbildung 6 zusammenfassend grafisch dargestellt ist $(\mathrm{p}<0,0001)$. Auch der Größenunterschied zwischen den L-428-Tumoren und den rein monozytären Läsionen war statistisch signifikant ( $\mathrm{p}=0,0004$, hier nicht dargestellt). 


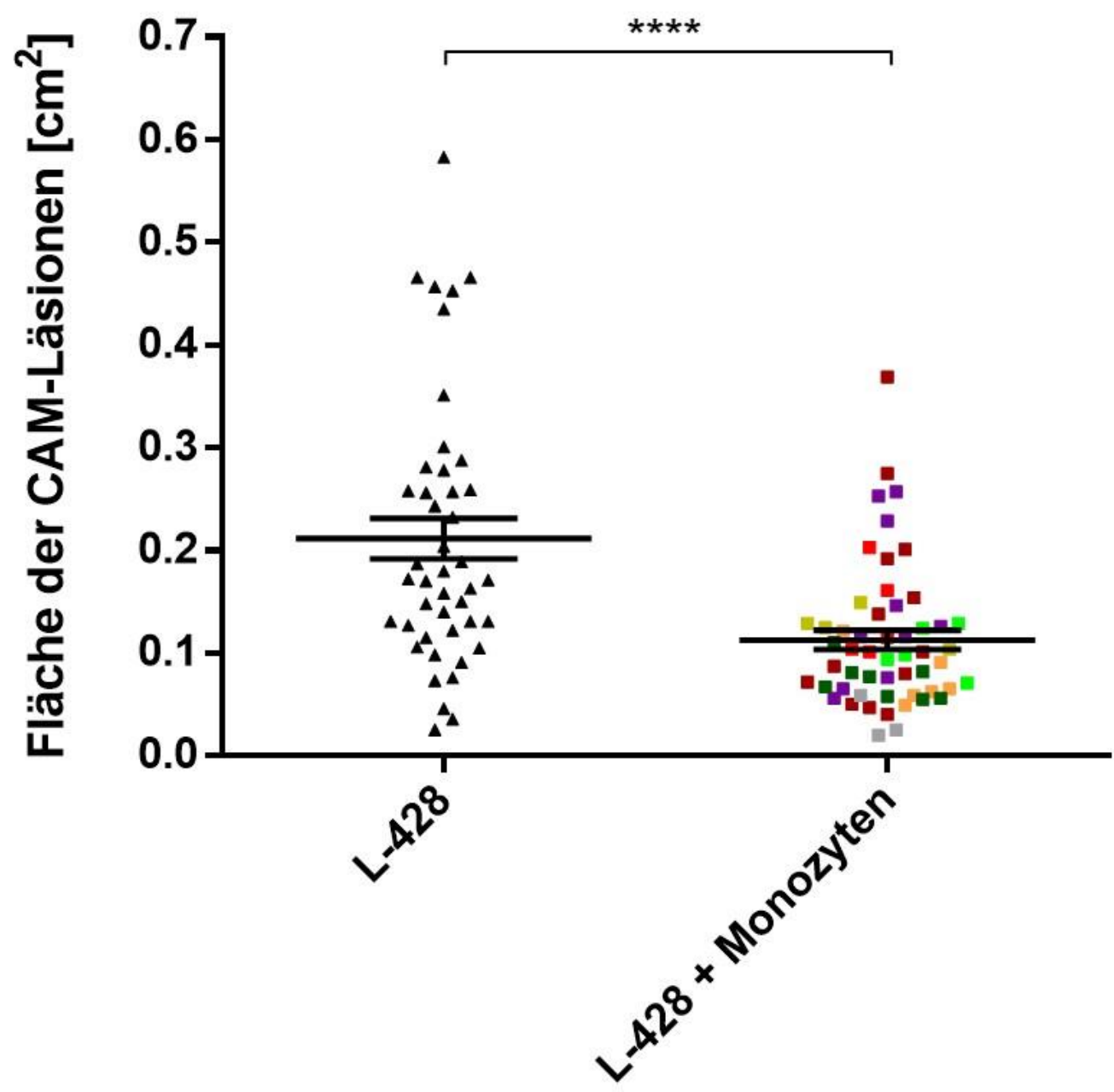

Abbildung 6: L-428-CD14+_PBMCs-Mischlymphome sind kleiner als L-428-Lymphome auf der CAM. Es wurden 54 Mischtumoren und 44 L-428-CAM-Lymphome untersucht. Mit dem Programm ImageJ wurden nach 96 Stunden Inkubationszeit die Flächen der CAM-Läsionen ermittelt. Die L-428-Tumoren waren im Mittel 0,21 $\mathrm{cm}^{2}$ groß und die Mischtumoren aus CD14+-PBMCs und Lymphomzellen hatten eine durchschnittliche Fläche von $0,113 \mathrm{~cm}^{2}$. Der Unterschied war signifikant (Mann-Whitney-U-Test: **** $\left.\mathrm{p}<0,0001\right)$. Die verschieden eingefärbten Vierecke, welche Mischtumoren repräsentieren, stehen für die unterschiedlichen Spender*innen der CD14+_PBMCs ( $\mathrm{n}=8$; vgl. Tabelle 9).

In Abbildung 7 sind repräsentative Aufsicht-Fotografien von reinen L-428-Lymphomen aus verschiedenen CAM-Beimpfungsversuchen dargestellt. Die extrahierten Tumoren waren flach bis leicht erhaben und zur umgebenden CAM gut abgrenzbar. Oftmals zeichneten sich die L-428-CAM-Tumoren makroskopisch durch großflächige hämorrhagische Zonen aus, die bei Konfluenz teils den gesamten Tumor ausfüllten (untere Reihe in Abbildung 7). Zum Teil waren aber auch nur kleine punktförmige Einblutungen zu finden. Die Morphologie der L-428-Lymphome auf der CAM entsprach jener aus Vorarbeiten der Arbeitsgruppe. 

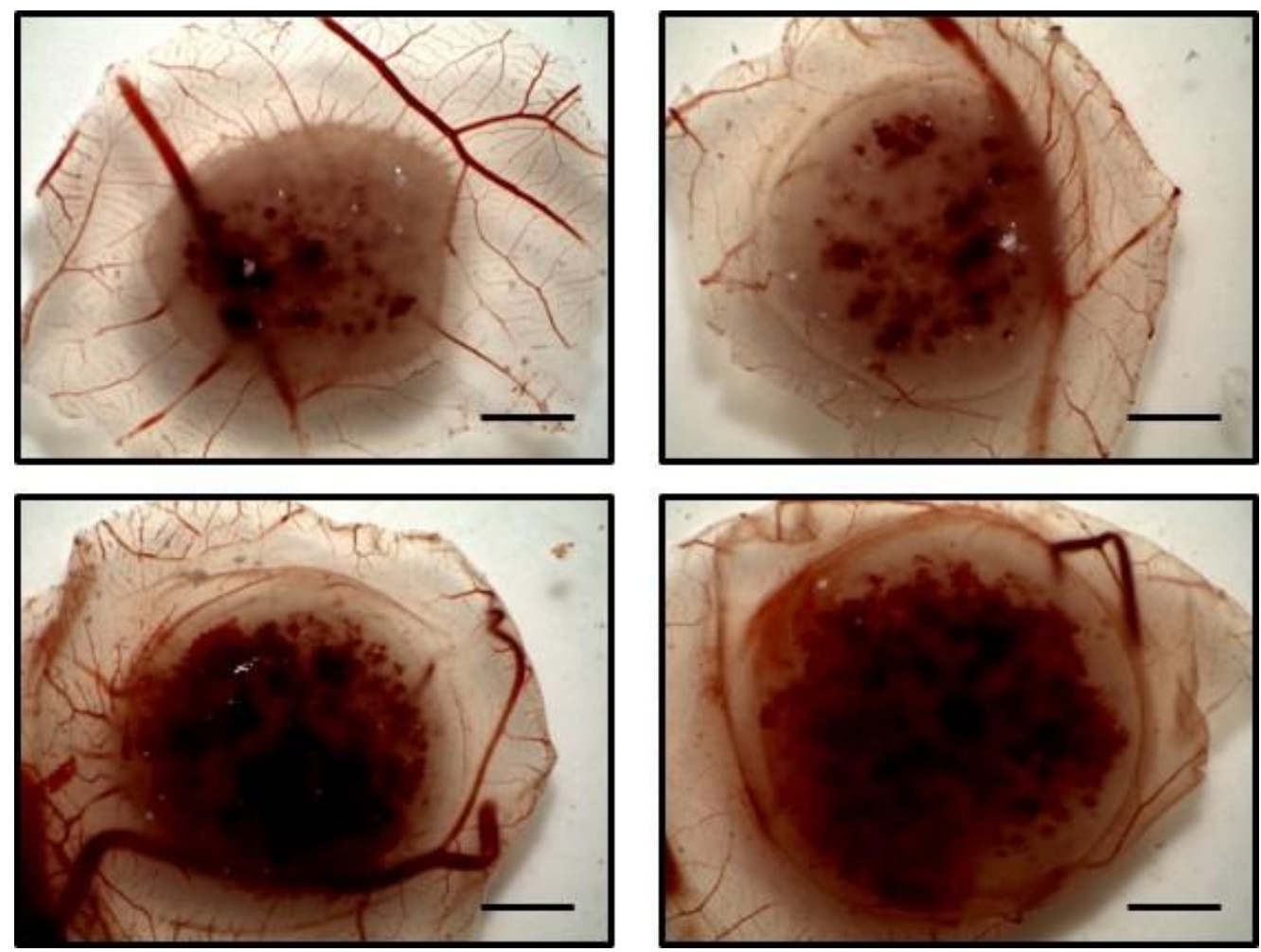

Abbildung 7: CAM-Lymphome der HL-Zelllinie L-428 sind durch großflächige Einblutungen charakterisiert. Repräsentative lichtmikroskopische Aufnahmen (Vergrößerung 7,82x) von Tumoren der Zelllinie L428. Es wurden jeweils $2 \cdot 10^{6} \mathrm{HRS}$-Zellen auf die CAM appliziert. Es zeigten sich großflächige, teils konfluierende Hämorrhagien in ovo. Die umgebende CAM war reichlich vaskularisiert. Die Maßstabsleiste umfasst $2 \mathrm{~mm}$ (schwarzer Balken).

Im Unterschied dazu zeichneten sich die CAM-Mischtumoren bei visueller Inspektion oftmals durch eine kompakte und kuppelförmige, halbrunde Form aus, wie in Abbildung 8 zu sehen ist. Dabei war schon in der Aufsicht offensichtlich, dass die Tumoren nicht nur wesentlich kleiner als reine Hodgkin-Läsionen auf der CAM waren, sondern sich auch durch deutlich weniger bis gar keine Hämorrhagien auszeichneten. Auch bei unmittelbarer Nähe zu größeren Blutgefäßen der CAM lagen keine Einblutungen in diesen Mischtumoren vor. In Abbildung 8 sind Aufsicht-Fotografien repräsentativer CAM-Mischtumoren aus Hodgkin-Lymphomzellen, CD14+-PBMCs und Matrigel von mehreren Monozyten-Spender*innen gezeigt. Auch diese ko-kultivierten CAM-Läsionen waren zur umgebenden physiologischen Chorion-Allantois-Membran leicht abgrenzbar. 

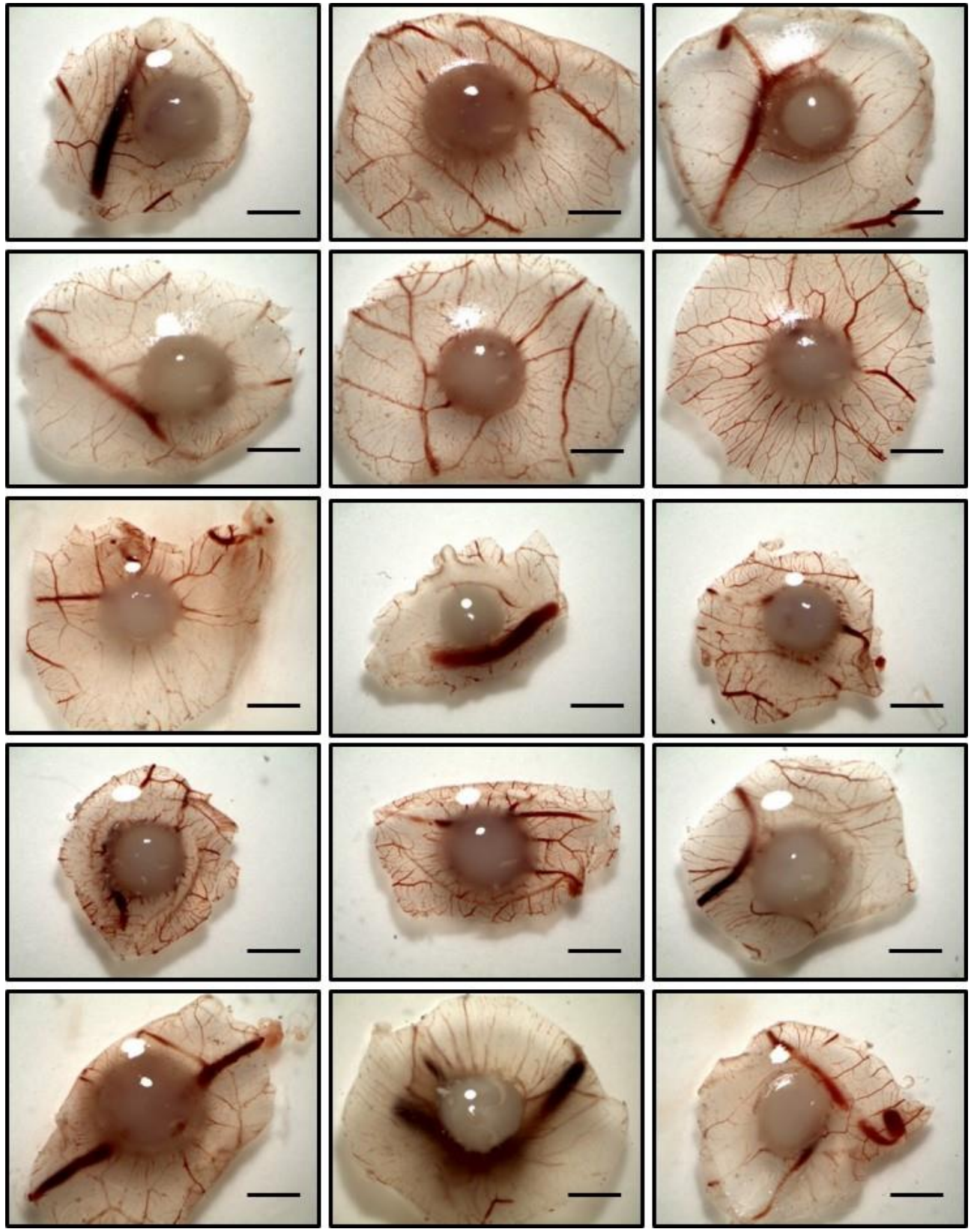

Abbildung 8: Aufsicht-Fotografien repräsentativer Mischtumoren aus HL-Zellen und Monozyten. Die CAM-Präparate sind in 7,82-facher Vergrößerung abgebildet. Die Maßstabsleiste umfasst 2 mm (schwarzer Balken).

Um eine Vorstellung von der feingeweblichen Struktur der CAM-Tumoren zu bekommen, wurden Formalin-fixierte, in Paraffin eingebettete und mit einer Trichrom-Färbung versehene Schnittpräparate angefertigt und die Läsionen lichtmikroskopisch untersucht. In Abbildung 9 sind als Vergleichswert zu den Mischtumoren zwei exemplarische reine L-428-Tumoren im CAM-Modell in Trichrom-Färbung und verschiedenen Vergrößerungen dargestellt. Schon in den auflichtmikroskopischen Aufnahmen in 7,82-facher Vergrößerung in Abbildung 9A und 9B imponieren konfluierende Hämorrhagien. 
In den weiteren Vergrößerungen (Abbildung 9C-J) zeigen die schwarzen respektive weißen Umrandungen den jeweils vergrößerten Ausschnitt in der darunterliegenden Abbildung an. In 100- und 200-facher Vergrößerung waren deutlich kernhaltige Hühner-Erythrozyten zu erkennen, die vermutlich aus durchlässigen und zerstörten Blutgefäßen der CAM ins Lymphomgewebe infiltrierten. Darüber hinaus sind die L-428-Tumoren relativ dicht mit HRSZellen gepackt gewesen. Die Hodgkin-Lymphomzellen waren in der Lymphomkappe, im zentralen Bereich der CAM-Läsion und an der Tumorbasis gleichmäßig verteilt, wie in der 50-fachen Vergrößerung der Trichrom-Schnitte gut zu erkennen ist (Abbildung 9E-F).

Im Vergleich zu dieser homogenen Tumorstruktur der reinen L-428-CAM-Lymphome zeigte sich bei den Mischtumoren eine Kompartimentierung der Läsionen mit einem zentral aufgelockerten Bereich aus extrazellulärer Matrix beziehungsweise restlichem Matrigel. Auch die Lymphomkappe wirkte aufgelockert, wohingegen der untere Bereich der Tumoren dichter angeordnete Zellpopulationen enthielt. Außerdem zeigten die Mischtumoren weniger dicht gepackte Lymphomzellen als reine L-428-Tumoren.

Der dreigliedrige Aufbau eines beispielhaften CAM-Mischtumors ist in Abbildung 10 dargestellt. Bei diesem Präparat konnte mit der Trichrom-Färbung der Verbleib des applizierten Matrigels in der generierten Läsion veranschaulicht werden (10A). Die wannenförmige Basis des CAM-Lymphoms erschien wesentlich zellreicher als die beiden darüber liegenden Kompartimente. Die 100-fache Vergrößerung des linken Übergangs zur physiologischen CAM in Abbildung 10B zeigt vereinzelte Einblutungen und abgelöste Gewebsteile, die als Artefakte im Rahmen der Fixierung entstanden. Die Invasionsfront zeigte eine dichte Population an Hodgkin-Lymphomzellen. In Analogie dazu ist auch der rechte CAM-Übergang vergrößert dargestellt (10C). 

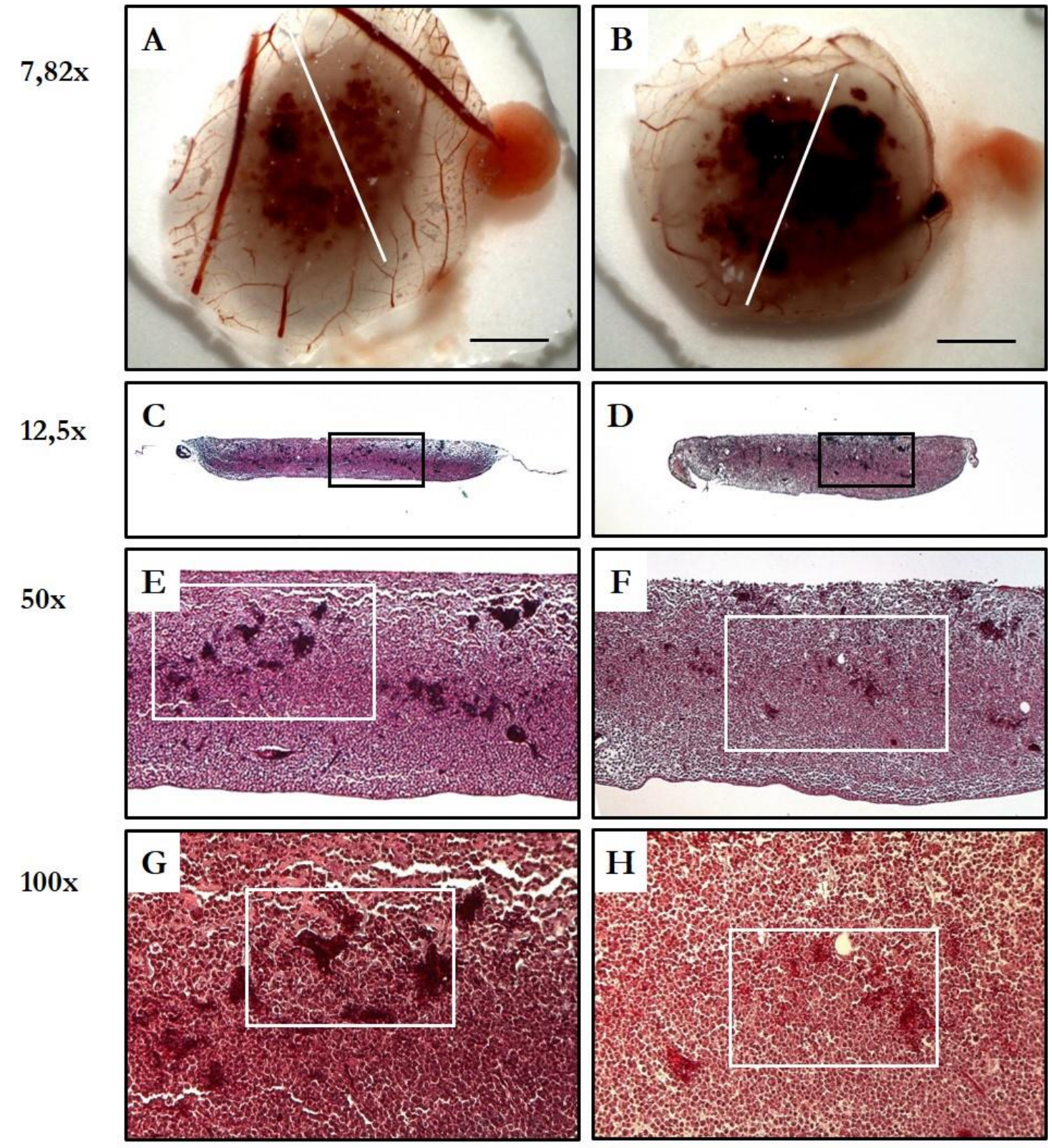

200x
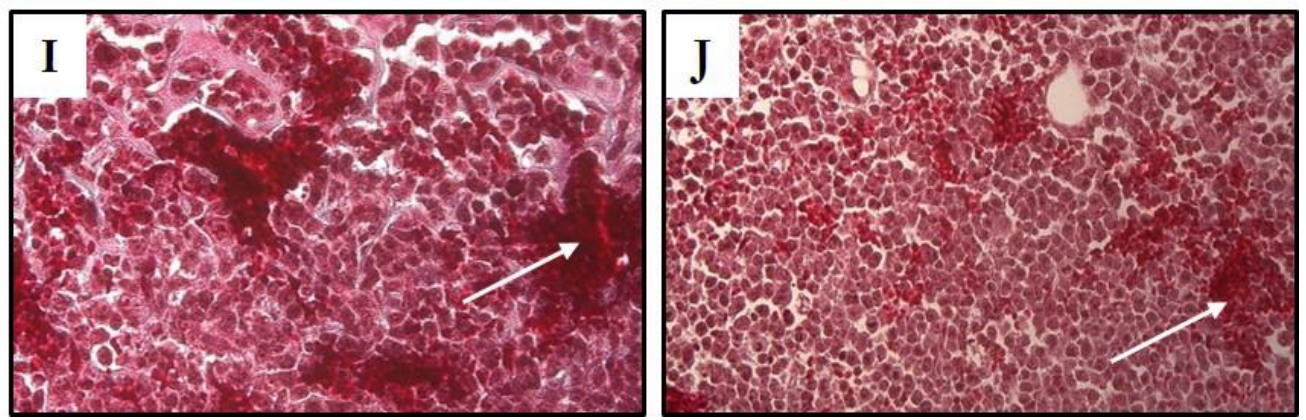

Abbildung 9: Morphologie zweier repräsentativer L-428-CAM-Lymphome. Zwei exemplarische L-428Tumoren sind nach Trichrom-Färbung und aufsteigender Vergrößerung dargestellt. Zu sehen sind Einblutungen (weiße Pfeile in I-J), die schon makroskopisch sichtbar sind (A-B), und zerstörte Blutgefäße der CAM darstellen. Ferner sind die CAM-Lymphome sehr dicht mit Lymphomzellen gepackt. Die Ebene des histologischen Schnittes ist in A und B mit einer weißen Linie markiert. Die Maßstabsleiste umfasst $2 \mathrm{~mm}$ (schwarzer Balken in A-B). Ausgewählte Tumorsektionen sind mit Kästen umrandet und darunter findet sich jeweils der entsprechende Ausschnitt vergrößert dargestellt (C-J). Es ist kaum noch Kollagen nachweisbar. 


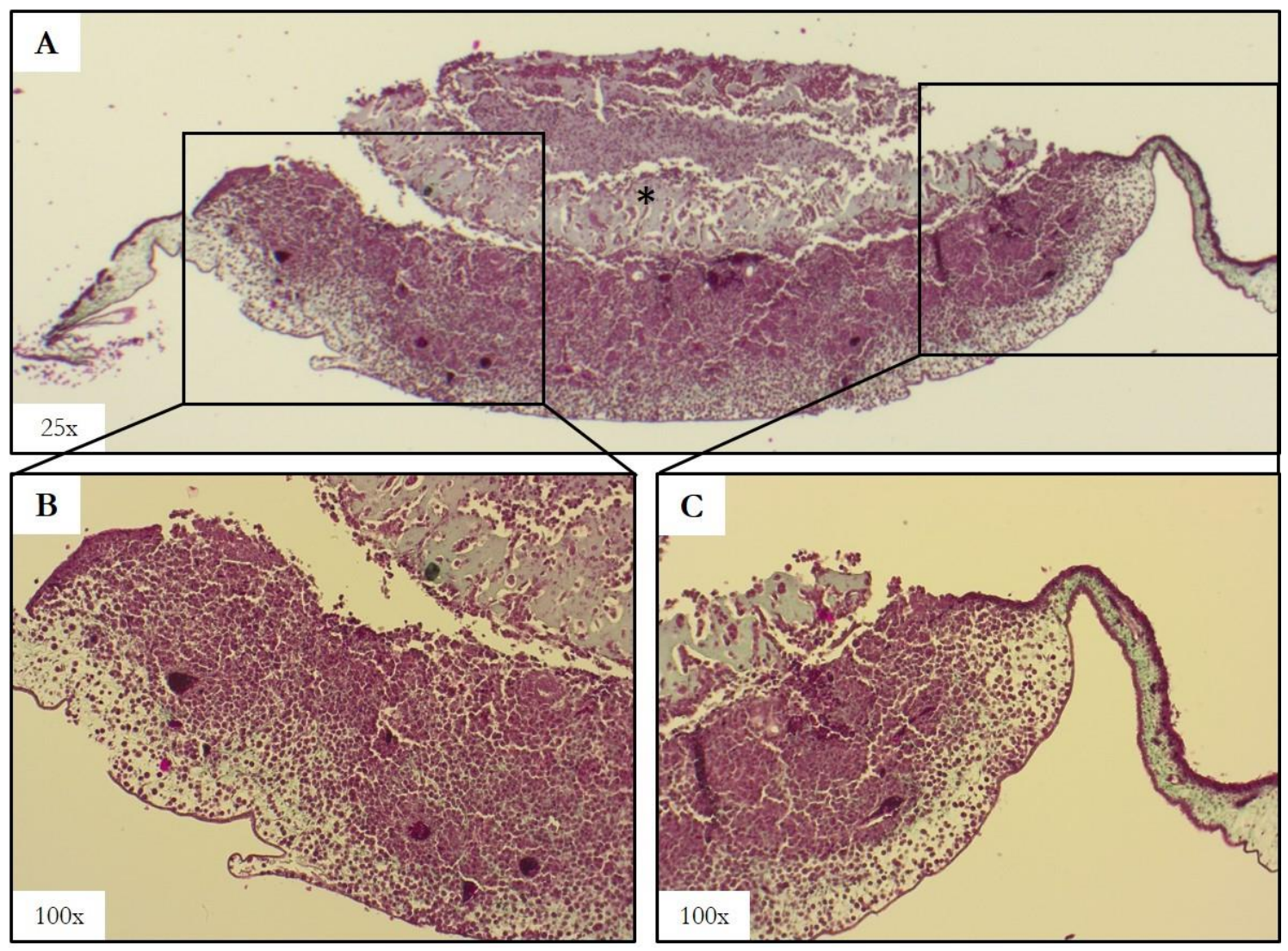

Abbildung 10: Ternäre Kompartimentierung eines CAM-Mischtumors aus L-428-Zellen und CD14+_ PBMCs. Die Trichrom-Färbung unterstreicht die dreigliedrige Struktur der Ko-Kultur-Läsionen. A. Die 25fach vergrößerte Übersicht zeigt einen zentral aufgelockerten Bereich aus Matrigelresten mit wenig Kollagen (*) zwischen der Lymphomkappe und einer breiten, wannenförmigen Tumorbasis. B. Gezeigt ist der linke Übergang zur physiologischen CAM in 100-facher Vergrößerung. C. Zu sehen ist hier das Korrelat auf der anderen Seite der Läsion. Der gleiche Tumor ist in Abbildung 14 immunhistochemisch angefärbt.

In Abbildung 11 sind drei weitere ausgewählte repräsentative Mischtumoren nach Trichrom-Anfärbung dargestellt. Im Unterschied zu reinen L-428-Lymphomen fiel auch hierbei eine Kompartimentierung der CAM-Tumoren auf. Besonders deutlich hatte sich bei Tumor 17-483 (Abbildung 11G-I) eine Drei-Zonen-Gliederung etabliert. Ein auffälliges gemeinsames Merkmal in den Schnittpräparaten der Mischtumoren war, dass die Lymphomzellen offenbar zu den Blutgefäßen rekrutiert worden waren, aber im Gegensatz zu den L-428-CAMLymphomen nicht so häufig zerstört wurden. Einblutungen der CAM-Läsionen können verschiedene Ursachen haben. Es ist nicht eindeutig, ob L-428-Zellen zu Neoangiogenese im CAM-Modell befähigt sind oder lediglich die Gefäße zwischen Chorion- und Allantoismembran ko-optieren und diese Gefäße dann zerstören können. Wenn hauptsächlich eine Neubildung von Lymphom-assoziierten Gefäßen vorläge, wären diese Gefäße vermutlich auch fragiler und leichter zu zerstören. 


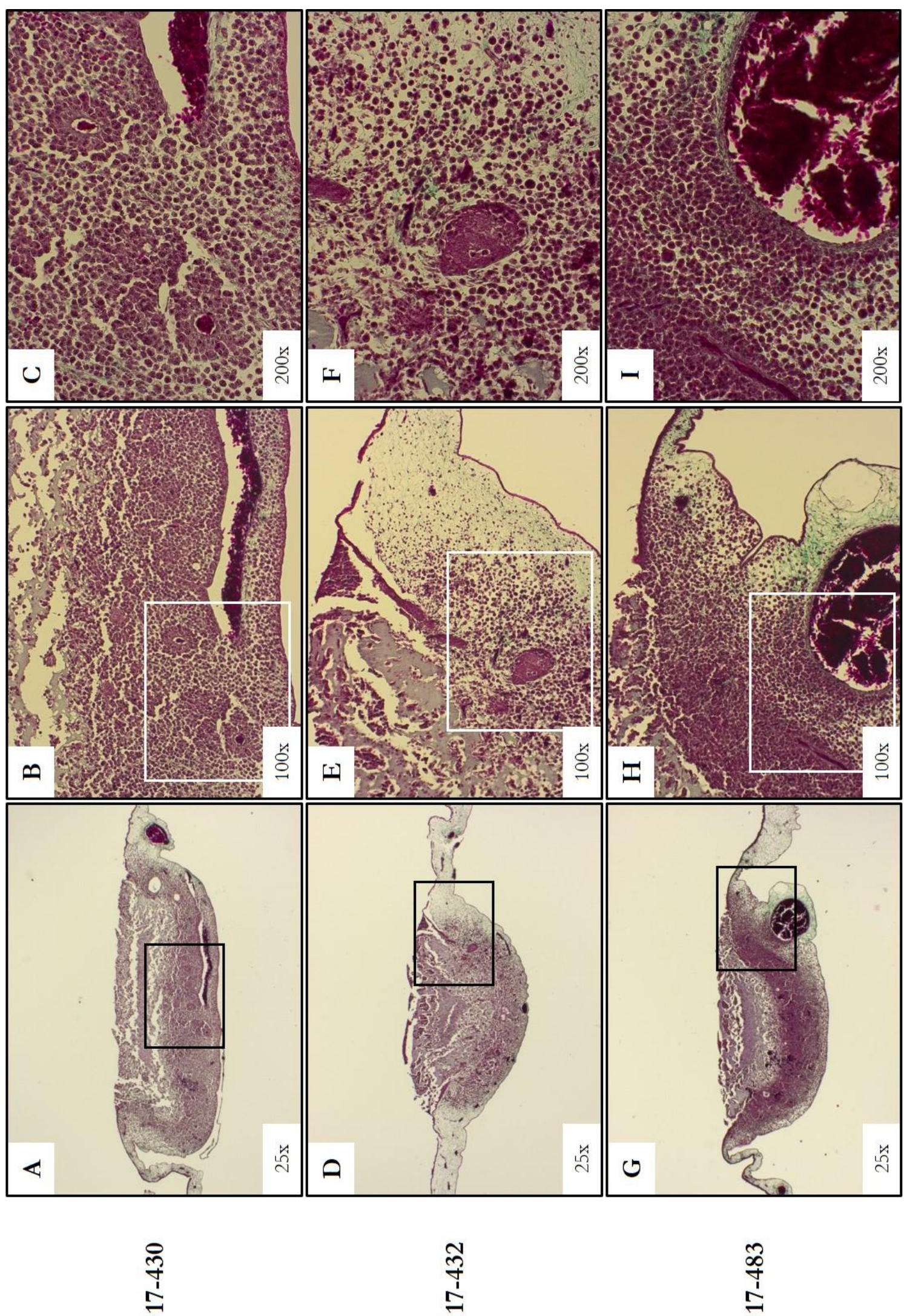

Abbildung 11: Trichrom-gefärbte CAM-Mischtumoren. Gezeigt sind drei repräsentative Mischtumoren aus HL-Zellen und CD14+-PBMCs von zwei verschiedenen Spender*innen. Die Tumoren 17-430 und 17-432 enthalten myeloide Zellen von dem*der gleichen Donor*in. Die schwarzen und weißen Rechtecke kennzeichnen den in der darauffolgenden Fotografie vergrößerten Bereich. In den 200-fachen Vergrößerungen sind Blutgefäße mit darum gruppierten Lymphomzellen zu sehen (C, F, I). 
In den 200-fachen Vergrößerungen der drei ausgewählten CAM-Tumoren (Abbildung 11C, F, I) kann man erkennen, dass sich HRS-Zellen teilweise palisadenförmig um Blutgefäße gruppieren. Die ko-optierten Gefäße befanden sich mitten im Tumor (11C) oder nahe am Übergang zur physiologischen Chorion-Allantois-Membran (11F, I). In der Trichrom-Färbung schien besonders der untere Bereich von Tumor 17-483 dicht besetzt mit Tumorzellen zu sein (Abbildung 11G). Das große Blutgefäß im rechten unteren Bereich befand sich in diesem Fall unter der Migrationsfront der HRS-Zellen und die Lymphomzellen ordneten sich um die Endothelzellen an (11H, I).

In Abbildung 12 ist ein weiterer exemplarischer CAM-Mischtumor präsentiert. In der 25fachen Vergrößerung (12A) konnte lichtmikroskopisch eine dreigliedrige Struktur herausgearbeitet werden. Die wannenförmige Tumorbasis schien dicht mit HRS-Zellen besetzt zu sein und sich bis zu den jeweiligen CAM-Übergängen auszubreiten. Zwischen der eher aufgelockerten Lymphomkappe und der Tumorbasis fand sich ein zentraler „aufgesprengter“ Bereich, der sich vorwiegend durch extrazelluläre Matrix auszuzeichnen schien und vermutlich mit myeloiden Zellen besetzt war.

In Abbildung 12B sind HRS-Zellen an ihrer Invasionsfront am linken CAM-Übergang des Tumors in 100-facher Vergrößerung zu sehen. Ähnlich wie in reinen L-428-CAM-Lymphomen schienen die Tumorzellen zur Migration befähigt zu sein. Man konnte hier von einer aktiven Mobilität der Lymphomzellen ausgehen. Auch in diesem Trichrom-Präparat wurde ein größeres Blutgefäß angeschnitten, das mit Hühnchen-Erythrozyten gefüllt war. Wiederum wurden Lymphomzellen zum Gefäß rekrutiert und bildeten eine mehrlagige Schicht an der Außenseite (12C-D). Auch in diesem Fall könnte man von einer sogenannten vessel cooption ausgehen. 


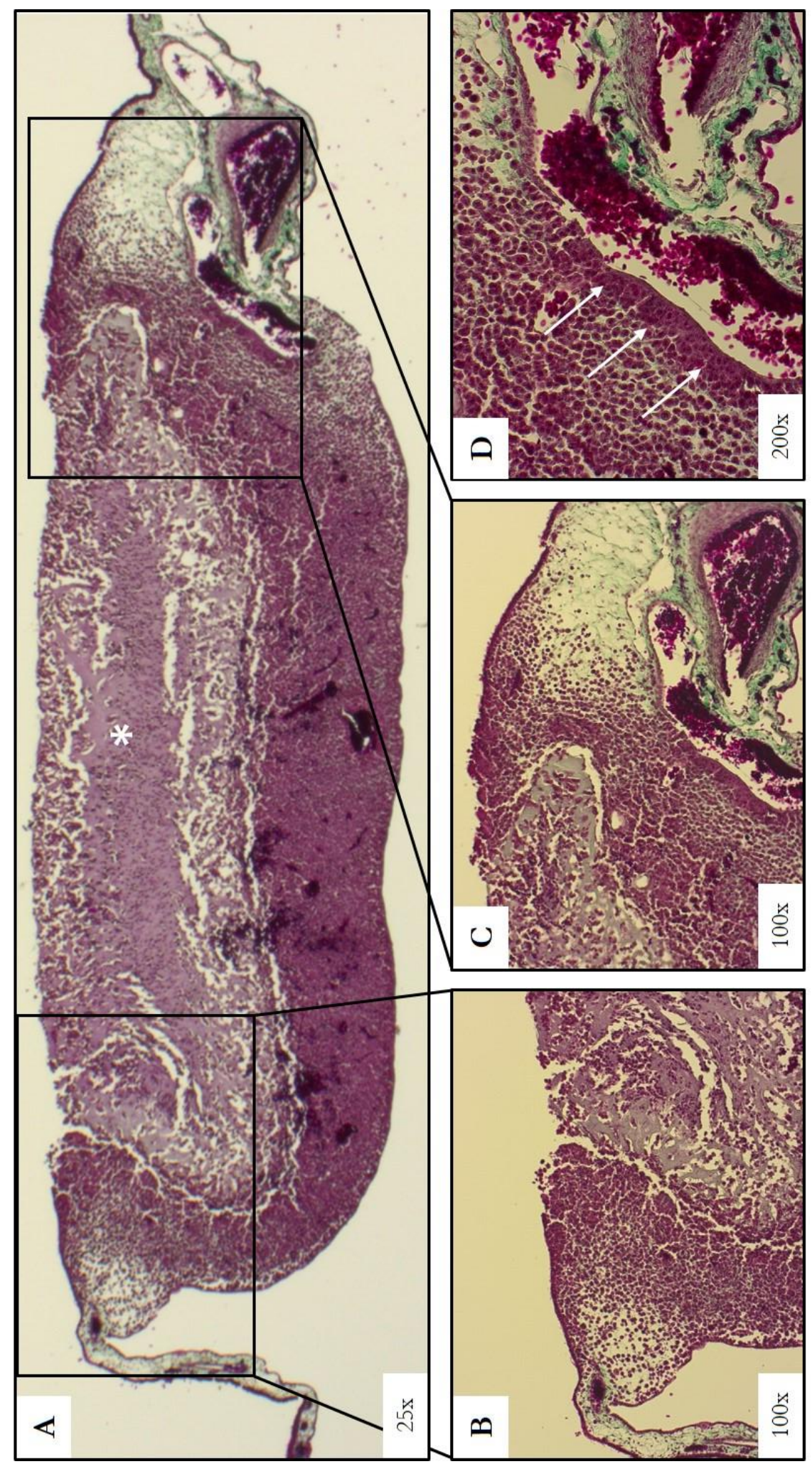

Abbildung 12: HL-Zellen und Monozyten bilden kompartimentierte CAM-Tumoren. Dieser Mischtumor zeigt eine Drei-Zonen-Gliederung. A. Die 25-fache Vergrößerung zeigt eine dicht mit Lymphomzellen besetzte wannenförmige Tumorbasis. Zwischen dieser und der Lymphomkappe befindet sich ein zentral aufgelockerter Bereich aus extrazellulärer Matrix (*). B. Diese 100-fache Vergrößerung des linken CAM-Übergangs lässt HRS-Zellen am Übergang zur physiologischen CAM erkennen. C. Das Lumen eines großen Blutgefäßes ist mit Hühner-Erythrozyten gefüllt. Der schwarz umrandete Bereich ist in D weiter vergrößert. D. An diesem Gefäß haben sich mehrere Schichten von Tumorzellen versammelt (weiße Pfeile). 
Um die Verteilung der HRS-Zellen in den reinen CAM-Lymphomen immunhistochemisch zu eruieren, wurden Peroxidase-gefärbte Schnittpräparate angefertigt. Als Zielantigen für die Lymphomzellen diente das CD30-Transmembranprotein. Wie in Abbildung $13 \mathrm{zu}$ sehen, wurde der gesamte Tumorbereich der reinen L-428-Läsionen bräunlich angefärbt. Das transmembranös exprimierte Oberflächenmolekül CD30 ist als Plasmamembran-Saum um die Tumorzellen herum gleichmäßig angefärbt. Diese ubiquitäre CD30-Expression zeigt, dass eine homogene Verteilung der HRS-Zellen beobachtet werden kann und das Lymphom sehr einheitlich durch die Chorionmembran in das Bindegewebe zwischen Chorion- und Allantoismembran invadiert ist. Dies spricht für ein recht invasives Wachstum. Klar zu erkennen ist ein Teil der zu vermutenden Invasionsfront. Die hier dargestellte Invasionsfront zeigt sich am Übergang vom kompakten Lymphom zu den eher locker angeordneten Lymphomzellen, die sich vom Lymphomkern weg zu bewegen scheinen (13B-C).

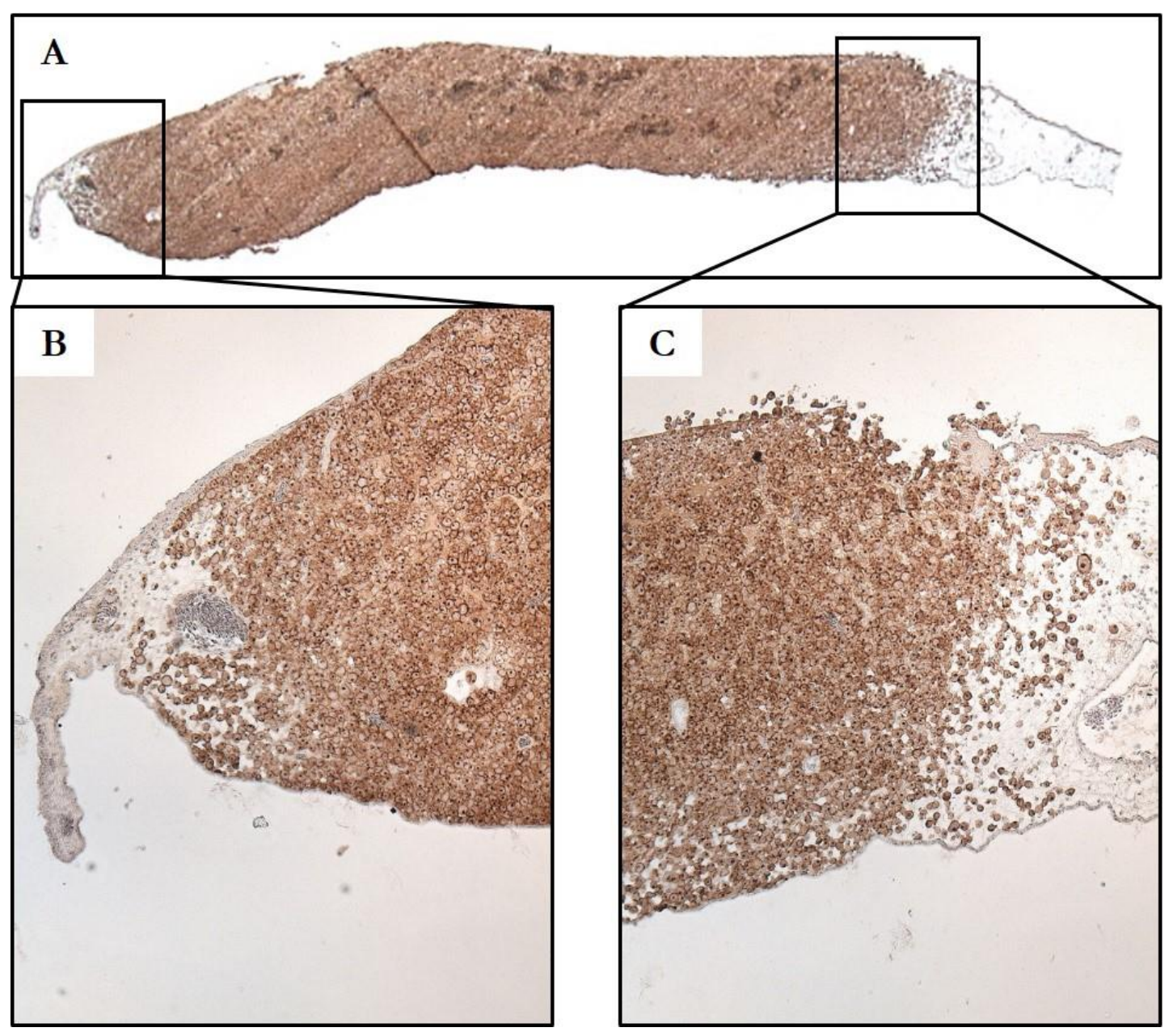

Abbildung 13: Ubiquitäre CD30-Expression in L-428-CAM-Lymphomen. Dargestellt ist in A die Übersichtsaufnahme (12,5x) eines immunhistochemisch gefärbten L-428-Tumors auf der CAM. Als Zielantigen wurde das CD30-Protein der HRS-Zellen markiert. Man erkennt eine homogene Verteilung der Hodgkin-Lymphomzellen im gesamten Tumorbereich. Darunter finden sich in 100-facher Vergrößerung der linke (B) und rechte (C) Übergang zur physiologischen CAM. Hier befindet sich jeweils auch die Migrationsfront der HLZellen. 
Um eine bessere Vorstellung von der Verteilung der Lymphomzellen und CD14 ${ }^{+}$-PBMCs der Mischlymphome zu bekommen, wurden auch die Mischtumoren mit CD30- beziehungsweise CD68-Antikörpern gefärbt. Die HRP-Reaktion lieferte Hinweise darauf, wo sich die cHL-Zellen respektive myeloiden Zellen bevorzugt in den CAM-Läsionen aufhielten. In Abbildung 14 ist gezeigt, dass die angewandte Immunhistochemie die beobachtete Kompartimentierung der Tumoren bestätigen konnte (vgl. Abbildung 10). CD30-positive Lymphomzellen waren im oberen und unteren Bereich der CAM-Mischtumoren lokalisiert und fehlten gleichzeitig fast vollständig im zentralen Bereich. CD68-positive Makrophagen dominierten den oberen und mittleren Bereich der Läsionen und fanden sich hierbei bevorzugt innerhalb des übrigen Matrigels oder in unmittelbarer Umgebung dazu.

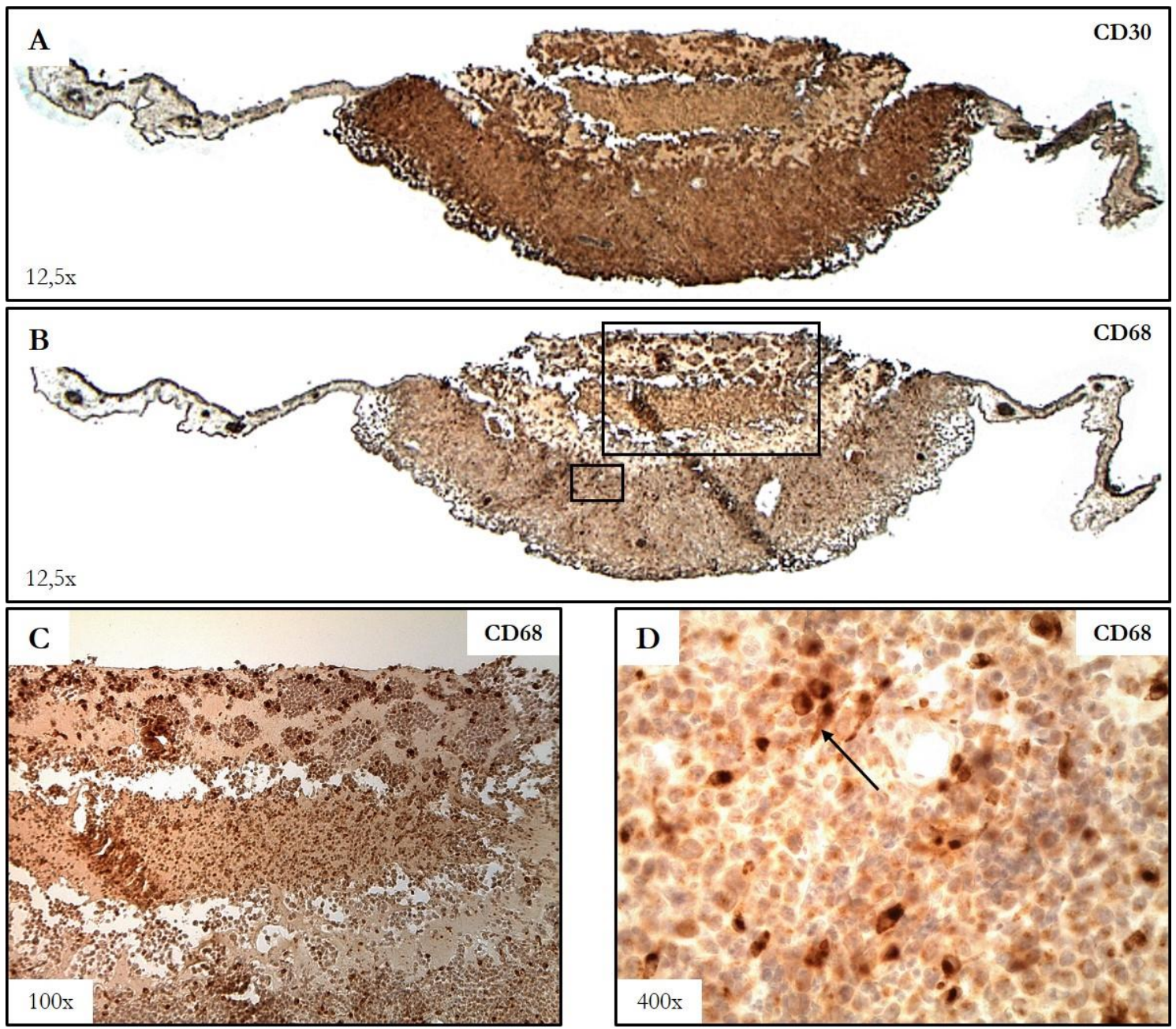

Abbildung 14: Peroxidase-Färbung an CAM-Mischtumoren zeigt Verteilung der Zellpopulationen. Dargestellt ist eine Ko-Kultur-Läsion von HL-Zellen und CD14+_PBMCs. A. Die 12,5-fach vergrößerte Übersichtsaufnahme mit CD30-Färbung zeigt, dass die HRS-Zellen vor allem in der Tumorbasis und der Lymphomkappe angesiedelt sind. B. Die myeloiden Zellen wurden über ihr CD68-Antigen identifiziert. Besonders zahlreich finden sie sich im oberen und zentralen Bereich des CAM-Tumors. Der Ausschnitt umrahmt vom großen Rechteck ist in C in 100-facher Vergrößerung zu finden, das kleine Kästchen umrahmt den in D 400-fach 
vergrößerten Bereich. C. Die braun angefärbten Monozyten respektive Makrophagen sind bevorzugt im Matrigel lokalisiert. D. Unterhalb der zentralen extrazellulären Matrix sind weniger dicht gepackt weitere Makrophagen zu finden. Der schwarze Pfeil zeigt auf die typische Spindelform eines amöboid beweglichen CD68positiven Makrophagen. Die immunhistochemische Färbung lässt insgesamt eine Dreiteilung der Läsion erkennen. Die Anzahl an CD68-positiven Zellen ist gering. Der gleiche Mischtumor ist in Abbildung 10 mit einer Trichrom-Färbung dargestellt.

In Abbildung 14A ist zu erkennen, dass die CD30-positiven Lymphomzellen besonders dicht in der Tumorbasis zu finden und im zentral aufgelockerten Bereich deutlich weniger anzutreffen waren. Die Verteilung der CD68-positiven myeloiden Zellen ist in Abbildung 14B dargestellt. Die 100-fache Vergrößerung eines zentralen Ausschnitts machte deutlich, dass die Monozyten respektive Makrophagen bevorzugt im Matrigel beziehungsweise der extrazellulären Matrix lokalisiert waren (14C). In der 400-fachen Vergrößerung (14D) war die typische Spindelform der CD68-positiven Makrophagen zu sehen, was für einen In-ovo-Differenzierungsprozess vom Monozyten hin zum amöboid beweglichen Makrophagen innerhalb von vier Tagen in direkter Nachbarschaft zu den L-428-Zellen spricht.

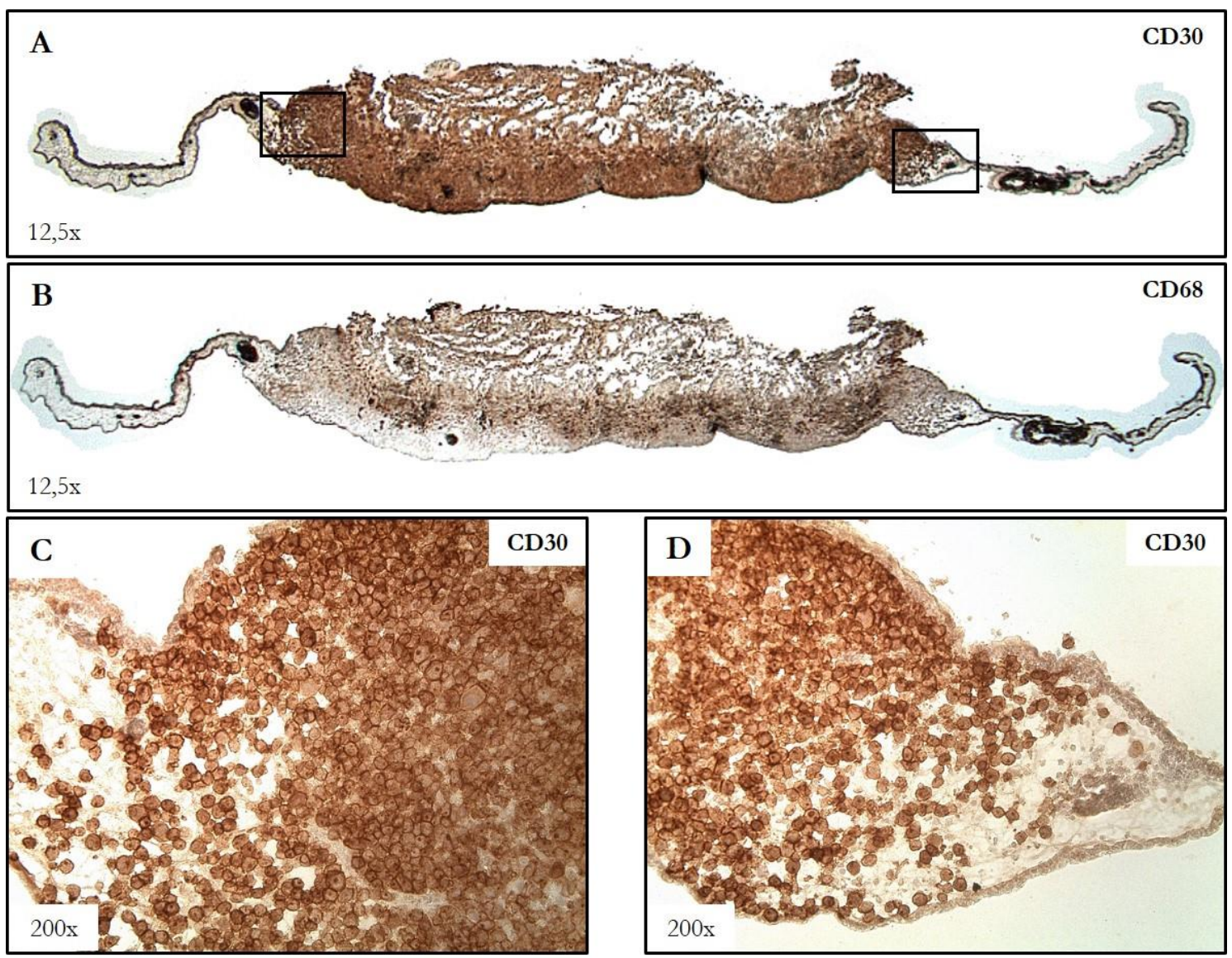

Abbildung 15: Lymphomzellen invadieren in den Zwischenraum zwischen Chorion- und Allantoismembran. Auch bei diesem Präparat handelt es sich um eine CAM-Ko-Kultur aus L-428-Zellen und CD14+PBMCs mit Peroxidase-Färbungen. Die CAM-Migrationsfronten der CD30-Färbung (schwarze Kästchen in A) sind in C und D 200-fach vergrößert. A. Die CD30-Färbung offenbart eine breite Tumorbasis aus HRS- 
Zellen. B. Die CD68-Färbung zeigt in 12,5-facher Vergrößerung auch einige Makrophagen im unteren Bereich der Läsion. C. Der linke CAM- Übergang in CD30-Färbung offenbart, dass die Lymphomzellen migrieren. D. In Analogie dazu finden sich die Tumorzellen auch am rechten Zwischenraum zwischen Chorion- und Allantoismembran.

Ein weiterer repräsentativer CAM-Mischtumor ist in Abbildung 15 gezeigt. Die CD30-Peroxidase-Färbung der cHL-Zellen (15A) offenbarte mit der 200-fachen Vergrößerung der Übergänge zur physiologischen Chorion-Allantois-Membran die aktive Migration der L-428Zellen (15C-D), auch wenn die HL-Zellen an den CAM-Übergängen weniger dicht gepackt als in reinen L-428-Lymphomen waren (vgl. Abbildung 13B-C). Die CD68-Färbung (15B) dokumentierte auch einige bräunlich gefärbte Makrophagen in der Tumorbasis unterhalb des applizierten Matrigels.

\subsection{CD206-Expression nach In-ovo-Ko-Kultur mit CD14+-PBMCs nachweisbar}

Um herauszufinden, ob im In-ovo-Modell auch initial unbehandelte CD14 ${ }^{+}$-PBMCs innerhalb von 96 Stunden CD206-Expression aufweisen, wurden CAM-Mischtumoren konsekutiv neben ihrer CD30- respektive CD68-Expression auch immunhistochemisch auf CD206 untersucht. Die Ergebnisse sind in diesem Teil der Arbeit dargestellt.

In der Abbildung 16 ist ein exemplarischer Mischtumor, der durch Ko-Inkubation von HRSZellen mit Monozyten generiert worden war, mit der entsprechenden HRP-Färbung für alle drei Antigene präsentiert. Auch bei diesem CAM-Tumor bestätigte sich, dass die CD30-positiven Lymphomzellen ubiquitär und besonders stark im oberen und unteren Teil des in drei Kompartimente aufgeteilten Tumors zu finden waren. Im zentral aufgelockerten Bereich des Matrigels fehlten sie weitgehend (Abbildung 16 oben). Der linksseitig 100-fach vergrößerte Ausschnitt des linken CAM-Überganges zeigt die aktive Migration der Tumorzellen. Die CD68-Färbung (Abbildung 16 Mitte) der ursprünglich unbehandelten Monozyten demonstrierte wiederum die Verteilung der Makrophagen im Mischtumor. Besonders in der Lymphomkappe konnten Makrophagen identifiziert werden. Darüber hinaus waren sie in der Tumorbasis zahlreich vertreten. Wie in der zugehörigen Vergrößerung des linken CAMÜberganges zu sehen ist, war die Invasionsfront dieser myeloiden Zellen allerdings nicht so weit zur physiologischen CAM verschoben wie bei den L-428-Zellen. In Abbildung 16 unten ist die CD206-Expression der Makrophagen nach 96 Stunden Ko-Kultur mit HL-Zellen im Xenograft-Modell der Chorion-Allantois-Membran gezeigt. 


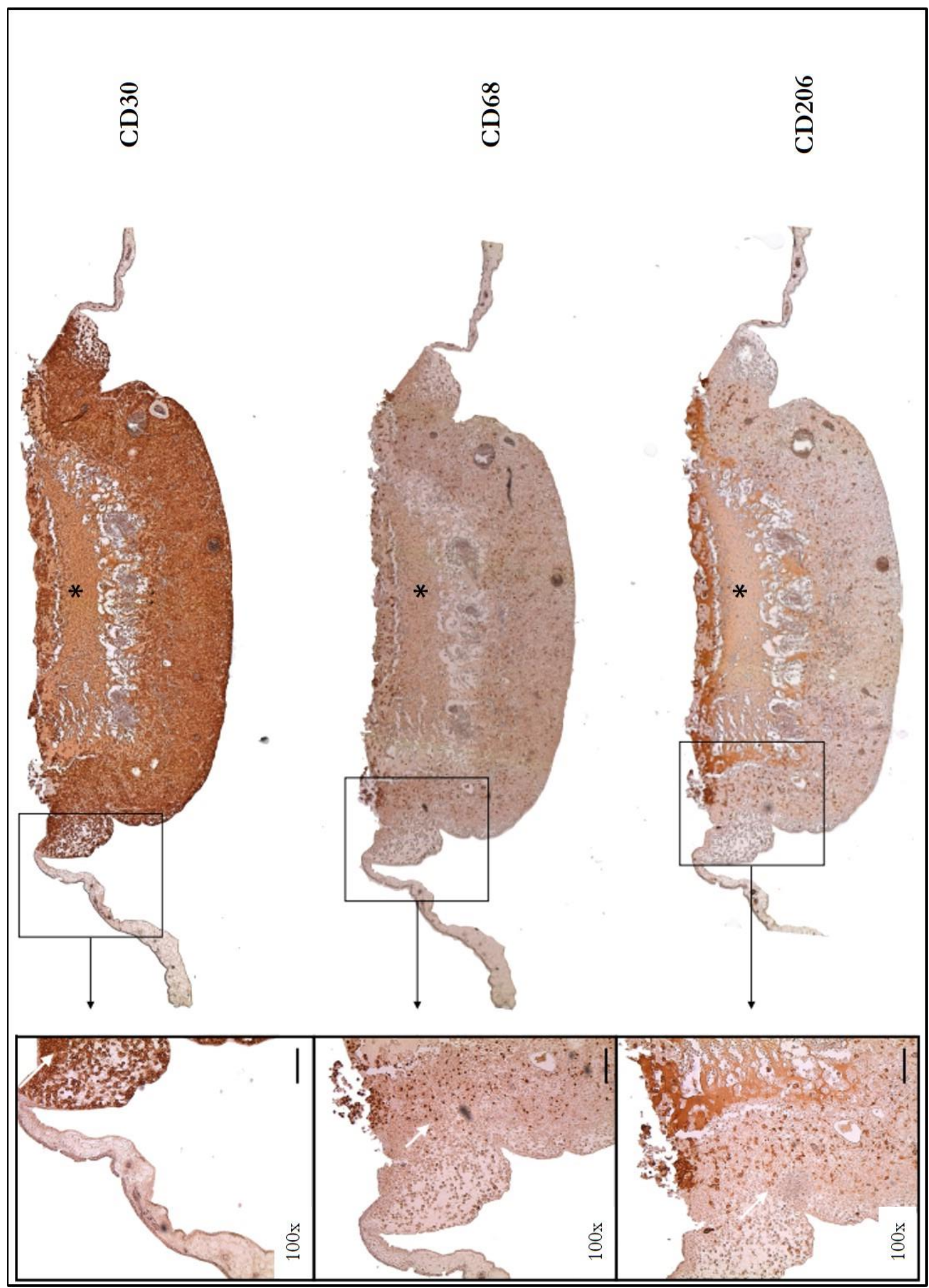

Abbildung 16: CD206-Expression von Makrophagen in CAM-Mischtumoren nach vier Tagen. Ein exemplarischer Mischtumor wurde mit Peroxidase-Färbungen versehen. Die links dargestellten 100-fachen Vergrößerungen zeigen jeweils den linken CAM-Übergang des Tumors. Der gleiche Tumor wurde auf CD30, CD68 und CD206 gefärbt. Die CD30-positiven cHL-Zellen sind ubiquitär zu finden, besonders jedoch in der Tumorbasis und der Lymphomkappe (oben). Die CD68-positiven Makrophagen finden sich in allen drei Kompartimenten des Mischtumors (Mitte). Neben CD68 ko-exprimieren die Makrophagen größtenteils auch 
CD206 (unten). Die Sterne kennzeichnen verbleibendes Matrigel $\left(^{*}\right)$. Die weißen Pfeile in den linken Ausschnitten zeigen korrespondierende CD30-, CD68- oder CD206-positive Zellen. Diese Abbildung ist Teil der Publikation Arlt et al. 2020.

Die immunhistochemische Färbung konnte damit In-vitro-Experimente bestätigen und zeigen, dass CD14+-PBMCs in einem In-ovo-Modell nach vier Tagen Inkubation mit L-428Lymphomzellen zu CD206-positiven (CD206 ${ }^{+}$-Makrophagen führen, da wir davon ausgehen, dass dies auch die CD68-positiven Zellen sind. Im histologischen Präparat ist zu erkennen, dass sich das CD206-Expressionsmuster größtenteils mit der CD68-Expression deckt (16 unten). Auch diese CD68- und CD206-ko-exprimierenden Makrophagen haben sich parallel oder in zeitlich enger Abfolge mit den HRS-Zellen in Richtung der Blutgefäße bewegt (Abbildung 16 unten links). Dies unterstützt unsere Hypothese, dass L-428-Zellen in CAMKo-Kultivierung CD14+-PBMCs so beeinflussen, dass eine deutliche CD68- und CD206Expression nachweisbar ist. Weitergehende Analysen müssen jetzt belegen, ob es sich hierbei um eine Aktivierung der CD14+-PBMCs oder bereits um eine Differenzierung hin zu M2ähnlichen HEMs handelt.

Das in Abbildung 17 dargestellte Blutgefäß der CAM befindet sich am unteren Tumorrand in der Basis des Mischtumors aus Abbildung 16. Zu sehen sind mehrere Lagen palisadenförmig angeordneter CD30-positiver HRS-Zellen (17A), die das Phänomen der vessel co-option zeigen, beziehungsweise vereinzelte CD206 ${ }^{+}$-Makrophagen direkt am oder nahe dem Gefäß (17B).
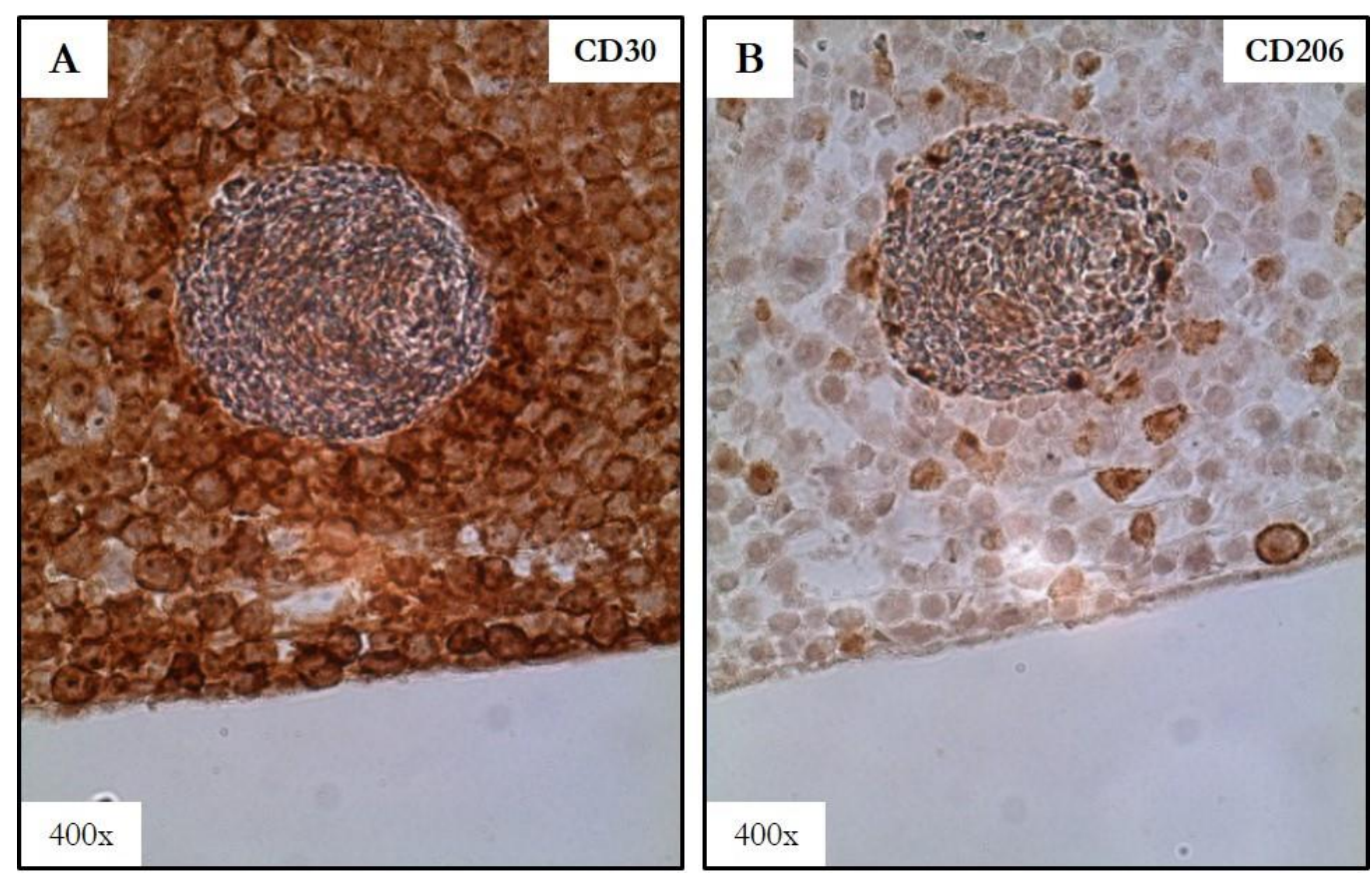

Abbildung 17: HRS-Zellen und CD206 ${ }^{+}$-Makrophagen an einem Blutgefäß der CAM. Dargestellt ist die 400-fache Vergrößerung eines Blutgefäßes, gefüllt mit Hühner-Erythrozyten, in der Tumorbasis des Mischtumors aus Abbildung 16. A. Die CD30-Färbung demonstriert, dass die Mehrheit der Zellen in der Tumorbasis 
von HL-Zellen gestellt wird. Diese lagern sich palisadenförmig in mehreren Lagen dem Gefäß direkt an. B. Vereinzelte CD206+-Makrophagen, ebenfalls braun angefärbt, befinden sich nahe oder direkt am Blutgefäß.

Es konnte also gezeigt werden, dass aus CD14+-PBMCs entstandene CD206 ${ }^{+}$-Zellen in KoKultivierung mit Lymphomzellen ebenfalls zu Blutgefäßen wandern. Da sowohl Makrophagen in der Lymphomkappe der Mischtumoren als auch an der Tumorbasis CD206 ${ }^{+}$waren, kann hierbei von einer einheitlichen Induktion der Expression des MRC1-Gens ausgegangen werden. Um dies jedoch abschließend zu beurteilen, müssen weitere In-vitro- und In-ovo-Untersuchungen durchgeführt werden.

Die 400-fachen Vergrößerungen der Gewebeschnitte nach CD206-Färbung in Abbildung 18 veranschaulichen zudem auch morphologisch den Makrophagen-Charakter der applizierten myeloiden Zellen mit ihrer Spindelform, welche für amöboide Beweglichkeit im Mischtumor mit seinem Matrigel und seinen dicht gepackten Zellpopulationen spricht. Dabei wird außerdem deutlich, dass sich diese Makrophagen auch nahe an Blutgefäßen der CAM aufhalten. Auch weiterhin bestätigte sich bei der Durchsicht der unteren Tumorhälfte verschiedener CAM-Mischtumoren der Eindruck, dass die Makrophagen in allen Bereichen der Läsionen CD206 exprimierten und oft in der Umgebung von Blutgefäßen zu finden waren. Wir gehen also davon aus, dass die CD206 ${ }^{+}$-Zellen gemeinsam mit den CD30-positiven Lymphomzellen zur vessel co-option neigen. 

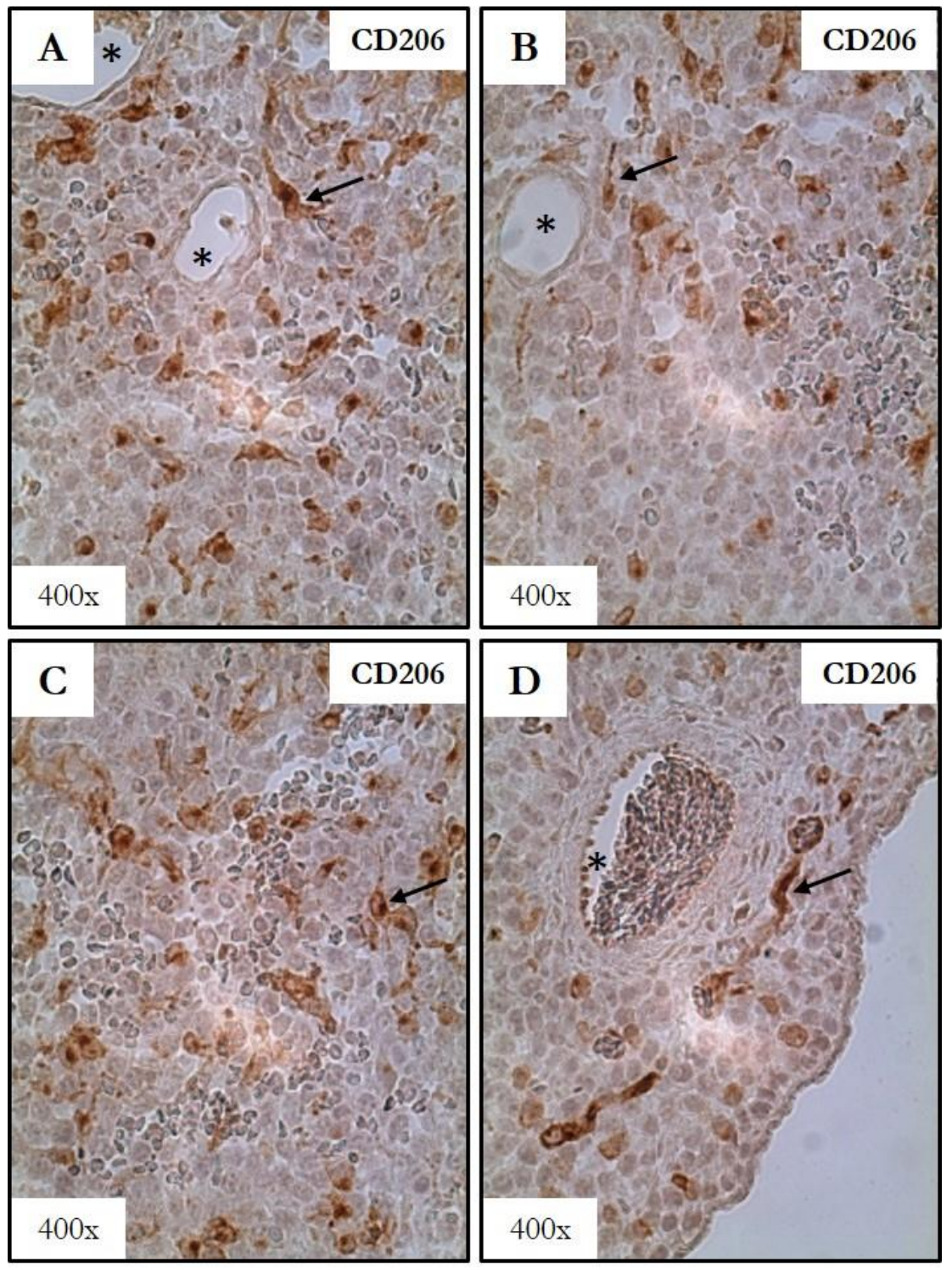

Abbildung 18: CD206-Expression von Zellen in der Basis eines CAM-Mischtumors. Es sind vier 400fach vergrößerte Ausschnitte aus der breiten Tumorbasis des CAM-Mischtumors aus Abbildung 16 zu sehen. Braun angefärbt wurden CD206-exprimierende Makrophagen. Lumina von Blutgefäßen sind mit einem Stern markiert $\left(^{*}\right)$. Die schwarzen Pfeile zeigen auf spindelförmige Makrophagen. A. Dieser Ausschnitt des Schnittpräparates stammt aus dem linken oberen Teil der Tumorbasis nahe der Matrigel-Zone. B. CD206 ${ }^{+}$-Makrophagen an einem Blutgefäß der Tumorbasis. Die Makrophagen haben unterschiedliche Formen. C. Vier Tage nach CAM-Inokulation exprimieren auch diese Makrophagen CD206. D. Das ovale Lumen des Gefäßes am rechten unteren Rand der Tumorbasis ist mit kernhaltigen Hühner-Erythrozyten gefüllt. Zu sehen sind langgezogene Makrophagen, die sich in der Umgebung der cHL-Zellen vermutlich amöboid zu Gefäßen oder dem CAM-Übergang bewegt haben. 


\section{Diskussion}

Die vorliegende Arbeit war Teil einer umfangreicheren Analyse zur Interaktion von HLZellen mit Zellen des Lymphom-Mikromilieus. Da aus klinischen Analysen aus der Literatur bekannt war, dass Monozyten respektive Makrophagen im cHL prognostische Relevanz haben könnten, begann die Arbeitsgruppe sich mit molekularen und zellbiologischen Mechanismen der Wechselwirkung von HL-Zellen mit Makrophagen zu beschäftigen. Das In-ovoXenograft-Modell der Chorion-Allantois-Membran befruchteter Hühnereier spielte hierbei als Modell der In-vivo-Interaktionen von HRS-Zellen mit Makrophagen eine wichtige Rolle. Im Rahmen der vorliegenden Arbeit wurden in diesem Kontext zwei Fragen bearbeitet. Zum einen sollte geklärt werden, ob eine Inokulation von $\mathrm{CD} 14^{+}-\mathrm{PBMCs}$, also undifferenzierten Monozyten, zusammen mit HL-Zellen auf die CAM zu Lymphomen führen kann, wie sie in Vorarbeiten bei der Ko-Applikation von HEMs mit HL-Zellen beobachtet wurden. Zum anderen sollte untersucht werden, ob in der Ko-Kultur aus HL-Zellen und CD14+_-PBMCs im CAM-Assay auch eine CD206-Expression bei den CD14+-PBMCs nachweisbar ist. Dies könnte ein Hinweis auf eine Lymphom-induzierte Aktivierung oder Differenzierung der Monozyten hin zum M2-ähnlichen Makrophagen-Phänotyp sein.

\subsection{Ko-Kultur von L-428-HL-Zellen mit CD14+-PBMCs führt zu kleineren Tumoren und verringerter Einblutung im CAM-Assay}

Das CAM-Modell ist eine etablierte Methode zur Untersuchung verschiedener Aspekte der Tumorgenese in ovo (Ribatti 2014) und kann auch genutzt werden, um eine definierte ZellZell-Interaktion, zum Beispiel von Lymphomzellen mit Monozyten und Makrophagen, zu charakterisieren (Arlt et al. 2020). Die Inokulation von $2 \cdot 10^{6} \mathrm{~L}-428-$ Zellen führte innerhalb von vier Tagen nach Applikation auf die CAM zur Bildung von Tumoren mit einer durchschnittlichen Fläche von $0,21 \mathrm{~cm}^{2}$. Mittels Immunhistochemie konnte gezeigt werden, dass in reinen L-428-Lymphomen, wie aus vorherigen Analysen bekannt, die CD30-positiven HLZellen ubiquitär und homogen im gesamten Tumor verteilt waren und die physiologische CAM gleichmäßig invadierten und durch teils konfluierende, großflächige Hämorrhagien charakterisiert waren (Arlt 2018; Harenberg 2019; Arlt et al. 2020).

Die Ko-Applikation von $1 \cdot 10^{6}$ Monozyten zu jeweils $2 \cdot 10^{6}$ L-428-Lymphomzellen im CAMModell führte innerhalb von vier Tagen zur Formation von deutlich veränderten Tumoren. Die mittlere Fläche der hierbei entstandenen CAM-Mischlymphome betrug 0,113 $\mathrm{cm}^{2}$. Dieser Unterschied war signifikant und weist daraufhin, dass zwischen CD14 ${ }^{+}$-PBMCs und den 
L-428-Zellen eine Wechselwirkung stattgefunden hat. Neben der Reduktion der Lymphomgröße wurden auch weniger Einblutungen beobachtet, was vermuten lässt, dass in Gegenwart von CD14+-PBMCs L-428-Zellen nicht mehr so aktiv zur Angiogenese und KapillarZerstörung beitragen. Eine klare Abhängigkeit von den Monozyten-Spender*innen konnte nicht gezeigt werden. Deutlicher wurden die Unterschiede bei der histologischen Betrachtung von entsprechenden Gewebeschnitten. Die CD14+-PBMCs führten zu einer Umstrukturierung des Tumoraufbaus. In vielen Präparaten hatte sich eine ternäre Kompartimentierung etabliert. Zumeist waren die CD30-positiven cHL-Zellen innerhalb dieser Drei-ZonenGliederung in der Lymphomkappe und der Tumorbasis lokalisiert und fehlten fast vollständig in der zentralen Auflockerung der extrazellulären Matrix. CD68-exprimierende Makrophagen exponierten teilweise einen spindelförmigen Phänotyp, was für eine amöboide Fortbewegung auch innerhalb dieser CAM-Mischtumoren spricht. Die Monozyten respektive Makrophagen als artifiziell hinzugefügtes Immuninfiltrat waren vor allem im oberen und zentralen Bereich der Mischtumoren anzutreffen und insbesondere in oder nahe am Matrigel zu finden. Ebenso wie die Lymphomzellen invadierten auch die Makrophagen die physiologische Chorion-Allantois-Membran, da sie an den jeweiligen CAM-Übergängen über ihre CD68-Expression identifiziert werden konnten.

Bei visueller Inspektion zeichneten sich die Ko-Kultur-Läsionen durch eine kompakte, halbrunde oder kuppelförmige Morphologie aus. Die extrahierten CAM-Mischtumoren hatten eine mittlere Fläche von $0,113 \mathrm{~cm}^{2}$ und waren damit signifikant kleiner als reine L-428-Lymphome. Außerdem waren in den Mischtumoren so gut wie keine Einblutungen nachzuweisen. Diese Beobachtungen zeigen, dass die Ko-Kulturen ähnliche Charakteristika aufwiesen wie jene CAM-Läsionen, bei denen mit M-CSF oder L-428-CM vordifferenzierte CD14 ${ }^{+}$ PBMCs in ovo mit HL-Zellen kultiviert wurden. Auch diese Mischtumoren waren kleiner und Lymphom-Einblutungen fehlten zumeist (Arlt 2018; Arlt et al. 2020). Die Ko-Kultur-Tumoren waren weniger dicht mit Lymphomzellen besiedelt als reine L-428-CAM-Lymphome. Dies könnte daran liegen, dass die HRS-Zellen vom Ort der Applikation migriert waren und unter Anwesenheit von Makrophagen in stärkerem Ausmaß die CAM besiedelt haben.

Wie beschrieben werden kollagene Bindegewebsfasern durch die Masson-Trichrom-Färbung bläulich-grün angefärbt. In reinen L-428-CAM-Lymphomen waren Kollagen-Reste kaum zu identifizieren, wohingegen in den nur mit CD14 ${ }^{+}$-PBMCs beimpften Präparaten das Kollagen als Teil der Matrigel-Proteinmischung reichlich vorhanden war. In den Mischtumoren war kollagenes Bindegewebe vor allem in der beschriebenen zentralen Auflockerung der extrazellulären Matrix zu finden. Hierbei handelte es sich mit großer Wahrscheinlichkeit um 
die Reste des Matrigels, in welchem die Zellen auf die CAM appliziert worden waren. Dies würde bedeuten, dass in Anwesenheit der CD14+2PBMCs die L-428-Zellen weniger aktiv das ko-applizierte Matrigel verdauen. In den Trichrom-Färbungen der Mischtumoren war außerdem ersichtlich, dass L-428-Zellen zu Blutgefäßen der CAM rekrutiert worden waren und zum Teil palisadenförmige Ansammlungen um die Endothelzellen bildeten. Dabei kann von einer sogenannten vessel co-option der HL-Zellen ausgegangen werden. Dies meint die Nutzung präexistenter Blutgefäße des umgebenden benignen Gewebes durch Tumorzellen (Kuczynski et al. 2019). Dieses Phänomen wurde bereits für BL-Zellen im CAM-Modell beschrieben (Wilming 2017). Ob und in welchem Ausmaß die Präsenz myeloider Zellen in den CAM-Läsionen die Rekrutierung der HL-Zellen zu Blutgefäßen beeinflusst und ob die Gefäße schon frühzeitig nach Inokulation ko-optiert werden, könnte in CAM-Versuchen in Gestalt einer Zeitreihe eruiert werden. Dabei könnten die Mischtumoren zu verschiedenen Zeitpunkten extrahiert und histologisch ausgewertet und auch die applizierte Menge an CD14 ${ }^{+}$-PBMCs variiert werden.

Die Tatsache, dass unstimulierte Monozyten in CAM-Ko-Kultur mit HL-Zellen zu kleineren und weniger eingebluteten Tumoren führen, ist kontraintuitiv zu bereits erhobenen klinischen Daten über einen aggressiveren Verlauf. Die Hinzugabe von Monozyten führte zu einer veränderten Tumorbildung in ovo. Dies geschah jedoch auf eine Weise, die konträr zu den erwarteten Auswirkungen der myeloiden Zellen war. Eine hohe Makrophagen-Last korrelierte in verschiedenen Studien mit negativen Prognosefaktoren. So fand man heraus, dass eine erhöhte Anzahl an CD68-positiven TAMs mit einer schlechteren Prognose im cHL einhergeht (Steidl et al. 2010; Hollander et al. 2018). Diese Ergebnisse stehen im Einklang mit weiteren Untersuchungen zur Bedeutung von Makrophagen im Hodgkin-Lymphom, die ebenfalls einen ungünstigen Krankheitsverlauf assoziierten (Tzankov et al. 2010; Greaves et al. 2013). Daher liegt es nahe, die CD68-Expression durch Makrophagen im TME als Biomarker in der Aufarbeitung von cHL-Fällen zu inkludieren (Venkataraman et al. 2014).

Die strukturellen Unterschiede zwischen L-428-Lymphomen und Mischtumoren mit Monozyten respektive Makrophagen sprechen für eine gegenseitige Interaktion der L-428-Zellen mit myeloiden Zellen und unterstützen das Konzept der Makrophagen als Modulatoren der extrazellulären Matrix. Zwischen den Mischtumoren, bei denen mit M-CSF oder L-428$\mathrm{CM}$ vordifferenzierte CD14 ${ }^{+}$-PBMCs in ovo mit HL-Zellen kultiviert worden waren, konnten jeweils keine größeren morphologischen Unterschiede in den CAM-Läsionen festgestellt werden (Arlt et al. 2020). Auch die in dieser Arbeit gezeigten CAM-Ko-Kulturen aus Hodg- 
kin-Lymphomzellen und nicht vorbehandelten CD14 ${ }^{+}$-PBMCs unterschieden sich morphologisch nicht wesentlich von den Läsionen mit vordifferenzierten Makrophagen. Insgesamt haben sich, wie angedeutet, die CAM-Mischtumoren aus L-428-Zellen und CD14+-PBMCs morphologisch nicht wesentlich von CAM-Tumoren unterschieden, die mit HL-CM- respektive M-CSF-vordifferenzierten Makrophagen und L-428-Zellen generiert worden waren (Arlt et al. 2020). Allerdings konnte in den Mischtumoren, die durch Ko-Applikation von L428-Zellen und vordifferenzierten Makrophagen generiert worden waren, regelmäßig die Migration von Lymphomzellen über Lymphgefäße an den Invasionsfronten der CAM-Läsionen gezeigt werden (Arlt et al. 2020). Die lymphogene Metastasierung von Tumorzellen in CAM-Ko-Kulturen aus L-428-Zellen und CD14+-PBMCs konnte in angefertigten Immunfluoreszenz-Bildern für diese Dissertation nicht gezeigt werden. Da die Addition von CD14 ${ }^{+}$-PBMCs offenbar nicht förderlich für ein weiteres Tumorwachstum im CAM-Assay ist, bleibt die Bedeutung der myeloiden Zellen in dieser Hinsicht unklar und sollte weiter untersucht werden.

In-ovo-Studien haben bereits eine Akkumulation von disseminierten Tumorzellen in Leber und Lunge des Hühnchen-Embryos nachweisen können (Zijlstra et al. 2008). Daher sollten in zukünftigen Experimenten auch vom Ort der Inokulation weiter entfernte Stellen im Hühnerei auf die Existenz von Lymphomzellen untersucht werden, um die reduzierte Anzahl an HRS-Zellen in CAM-Mischtumoren zu klären. Die Lymphomzellen könnten nach Invasion in das CAM-Bindegewebe lymphogen disseminieren, wie wir das in den HEMs-L-428-CAMKo-Kulturen beobachten konnten. Dafür müssten in Zukunft weiterführende Analysen von Lymphgefäßen mittels Immunfluoreszenz durchgeführt werden. Eine hämatogene Disseminierung erscheint aktuell eher unwahrscheinlich, da zumindest in der Trichrom-Färbung der Gewebeschnitte und immunhistochemisch zwar eine vessel co-option gefunden wurde, aber keine CD30-positiven Zellen in den größeren Blutgefäßen nachweisbar waren.

\subsection{CD206-Expression in Mischtumoren aus L-428 und CD14+- PBMCs}

Die zweite wichtige Frage adressierte die Möglichkeit einer CD206-Expression durch die applizierten Monozyten im CAM-Assay. In dieser Dissertation konnte gezeigt werden, dass L-428-HL-Zellen unbehandelte CD14+-PBMCs in einem In-ovo-Xenograft-Modell zur Expression von CD206 stimulieren können. Da CD206 ein Aktivierungsmarker für M2-Makrophagen ist, kann postuliert werden, dass die von cHL-Zellen sezernierten Faktoren auch 
in ovo eine Differenzierung naiver CD14+-PBMCs hin zum M2-ähnlichen Makrophagen-Phänotyp induzieren. Die Ko-Expression von CD68 und CD206 durch Makrophagen nach 96 h Inkubationszeit konnte immunhistochemisch nachgewiesen werden. Für die Detektion der CD206-Expression durch CAM-Makrophagen war ein Differenzierungsprozess von vier Tagen Dauer ausreichend. Außerdem wurden die ko-exprimierenden Makrophagen zu Blutgefäßen der CAM rekrutiert und invadierten ebenso wie die Tumorzellen die physiologische CAM. Festzustellen war, dass die Migrationsfront der myeloiden Zellen dabei etwas weniger weit fortgeschritten war als die der Lymphomzellen. Die Ko-Expression von CD68 und CD206 betraf Makrophagen in allen drei Kompartimenten der CAM-Mischtumoren. Darüber hinaus war die CD206-Expression unabhängig von den jeweiligen Monozyten-Spender*innen. In der histologischen Begutachtung konnte herausgearbeitet werden, dass sich in den CAM-Mischtumoren zwei Makrophagen-Populationen entwickelten. Eine Fraktion der CD206-exprimierenden Makrophagen schien resident zu sein und am Ort der Applikation zu verharren, beispielsweise innerhalb des Matrigels oder in der Tumorbasis. Die zweite Fraktion der myeloiden Zellen schien mit den HRS-Zellen zu migrieren. In beiden Makrophagen-Gruppen entwickelte sich unter den CD68- und CD206-ko-exprimierenden Zellen teilweise ein spindelförmiger Phänotyp, der stets für amöboide Beweglichkeit innerhalb der Tumormasse sprach und die morphologische Differenzierung vom kugeligen Monozyten hin zum Makrophagen verkörperte.

CD206 ist ein an Kohlenhydrate bindender Rezeptor, der von Makrophagen, dendritischen Zellen und Lymphendothelzellen exprimiert wird und eine konservierte Struktur aufweist (vgl. Kapitel 1.2; Taylor et al. 2005; Wilting et al. 2009). Welche Rolle CD206 beim beobachteten reduzierten Abbau des ko-applizierten Matrigels spielt, konnte leider im Rahmen dieser Arbeit nicht untersucht werden. Ausgehend von Vorarbeiten der Arbeitsgruppe hätte man vermuten können, dass CD206 ${ }^{+}$-Makrophagen eher zu einer verstärkten Kollagen- und Mikromilieu-Veränderung beitragen. Weitere Analysen können zukünftig diese Fragestellung untersuchen. Auf Monozyten findet sich normalerweise kein CD206 (Martinez-Pomares 2012). Um die Frage der Bedeutung von CD206 auf Makrophagen besser beantworten zu können, sollten die CD14+-PBMCs bei zukünftigen CAM-Experimenten vor der Inokulation auf die Expression von CD68 beziehungsweise CD206 mittels FACS-Analysen untersucht werden. Außerdem sollten in Zukunft CD206 ${ }^{+}$-Zellen der generierten Mischtumoren aus der CAM isoliert und molekular- und zellbiologisch weiter charakterisiert werden. 
Da HL-CM-behandelte Makrophagen Kollagen Typ I aufnehmen können, liegt es nahe, dass diese M2-ähnlichen Makrophagen eine spezifische CD206-mediierte Rolle in der Umgestaltung des Lymphomgewebes spielen. Der Umbau der extrazellulären Matrix ist ein Phänomen, das häufig mit Tumorprogression oder Metastasierung assoziiert ist. Das TumorStroma wird durch proteolytische Degradierung umgeformt (Tataroglu et al. 2007; Cox und Erler 2011; Nakayama et al. 2016). Im Mausmodell eines Lungentumors konnte gezeigt werden, dass die Degradierung der extrazellulären Matrix und Kollagen-Aufnahme durch Makrophagen zumindest teilweise abhängig von CD206 ist (Madsen et al. 2017). Eine bemerkenswerte Eigenschaft des cHL-Subtyps der nodulären Sklerose ist die Fülle an Kollagenfasern, die als fibrotische Bänder die knotenförmigen Ansammlungen von inflammatorischen und neoplastischen Zellen umgeben (Arlt et al. 2020). L-428-Zellen stammen ebenfalls vom Typ der Nodularsklerose ab (vgl. Kapitel 2.2.1.1). Die in dieser Dissertation gezeigte Fähigkeit der L-428-Zellen, in ovo einen spezifischen Makrophagen-Subtyp mit starker CD206Expression zu induzieren, und die veränderte phänotypische Ausprägung der CAM-Tumoren mit myeloiden Zellen akzentuieren in Zusammenschau mit der in vitro gezeigten Kollagen-Aufnahme über CD206 die Annahme, dass die Umstrukturierung des Tumorgewebes über eine Wechselwirkung von Lymphomzellen mit Stromazellen stattfindet. Diese Hypothese kann als Ergänzung der beschriebenen Mastzell-Infiltration und Fibrose im HodgkinLymphom betrachtet werden (Nakayama et al. 2016; Arlt et al. 2020).

Die Mikroumgebung im Hodgkin-Lymphom spielt eine entscheidende Rolle in der Pathogenese dieser B-Zell-Neoplasie und TAMs sind ein regelmäßiger Bestandteil des reaktiven Immuninfiltrates. Daher ist es wichtig zu verstehen, welche Mechanismen HRS-Zellen befähigen, Monozyten zu rekrutieren und in TAMs respektive M2-ähnliche Makrophagen umzuprogrammieren (Aldinucci et al. 2010; Steidl et al. 2011). Bekannt ist mittlerweile, dass eine Vielzahl an PD-L1-positiven Makrophagen, die physisch ko-lokalisert zu ebenfalls PD-L1positiven HRS-Zellen zu finden sind, mit PD-1-exponierenden T-Zellen im cHL interagieren. Die Lymphomzellen selbst kommunizieren insbesondere mit den CD4 ${ }^{+}-\mathrm{T}$-Zellen (Carey et al. 2017). Diese einzigartige Topologie im cHL mit PD-L1-positiven TAMs, welche die malignen Zellen direkt umgeben, impliziert CD4 ${ }^{+}-\mathrm{T}-$ Zellen als Angriffspunkt einer PD-1Blockade, was seit einiger Zeit schon klinische Relevanz hat (vgl. Kapitel 1.1; Carey et al. 2017).

In-vitro-Analysen der Arbeitsgruppe konnten zeigen, dass der JAK/STAT-Signalweg und IL13 an der positiven Regulation der MRC1-Genexpression und der Stärke der Expression dieses Markers auf der Oberfläche von HL-konditionierten Makrophagen beteiligt sind (Arlt 
et al. 2020). IL-13 scheint nicht nur ein autokriner Wachstumsfaktor der HRS-Zellen selbst zu sein, sondern auch ein HL-sekretierter Faktor, welcher Umbauprozesse der extrazellulären Matrix und Immunsuppression durch HL-konditionierte Makrophagen mediiert. Diese Vorgänge erhöhen wiederum das Disseminierungspotenzial der Lymphomzellen (Skinnider und Mak 2002; Arlt et al. 2020). Darüber hinaus soll IL-13 das Überleben von Monozyten fördern (McKenzie et al. 1993). In vitro werden signifikant mehr Makrophagen nach Differenzierung mit HL-CM beobachtet als nach Konditionierung mit DLBCL-CM oder M-CSF. Auch die HL-Zelllinie L-428 exprimiert M-CSF, welches eine M2-Polarisierung von Makrophagen fördert. Eine erhöhte Sekretion von M-CSF ist auch in anderen Tumorentitäten beschrieben (El-Gamal et al. 2018) und wird mit einer erhöhten Proliferationskapazität von Makrophagen in Verbindung gebracht (Tymoszuk et al. 2014). Neben M-CSF wurden auch C-X-C motif chemokine (CXCL) 13 und CCL5 als zentrale Akteure in der Interaktion von HLZellen mit Makrophagen identifiziert (Scott und Steidl 2014; Tudor et al. 2014; Ford et al. 2015; Carey et al. 2017; Ruella et al. 2017; Casagrande et al. 2019; Locatelli et al. 2019). Gleichwohl kann die starke CD206-Expression in vitro und in den CAM-Präparaten in ovo nicht allein der M-CSF-Sekretion durch HL-Zellen zugeschrieben werden. Arlt et al. (2020) haben beobachtet, dass IL-13 die frühe messenger ribonucleic acid (mRNA)-Hochregulation von MRC1 und eine verstärkte Integration von CD206 in die Plasmamembran fördert. Eine verstärkte IL-13-Expression ist ein Charakteristikum des Hodgkin-Lymphoms und IL-13 kann die Makrophagen-Differenzierung unterstützen (McKenzie et al. 1993; Skinnider et al. 2001; Arlt et al. 2020).

IL-13 bindet an ein Rezeptor-Heterodimer, das intrazellulär mit JAK1 und JAK2 interagiert (Bhattacharjee et al. 2013). Die fehlende MRC1-Genexpression durch Makrophagen nach Behandlung mit dem Tyrosinkinase-Inhibitor Ruxolitinib suggeriert, dass die Januskinasen ein M2-Genxpressionsmuster induzieren (Arlt et al. 2020). Somit scheint IL-13 ein wichtiger Effektor für die Umgestaltung des HL-Mikromilieus durch Makrophagen-Differenzierung und Hochregulation der CD206-Expression zu sein (Arlt et al. 2020), was wiederum therapeutische Implikationen nach sich ziehen könnte. Ein Ansatz, das TME im Hodgkin-Lymphom zu adressieren, könnte also eine Blockade des JAK/STAT-Signalweges sein (Kim et al. 2019). Auch der Bruton's tyrosine kinase (BTK)-Signalweg und phosphatidylinositol 3-kinases (PI3K)-regulierte Signalwege scheinen in der Pathogenese des cHL involviert, da entsprechende Inhibitoren sowohl die M-CSF- als auch die L-428-CM-getriggerte MakrophagenKonditionierung beeinflussen (Arlt et al. 2020). Damit im Einklang stehen präklinische Beobachtungen mit dem small molecule Tenalisib (RP6530), einem PI3K-Inhibitor (Locatelli et al. 2019). M-CSF scheint ein Netzwerk an Signalwegen für Makrophagen-Differenzierung zu 
induzieren, wohingegen IL-13 auf direktem Wege eine frühe Differenzierung fördert (Arlt et al. 2020). Ungeachtet dessen sind weitere Faktoren an der Makrophagen-Differenzierung im HL beteiligt (Zheng et al. 1999; Kowalska et al. 2012; Casagrande et al. 2019). Auch GMCSF und IL-4 tragen zur Induktion der Expression des MRC1-Gens in humanen Monozyten bei (Martinez et al. 2006; Däbritz et al. 2015; Arlt 2018).

Die Untersuchung von Gewebeproben von HL-Patient*innen konnte eine hohe CD206Expression durch TAMs mit fortgeschrittenen Krankheitsstadien korrelieren (Arlt et al. 2020). Die dargelegten In-ovo-Beobachtungen zur Regulation der CD206-Expression von Makrophagen im cHL legen den Schluss nahe, dass diese auch in vivo auftreten könnte und zu hoher CD206-Expression in fortgeschrittenen Stadien des Hodgkin-Lymphoms beiträgt. Die Experimente im CAM-Modell identifizieren CD206 als möglichen pharmakologischen Angriffspunkt für die Modulation der Makrophagen-Aktivierung, neben dem Augenmerk auf den diskutierten Colony stimulating factor 1 receptor (CSF1R) (Luo et al. 2006; Pyonteck et al. 2013; Ries et al. 2014; Zhu et al. 2014; Martín-Moreno et al. 2015; Pham et al. 2018; Wang et al. 2018). Die Inhibition des JAK/STAT-Signalweges könnte sich als dualer Therapieansatz im cHL entpuppen, da nicht nur die Lymphomzellen selbst, sondern auch die HRS-getriggerte Makrophagen-Entwicklung möglicherweise beeinflusst werden (Arlt et al. 2020).

M2-Makrophagen sind durch ihr inhibitorisches Potenzial auf T-Zell-Proliferation charakterisiert, was auch in Tumorzell-konditionierten Makrophagen beobachtet wurde (Duluc et al. 2007; Huber et al. 2010; Yue et al. 2015; Lievense et al. 2016; Oishi et al. 2016). Daher könnten die in ovo gezeigten CD206-exprimierenden Makrophagen auch eine bedeutende Rolle in der Pathogenese des cHL haben. Unabhängig davon wurde für CD206 ${ }^{+}$-dendritische Zellen gezeigt, dass die über CD206 aufgenommenen Antigene vermehrt T-Zellen präsentiert wurden (Burgdorf et al. 2006). Da auch Makrophagen zu den Antigen-präsentierenden Zellen gehören, welche T-Zellen aktivieren, wäre es denkbar, dass eine verbesserte Antigenpräsentation infolge einer erhöhten CD206-Expression auftritt (Hilhorst et al. 2014; Arlt 2018). Dieser Aspekt sollte in Zukunft weiter untersucht werden, zumal die immunsuppressiven Funktionen, die den TAMs zugeschrieben werden, konträr zu gesteigerter T-Zell-Aktivierung wären.

\subsection{Ausblick}

In der vorliegenden Dissertation konnte einerseits der Einfluss von CD14+-PBMCs beziehungsweise Monozyten auf die Tumorbildung durch HL-Zellen der Linie L-428 in ovo charakterisiert werden, andererseits aber auch nachgewiesen werden, dass L-428-Zellen in ovo in 
der Lage sind, bei CD14 ${ }^{+}$-PBMCs innerhalb von vier Tagen eine CD206-Expression zu induzieren. Der viertägige Differenzierungsprozess vom Monozyten zum CD206 ${ }^{+} \mathrm{M} 2-a ̈ h n l i-$ chen Makrophagen wurde bisher für das Hodgkin-Lymphom in einem Xenograft-Modell nicht beschrieben. Um den M2-ähnlichen Phänotyp der TAMs im Hodgkin-Lymphom in Zukunft noch ausführlicher zu beschreiben, könnten weitere M2-Marker wie CD163 in die histologischen Analysen von CAM-Tumor-Schnittpräparaten mit einbezogen werden. Ferner sollten weitere cHL-Zelllinien im Wechselspiel mit Monozyten und Makrophagen untersucht werden, um Ähnlichkeiten und Unterschiede zu definieren. Außerdem wäre es interessant zu sehen, wie sehr selektive Inhibitoren deregulierter Signalwege im HL (JAK/STAT, PI3K, BTK) die Ausgestaltung von CAM-Mischtumoren beeinflussen und welchen Einfluss sie beispielsweise auf den Makrophagen-Subtyp haben, wenn Lymphomzellen vor Inokulation mit diesen small molecules inkubiert werden. Ein besonderes Augenmerk sollte dabei auf die Struktur der CAM-Lymphome und das Verhalten von Tumorzellen und myeloiden Zellen an den CAM-Invasionsfronten gelegt werden. Um das Disseminationsverhalten von Lymphomzellen in ovo besser verstehen zu können, könnte die Präparation der HühnchenLeber ein weiterer Ansatz sein.

Langfristig stellt sich die Frage, ob von TAMs im Hodgkin-Lymphom exprimierte Proteine wie CD68 oder CD206 geeignete Angriffspunkte für rezidivierte oder therapierefraktäre Fälle oder fortgeschrittene Krankheitsstadien sein könnten. Die Anzahl an CD68-positiven Makrophagen korreliert mit einer schlechteren Prognose (Steidl et al. 2010; Scott und Steidl 2014). Die Last an CD68-positiven Makrophagen im Tumorgewebe könnte daher als Biomarker für eine bessere Risikostratifizierung im cHL dienen (Steidl et al. 2010). Daher scheint die Interaktion von HRS-Zellen und TAMs ein aussichtsreicher Angriffspunkt in der Therapie des Hodgkin-Lymphoms zu sein (Ruella et al. 2017; Locatelli et al. 2019). Da CD68 vorwiegend intrazellulär exprimiert wird, könnte CD206 pharmakologisch leichter erreichbar sein. Falls sich CD206 im Hodgkin-Lymphom als prognostischer Parameter bei der Erstdiagnose eignen sollte, könnten exstirpierte Lymphknoten von cHL-Patient*innen in Zukunft auf eine entsprechende Expression durch TAMs untersucht werden.

Neue therapeutische Strategien für die Behandlung des cHL werden auch darauf setzen, die Ausbildung des TME zu inhibieren, der immunsuppressiven Programmierung von T-Zellen und Monozyten gegenzusteuern und Monozyten respektive TAMs direkt ins Visier zu nehmen (Aldinucci et al. 2019; Casagrande et al. 2019; Locatelli et al. 2019). In Zukunft könnte sich eine targeted therapy, welche TAMs und das restliche Mikromilieu im Hodgkin-Lymphom 
adressiert, als wertvolle Ergänzung der konventionellen Therapie erweisen. Schon heute haben PD-1-Antikörper unter bestimmten Voraussetzungen die HL-Therapie bereichert. Gegenwärtig steht die Minimierung der Toxizität im Fokus der Chemotherapie-Optimierung. Diesem Ziel könnte man durch den vermehrten Einsatz von Immuncheckpoint-Inhibitoren und Immuntoxinen näherkommen. 


\section{$5 \quad$ Zusammenfassung}

Das klassische Hodgkin-Lymphom ist eine häufige maligne B-Zell-Neoplasie. Diese Tumorentität ist durch wenige Hodgkin-Reed-Sternberg-Zellen vor dem Hintergrund eines ausgedehnten reaktiven Immuninfiltrates benigner Zellen charakterisiert, wobei Monozyten respektive Makrophagen von prognostischer Bedeutung sind. Deshalb ist die Untersuchung der Mechanismen der vielfältigen Wechselwirkungen von Lymphomzellen und den Zellen ihrer Mikroumgebung, speziell der Makrophagen, von außerordentlicher klinischer Relevanz. Um herauszufinden, welche Auswirkung eine Ko-Kultur von CD14-positiven (CD14 $\left.{ }^{+}\right) p^{e^{-}}$ ripheral blood mononuclear cells (PBMCs) mit Hodgkin-Zellen in einem präklinischen XenograftModell hat, wurden Tumoren im Chorion-Allantois-Membran-(CAM)-Assay des befruchteten Hühnereis generiert. In diesem neu etablierten CAM-Modell wurden Lymphome der Zelllinie L-428 in An- und Abwesenheit von CD14 ${ }^{+}$-PBMCs untersucht. Mischtumoren aus Lymphomzellen und CD14+-PBMCs führten im Vergleich zu reinen L-428-CAM-Lymphomen zu signifikant kleineren CAM-Läsionen, in denen so gut wie keine Hämorrhagien nachgewiesen werden konnten. Die Mischtumoren hatten eine kugelige, halbrunde Form und zeichneten sich histologisch durch eine dreigliedrige Kompartimentierung aus. Sowohl Lymphomzellen als auch Makrophagen zeigten nach vier Tagen in ovo Migrationsverhalten an den Invasionsfronten zur physiologischen CAM.

Eine wichtige Beobachtung war, dass im CAM-Modell histologisch die Expression von CD206 auf CD68-positiven Zellen in Mischtumoren aus L-428-Lymphomzellen mit CD14 ${ }^{+}$ PBMCs nachweisbar war. Dies spricht für einen Lymphom-induzierten Aktivierungs- oder Differenzierungsprozess von den CD14+-PBMCs hin zu alternativ aktivierten M2-ähnlichen Makrophagen und gegebenenfalls sogar hin zu Hodgkin lymphoma-educated macrophages (HEMs). Da CD206 durch zahlreiche endozytotische Prozesse, unter anderem durch Kollagen-Aufnahme, charakterisiert ist, kommt den CD206-exprimierenden TAMs im Hodgkin-Lymphom vermutlich eine Rolle als aktiver Modulator in der Umgestaltung der LymphomMikroumgebung zu. Dies gilt es jedoch in der Zukunft noch eingehender zu untersuchen.

In Zukunft könnte sich CD206 als diagnostischer Biomarker im Hodgkin-Lymphom herausstellen, vielleicht könnte es aber auch zur Therapiesteuerung und unter Umständen auch als Zielstruktur zur selektiven Inhibition von HEMs geeignet sein, auch vor dem Hintergrund der neueren Immuncheckpoint-Therapien bei Patient*innen mit Hodgkin-Lymphom. 


\section{$6 \quad$ Literaturverzeichnis}

Albini A, Bruno A, Gallo C, Pajardi G, Noonan DM, Dallaglio K (2015): Cancer stem cells and the tumor microenvironment: interplay in tumor heterogeneity. Connect Tissue Res $\underline{56}, 414$ 425

Aldinucci D, Gloghini A, Pinto A, De Filippi R, Carbone A (2010): The classical Hodgkin's lymphoma microenvironment and its role in promoting tumour growth and immune escape. J Pathol 221, 248-263

Aldinucci D, Celegato M, Casagrande N (2016): Microenvironmental interactions in classical Hodgkin lymphoma and their role in promoting tumor growth, immune escape and drug resistance. Cancer Lett $\underline{380}, 243-252$

Aldinucci D, Borghese C, Casagrande N (2019): Formation of the immunosuppressive microenvironment of classic Hodgkin lymphoma and therapeutic approaches to counter it. Int J Mol Sci $\underline{20}, 2416$

Alonso-Álvarez S, Vidriales MB, Caballero MD, Blanco O, Puig N, Martin A, Peñarrubia MJ, Zato E, Galende J, Bárez A et al. (2017): The number of tumor infiltrating T-cell subsets in lymph nodes from patients with Hodgkin lymphoma is associated with the outcome after first line ABVD therapy. Leuk Lymphoma $\underline{58}, 1144-1152$

Amin MSA, Brunckhorst O, Scott C, Wrench D, Gleeson M, Kazmi M, Ahmed K (2020): ABVD and BEACOPP regimens' effects on fertility in young males with Hodgkin lymphoma. Clin Transl Oncol 23, 1067-1077

Ansell SM (2018): Hodgkin lymphoma: 2018 update on diagnosis, risk-stratification, and management. Am J Hematol 933, 704-715

Ansell SM, Lesokhin AM, Borrello I, Halwani A, Scott EC, Gutierrez M, Schuster SJ, Millenson MM, Cattry D, Freeman GJ et al. (2015): PD-1 blockade with nivolumab in relapsed or refractory Hodgkin's lymphoma. N Engl J Med $\underline{372}$, 311-319

Arlt A: Hodgkin lymphoma secreted factors determine macrophage polarization and function. PhD thesis in Molecular Medicine. Göttingen 2018

Arlt A, von Bonin F, Rehberg T, Perez-Rubio P, Engelmann JC, Limm K, Reinke S, Dullin C, Sun X, Specht R et al. (2020): High CD206 levels in Hodgkin lymphoma-educated macrophages are linked to matrix-remodeling and lymphoma dissemination. Mol Oncol 14, 571589

Armand P, Shipp MA, Ribrag V, Michot JM, Zinzani PL, Kuruvilla J, Snyder ES, Ricart AD, Balakumaran A, Rose S, Moskowitz CH (2016): Programmed death-1 blockade with pembrolizumab in patients with classical Hodgkin lymphoma after brentuximab vedotin failure. J Clin Oncol 34, 3733-3739

Armstrong PB, Quigley JP, Sidebottom E (1982): Transepithelial invasion and intramesenchymal infiltration of the chick embryo chorioallantois by tumor cell lines. Cancer Res $\underline{42}$, 18261837

Ausprunk DH, Knighton DR, Folkman J (1974): Differentiation of vascular endothelium in the chick chorioallantois: a structural and autoradiographic study. Dev Biol $\underline{38}$, 237-248

Aziz A, Soucie E, Sarrazin S, Sieweke MH (2009): MafB/c-Maf deficiency enables self-renewal of differentiated functional macrophages. Science $\underline{326}, 867-871$ 
Barros MHM, Hassan R, Niedobitek G (2012): Tumor-associated macrophages in pediatric classical Hodgkin lymphoma: association with Epstein-Barr virus, lymphocyte subsets, and prognostic impact. Clin Cancer Res 18, 3762-3771

Barros MHM, Segges P, Vera-Lozada G, Hassan R, Niedobitek G (2015): Macrophage polarization reflects $\mathrm{T}$ cell composition of tumor microenvironment in pediatric classical Hodgkin lymphoma and has impact on survival. PLoS One 10, e0124531

Basso K, Dalla-Favera R (2015): Germinal centres and B cell lymphomagenesis. Nat Rev Immunol $\underline{15}, 172-184$

Becker J, Covelo-Fernandez A, von Bonin F, Kube D, Wilting J (2012): Specific tumor-stroma interactions of EBV-positive Burkitt's lymphoma cells in the chick chorioallantoic membrane. Vasc Cell $\underline{4}, 3$

Bhattacharjee A, Shukla M, Yakubenko VP, Mulya A, Kundu S, Cathcart MK (2013): IL-4 and IL13 employ discrete signaling pathways for target gene expression in alternatively activated monocytes/macrophages. Free Radic Biol Med $\underline{54}, 1-16$

Borchmann P, Eichenauer DA, Engert A (2012): State of the art in the treatment of Hodgkin lymphoma. Nat Rev Clin Oncol $\underline{9}$, 450-459

Brady G, MacArthur GJ, Farrell PJ (2007): Epstein-Barr virus and Burkitt lymphoma. J Clin Pathol $\underline{60}, 1397-1402$

Burgdorf S, Lukacs-Kornek V, Kurts C (2006): The mannose receptor mediates uptake of soluble but not of cell-associated antigen for cross-presentation. J Immunol 176, 6770-6776

Canellos GP, Rosenberg SA, Friedberg JW, Lister TA, Devita VT (2014): Treatment of Hodgkin lymphoma: a 50-year perspective. J Clin Oncol $\underline{32}, 163-168$

Canioni D, Deau-Fischer B, Taupin P, Ribrag V, Delarue R, Bosq J, Rubio M-T, Roux D, Vasiliu V, Varet B et al. (2009): Prognostic significance of new immunohistochemical markers in refractory classical Hodgkin lymphoma: a study of 59 cases. PLoS One $\underline{4}$, e6341

Carbone A, Gloghini A, Gruss HJ, Pinto A (1995): CD40 ligand is constitutively expressed in a subset of $\mathrm{T}$ cell lymphomas and on the microenvironmental reactive $\mathrm{T}$ cells of follicular lymphomas and Hodgkin's disease. Am J Pathol 147, 912-922

Carbone A, Gloghini A, Castagna L, Santoro A, Carlo-Stella C (2015): Primary refractory and earlyrelapsed Hodgkin's lymphoma: strategies for therapeutic targeting based on the tumour microenvironment. J Pathol 237, 4-13

Carbone PP, Kaplan HS, Musshoff K, Smithers DW, Tubiana M (1971): Report of the committee on Hodgkin's disease staging classification. Cancer Res $\underline{31}, 1860-1861$

Carey CD, Gusenleitner D, Lipschitz M, Roemer MGM, Stack EC, Gjini E, Hu X, Redd R, Freeman GJ, Neuberg D et al. (2017): Topological analysis reveals a PD-L1-associated microenvironmental niche for Reed-Sternberg cells in Hodgkin lymphoma. Blood 130, 24202430

Casagrande N, Borghese C, Visser L, Mongiat M, Colombatti A, Aldinucci D (2019): CCR5 antagonism by maraviroc inhibits Hodgkin lymphoma microenvironment interactions and xenograft growth. Haematologica 104, 564-575

Cavaillon JM (2011): The historical milestones in the understanding of leukocyte biology initiated by Elie Metchnikoff. J Leukoc Biol 90, 413-424 
Chevrier S, Levine JH, Zanotelli VRT, Silina K, Schulz D, Bacac M, Ries CH, Ailles L, Jewett MAS, Moch $\mathrm{H}$ et al. (2017): An immune atlas of clear cell renal cell carcinoma. Cell 169, 736-749

Chiu J, Ernst DM, Keating A (2018): Acquired natural killer cell dysfunction in the tumor microenvironment of classic Hodgkin lymphoma. Front Immunol q, 267

Cox TR, Erler JT (2011): Remodeling and homeostasis of the extracellular matrix: implications for fibrotic diseases and cancer. Dis Model Mech 4 , 165-178

Crane GM, Samols MA, Morsberger LA, Yonescu R, Thiess ML, Batista DAS, Ning Y, Burns KH, Vuica-Ross M, Borowitz MJ et al. (2016): Tumor-infiltrating macrophages in post-transplant, relapsed classical Hodgkin lymphoma are donor-derived. PLoS One 11, e0163559

Däbritz J, Weinhage T, Varga G, Wirth T, Walscheid K, Brockhausen A, Schwarzmaier D, Brückner M, Ross M, Bettenworth D et al. (2015): Reprogramming of monocytes by GM-CSF contributes to regulatory immune functions during intestinal inflammation. J Immunol $\underline{194}$, 2424-2438

Deryugina EI, Quigley JP (2008): Chick embryo chorioallantoic membrane model systems to study and visualize human tumor cell metastasis. Histochem Cell Biol 130, 1119-1130

Diefenbach C, Steidl C (2013): New strategies in Hodgkin lymphoma: better risk profiling and novel treatments. Clin Cancer Res 19, 2797-2803

Duluc D, Delneste Y, Tan F, Moles MP, Grimaud L, Lenoir J, Preisser L, Anegon I, Catala L, Ifrah $\mathrm{N}$ et al. (2007): Tumor-associated leukemia inhibitory factor and IL-6 skew monocyte differentiation into tumor-associated macrophage-like cells. Blood 110, 4319-4330

Eberle FC, Mani H, Jaffe ES (2009): Histopathology of Hodgkin's lymphoma. Cancer J 15, 129_ 137

Edwards RH, Dekroon R, Raab-Traub N (2019): Alterations in cellular expression in EBV infected epithelial cell lines and tumors. PLoS Pathog $\underline{15}$, e1008071

Egeblad M, Nakasone ES, Werb Z (2010): Tumors as organs: complex tissues that interface with the entire organism. Dev Cell 18, 884-901

Eichenauer DA, Engert A (2017): Nodular lymphocyte-predominant Hodgkin lymphoma: a unique disease deserving unique management. Hematol Am Soc Hematol Educ Program 2017, $324-328$

El-Gamal MI, Al-Ameen SK, Al-Koumi DM, Hamad MG, Jalal NA, Oh CH (2018): Recent advances of colony-stimulating factor-1 receptor (CSF-1R) kinase and its inhibitors. J Med Chem $\underline{61}, 5450-5466$

Engert A (2016): ABVD or BEACOPP for advanced Hodgkin lymphoma. J Clin Oncol $\underline{34}, 1167-$ 1169

Engert A, Eichenauer DA, Dreyling M, ESMO Guidelines Working Group (2010): Hodgkin's lymphoma: ESMO clinical practice guidelines for diagnosis, treatment and follow-up. Ann Oncol 21 Suppl 5, v168-171

Farrell K, Jarrett RF (2011): The molecular pathogenesis of Hodgkin lymphoma. Histopathology $\underline{58}, 15-25$

Fiete DJ, Beranek MC, Baenziger JU (1998): A cysteine-rich domain of the „mannose“ receptor mediates GalNAc-4-SO4 binding. Proc Natl Acad Sci U S A 모, 2089-2093 
Fischer M, Juremalm M, Olsson N, Backlin C, Sundström C, Nilsson K, Enblad G, Nilsson G (2003): Expression of CCL5/RANTES by Hodgkin and Reed-Sternberg cells and its possible role in the recruitment of mast cells into lymphomatous tissue. Int J Cancer 107, 197201

Ford CA, Petrova S, Pound JD, Voss JJLP, Melville L, Paterson M, Farnworth SL, Gallimore AM, Cuff S, Wheadon H et al. (2015): Oncogenic properties of apoptotic tumor cells in aggressive B cell lymphoma. Curr Biol CB $\underline{25}, 577-588$

Franco V, Tripodo C, Rizzo A, Stella M, Florena AM (2004): Bone marrow biopsy in Hodgkin's lymphoma. Eur J Haematol $\underline{73}, 149-155$

Franklin J, Pluetschow A, Paus M, Specht L, Anselmo AP, Aviles A, Biti G, Bogatyreva T, Bonadonna G, Brillant $C$ et al. (2006): Second malignancy risk associated with treatment of Hodgkin's lymphoma: meta-analysis of the randomised trials. Ann Oncol 17, 1749-1760

Gandhi MK, Lambley E, Duraiswamy J, Dua U, Smith C, Elliott S, Gill D, Marlton P, Seymour J, Khanna R (2006): Expression of LAG-3 by tumor-infiltrating lymphocytes is coincident with the suppression of latent membrane antigen-specific CD8+ T-cell function in Hodgkin lymphoma patients. Blood 108, 2280-2289

Girard J-P, Moussion C, Förster R (2012): HEVs, lymphatics and homeostatic immune cell trafficking in lymph nodes. Nat Rev Immunol $\underline{12}, 762-773$

Glaser SL, Jarrett RF (1996): The epidemiology of Hodgkin's disease. Baillieres Clin Haematol $\underline{9}$, $401-416$

Glaser SL, Lin RJ, Stewart SL, Ambinder RF, Jarrett RF, Brousset P, Pallesen G, Gulley ML, Khan G, O'Grady J et al. (1997): Epstein-Barr virus-associated Hodgkin's disease: epidemiologic characteristics in international data. Int J Cancer $\underline{70}, 375-382$

Glimelius I, Edström A, Fischer M, Nilsson G, Sundström C, Molin D, Amini RM, Enblad G (2005): Angiogenesis and mast cells in Hodgkin lymphoma. Leukemia 19, 2360-2362

Gordon S (2003): Alternative activation of macrophages. Nat Rev Immunol $\underline{3}$, 23-35

Gotti M, Nicola M, Lucioni M, Fiaccadori V, Ferretti V, Sciarra R, Costanza M, Bono E, Molo S, Maffi A et al. (2017): Independent prognostic impact of tumour-infiltrating macrophages in early-stage Hodgkin's lymphoma. Hematol Oncol $\underline{35}$, 296-302

Greaves P, Clear A, Coutinho R, Wilson A, Matthews J, Owen A, Shanyinde M, Lister TA, Calaminici M, Gribben JG (2013): Expression of FOXP3, CD68, and CD20 at diagnosis in the microenvironment of classical Hodgkin lymphoma is predictive of outcome. J Clin Oncol $\underline{31}, 256-262$

Green MR, Monti S, Rodig SJ, Juszczynski P, Currie T, O'Donnell E, Chapuy B, Takeyama K, Neuberg D, Golub TR et al. (2010): Integrative analysis reveals selective 9p24.1 amplification, increased PD-1 ligand expression, and further induction via JAK2 in nodular sclerosing Hodgkin lymphoma and primary mediastinal large B-cell lymphoma. Blood $\underline{116}$, 3268-3277

Grufferman S, Cole P, Smith PG, Lukes RJ (1977): Hodgkin's disease in siblings. N Engl J Med 296, 248-250

Guermazi A, Brice P, de Kerviler E E, Fermé C, Hennequin C, Meignin V, Frija J (2001): Extranodal Hodgkin disease: spectrum of disease. Radiographics 21, 161-179 
Guo B, Cen H, Tan X, Ke Q (2016): Meta-analysis of the prognostic and clinical value of tumorassociated macrophages in adult classical Hodgkin lymphoma. BMC Med 14, 159

Hamel KM, Liarski VM, Clark MR (2012): Germinal center B-cells. Autoimmunity 4ㄷ, 333-347

Hanahan D, Weinberg RA (2000): The hallmarks of cancer. Cell 100, 57-70

Harenberg M: Die Rolle des Transkriptionsfaktors LEF-1 im Hodgkin-Lymphom. Med. Diss. Göttingen 2019

Herold G: Innere Medizin 2017. Gerd Herold (Verlag), Köln 2016

Heusinkveld M, van der Burg SH (2011): Identification and manipulation of tumor associated macrophages in human cancers. J Transl Med $\underline{9}, 216$

Hilhorst M, Shirai T, Berry G, Goronzy JJ, Weyand CM (2014): T cell-macrophage interactions and granuloma formation in vasculitis. Front Immunol $\underline{5}, 432$

Hinz M, Löser P, Mathas S, Krappmann D, Dörken B, Scheidereit C (2001): Constitutive NF-kap$\mathrm{paB}$ maintains high expression of a characteristic gene network, including CD40, CD86, and a set of antiapoptotic genes in Hodgkin/Reed-Sternberg cells. Blood 97, 2798-2807

Hodgkin T (1832): On some morbid appearances of the absorbent glands and spleen. Med Chir Trans 17, 68-114

Hollander P, Rostgaard K, Smedby KE, Molin D, Loskog A, de Nully Brown P, Enblad G, Amini RM, Hjalgrim H, Glimelius I (2018): An anergic immune signature in the tumor microenvironment of classical Hodgkin lymphoma is associated with inferior outcome. Eur J Haematol $\underline{100}, 88-97$

Holtick U, Vockerodt M, Pinkert D, Schoof N, Stürzenhofecker B, Kussebi N, Lauber K, Wesselborg S, Löffler D, Horn F et al. (2005): STAT3 is essential for Hodgkin lymphoma cell proliferation and is a target of tyrphostin AG17 which confers sensitization for apoptosis. Leukemia 19, 936-944

Hoppe RT, Advani RH, Ai WZ, Ambinder RF, Aoun P, Bello CM, Benitez CM, Bernat K, Bierman PJ, Blum KA et al. (2017): Hodgkin lymphoma version 1.2017, NCCN clinical practice guidelines in oncology. J Natl Compr Canc Netw 15, 608-638

Howard MJ, Isacke CM (2002): The C-type lectin receptor Endo180 displays internalization and recycling properties distinct from other members of the mannose receptor family. J Biol Chem 277, 32320-32331

Huber S, Hoffmann R, Muskens F, Voehringer D (2010): Alternatively activated macrophages inhibit T-cell proliferation by Stat6-dependent expression of PD-L2. Blood 116, 3311-3320

Huh J (2012): Epidemiologic overview of malignant lymphoma. Korean J Hematol 47, 92-104

Hummel M, Marafioti T, Ziemann K, Stein H (1996): Ig rearrangements in isolated Reed-Sternberg cells: conclusions from four different studies. Ann Oncol 7 Suppl 4, 31-33

Inghirami G, Macri L, Rosati S, Zhu BY, Yee HT, Knowles DM (1994): The Reed-Sternberg cells

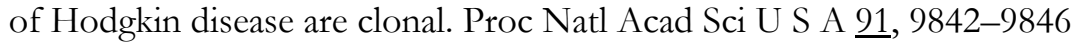

Jiang Q, Akashi S, Miyake K, Petty HR (2000): Lipopolysaccharide induces physical proximity between CD14 and toll-like receptor 4 (TLR4) prior to nuclear translocation of NF-kappa B. J Immunol 165, 3541-3544 
Kanzler H, Küppers R, Hansmann ML, Rajewsky K (1996): Hodgkin and Reed-Sternberg cells in Hodgkin's disease represent the outgrowth of a dominant tumor clone derived from (crippled) germinal center B cells. J Exp Med 184, 1495-1505

Kerkar SP, Restifo NP (2012): Cellular constituents of immune escape within the tumor microenvironment. Cancer Res $\underline{72}, 3125-3130$

Khanna C, Hunter K (2005): Modeling metastasis in vivo. Carcinogenesis 26, $513-523$

Kim SJ, Yoon DH, Kang HJ, Hong JY, Lee HS, Oh SY, Shin H-J, Kong JH, Yi JH, Sakamoto K et al. (2019): Ruxolitinib shows activity against Hodgkin lymphoma but not primary mediastinal large B-cell lymphoma. BMC Cancer $\underline{19}, 1080$

Kiss M, Van Gassen S, Movahedi K, Saeys Y, Laoui D (2018): Myeloid cell heterogeneity in cancer: not a single cell alike. Cell Immunol $\underline{330}, 188-201$

Klingenberg M, Becker J, Eberth S, Kube D, Wilting J (2014): The chick chorioallantoic membrane as an in vivo xenograft model for Burkitt lymphoma. BMC Cancer 14, 339

Koh YW, Park C-S, Yoon DH, Suh C, Huh J (2014): CD163 expression was associated with angiogenesis and shortened survival in patients with uniformly treated classical Hodgkin lymphoma. PLoS One $\underline{9}$, e87066

Koreishi AF, Saenz AJ, Persky DO, Cui H, Moskowitz A, Moskowitz CH, Teruya-Feldstein J (2010): The role of cytotoxic and regulatory T cells in relapsed/refractory Hodgkin lymphoma. Appl Immunohistochem Mol Morphol 18, 206-211

Kowalska M, Tajer J, Chechlinska M, Fuksiewicz M, Kotowicz B, Kaminska J, Walewski J (2012): Serum macrophage colony-stimulating factor (M-CSF) in patients with Hodgkin lymphoma. Med Oncol 르, 2143-2147

Kridel R, Xerri L, Gelas-Dore B, Tan K, Feugier P, Vawda A, Canioni D, Farinha P, Boussetta S, Moccia AA et al. (2015a): The prognostic impact of CD163-positive macrophages in follicular lymphoma: a study from the BC cancer agency and the lymphoma study association. Clin Cancer Res 21, 3428-3435

Kridel R, Steidl C, Gascoyne RD (2015b): Tumor-associated macrophages in diffuse large B-cell lymphoma. Haematologica $\underline{100}, 143-145$

Kryczek I, Zou L, Rodriguez P, Zhu G, Wei S, Mottram P, Brumlik M, Cheng P, Curiel T, Myers L et al. (2006): B7-H4 expression identifies a novel suppressive macrophage population in human ovarian carcinoma. J Exp Med 203, 871-881

Kube D, Holtick U, Vockerodt M, Ahmadi T, Haier B, Behrmann I, Heinrich PC, Diehl V, Tesch H (2001): STAT3 is constitutively activated in Hodgkin cell lines. Blood $\underline{98}$, 762-770

Kuczynski EA, Vermeulen PB, Pezzella F, Kerbel RS, Reynolds AR (2019): Vessel co-option in cancer. Nat Rev Clin Oncol 16, 469-493

Küppers R (2009a): Molecular biology of Hodgkin lymphoma. Hematol Am Soc Hematol Educ Program 491-496

Küppers R (2009b): The biology of Hodgkin's lymphoma. Nat Rev Cancer $\underline{9}$, 15-27

Küppers R, Rajewsky K, Zhao M, Simons G, Laumann R, Fischer R, Hansmann ML (1994): Hodgkin disease: Hodgkin and Reed-Sternberg cells picked from histological sections show 
clonal immunoglobulin gene rearrangements and appear to be derived from $\mathrm{B}$ cells at various stages of development. Proc Natl Acad Sci U S A 1ㅜ, 10962-10966

Küppers R, Engert A, Hansmann ML (2012): Hodgkin lymphoma. J Clin Invest 122, 3439-3447

Lamprecht B, Kreher S, Anagnostopoulos I, Jöhrens K, Monteleone G, Jundt F, Stein H, Janz M, Dörken B, Mathas S (2008): Aberrant expression of the Th2 cytokine IL-21 in Hodgkin lymphoma cells regulates STAT3 signaling and attracts Treg cells via regulation of MIP3alpha. Blood 112, 3339-3347

Lavin Y, Kobayashi S, Leader A, Amir ED, Elefant N, Bigenwald C, Remark R, Sweeney R, Becker CD, Levine JH et al. (2017): Innate immune landscape in early lung adenocarcinoma by paired single-cell analyses. Cell $\underline{169}, 750-765 . e 17$

Lee SJ, Zheng NY, Clavijo M, Nussenzweig MC (2003): Normal host defense during systemic candidiasis in mannose receptor-deficient mice. Infect Immun $\underline{71}, 437-445$

LeMieux MH, Solanki AA, Mahmood U, Chmura SJ, Koshy M (2015): Risk of second malignancies in patients with early-stage classical Hodgkin's lymphoma treated in a modern era. Cancer Med 4, 513-518

Lenz G, Wright G, Dave SS, Xiao W, Powell J, Zhao H, Xu W, Tan B, Goldschmidt N, Iqbal J et al. (2008): Stromal gene signatures in large-B-cell lymphomas. N Engl J Med 359, 23132323

Lievense LA, Cornelissen R, Bezemer K, Kaijen-Lambers MEH, Hegmans JPJJ, Aerts JGJV (2016): Pleural effusion of patients with malignant mesothelioma induces macrophage-mediated $\mathrm{T}$ cell suppression. J Thorac Oncol 11, 1755-1764

Liu WR, Shipp MA (2017): Signaling pathways and immune evasion mechanisms in classical Hodgkin lymphoma. Blood 130, 2265-2270

Liu Y, Sattarzadeh A, Diepstra A, Visser L, van den Berg A (2014): The microenvironment in classical Hodgkin lymphoma: an actively shaped and essential tumor component. Semin Cancer Biol 24, 15-22

Locatelli SL, Careddu G, Serio S, Consonni FM, Maeda A, Viswanadha S, Vakkalanka S, Castagna L, Santoro A, Allavena P et al. (2019): Targeting cancer cells and tumor microenvironment in preclinical and clinical models of Hodgkin lymphoma using the dual PI3K $\delta / \gamma$ inhibitor RP6530. Clin Cancer Res 로, 1098-1112

Lollies A, Hartmann S, Schneider M, Bracht T, Weiß AL, Arnolds J, Klein-Hitpass L, Sitek B, Hansmann ML, Küppers R, Weniger MA (2018): An oncogenic axis of STAT-mediated BATF3 upregulation causing MYC activity in classical Hodgkin lymphoma and anaplastic large cell lymphoma. Leukemia $\underline{32}, 92-101$

Luciani MG, Stoppacciaro A, Peri G, Mantovani A, Ruco LP (1998): The monocyte chemotactic protein a (MCP-1) and interleukin 8 (IL-8) in Hodgkin's disease and in solid tumours. Mol Pathol MP $\underline{51}, 273-276$

Luo Y, Zhou H, Krueger J, Kaplan C, Lee SH, Dolman C, Markowitz D, Wu W, Liu C, Reisfeld RA, Xiang R (2006): Targeting tumor-associated macrophages as a novel strategy against breast cancer. J Clin Invest 116, 2132-2141

Madsen DH, Jürgensen HJ, Siersbæk MS, Kuczek DE, Grey Cloud L, Liu S, Behrendt N, Grøntved L, Weigert R, Bugge TH (2017): Tumor-associated macrophages derived from circulating inflammatory monocytes degrade collagen through cellular uptake. Cell Rep 21, 3662-3671 
Mantovani A, Sica A (2010): Macrophages, innate immunity and cancer: balance, tolerance, and diversity. Curr Opin Immunol 22, 231-237

Mantovani A, Sozzani S, Locati M, Allavena P, Sica A (2002): Macrophage polarization: tumor-associated macrophages as a paradigm for polarized M2 mononuclear phagocytes. Trends Immunol 23, 549-555

Mantovani A, Marchesi F, Malesci A, Laghi L, Allavena P (2017): Tumour-associated macrophages as treatment targets in oncology. Nat Rev Clin Oncol 14, 399-416

Marshall NA, Christie LE, Munro LR, Culligan DJ, Johnston PW, Barker RN, Vickers MA (2004): Immunosuppressive regulatory $\mathrm{T}$ cells are abundant in the reactive lymphocytes of Hodgkin lymphoma. Blood $\underline{103}, 1755-1762$

Martinez FO, Gordon S (2014): The M1 and M2 paradigm of macrophage activation: time for reassessment. F1000Prime Rep $\underline{6}, 13$

Martinez FO, Gordon S, Locati M, Mantovani A (2006): Transcriptional profiling of the human monocyte-to-macrophage differentiation and polarization: new molecules and patterns of gene expression. J Immunol $\underline{177}, 7303-7311$

Martinez-Pomares L (2012): The mannose receptor. J Leukoc Biol 92, 1177-1186

Martinez-Pomares L, Wienke D, Stillion R, McKenzie EJ, Arnold JN, Harris J, McGreal E, Sim RB, Isacke CM, Gordon S (2006): Carbohydrate-independent recognition of collagens by the macrophage mannose receptor. Eur J Immunol $\underline{36}$, 1074-1082

Martín-Moreno AM, Roncador G, Maestre L, Mata E, Jiménez S, Martínez-Torrecuadrada JL, Reyes-García AI, Rubio C, Tomás JF, Estévez M et al. (2015): CSF1R protein expression in reactive lymphoid tissues and lymphoma: its relevance in classical Hodgkin lymphoma. PLoS One $\underline{10}$, e0125203

Mathas S, Hartmann S, Küppers R (2016): Hodgkin lymphoma: Pathology and biology. Semin Hematol $\underline{53}, 139-147$

McKenzie AN, Culpepper JA, de Waal Malefyt R, Brière F, Punnonen J, Aversa G, Sato A, Dang W, Cocks BG, Menon S (1993): Interleukin 13, a T-cell-derived cytokine that regulates human monocyte and B-cell function. Proc Natl Acad Sci U S A 무, 3735-3739

Melkonian G, Munoz N, Chung J, Tong C, Marr R, Talbot P (2002): Capillary plexus development in the day five to day six chick chorioallantoic membrane is inhibited by cytochalasin D and suramin. J Exp Zool 292, 241-254

Menck K, Behme D, Pantke M, Reiling N, Binder C, Pukrop T, Klemm F (2014): Isolation of human monocytes by double gradient centrifugation and their differentiation to macrophages in teflon-coated cell culture bags. J Vis Exp 1ㅜ, e51554

Mills CD, Kincaid K, Alt JM, Heilman MJ, Hill AM (2000): M-1/M-2 macrophages and the Th1/Th2 paradigm. J Immunol 164, 6166-6173

Montanari F, Diefenbach C (2014): Relapsed Hodgkin lymphoma: management strategies. Curr Hematol Malig Rep $\underline{9}$, 284-293

Mosser DM, Edwards JP (2008): Exploring the full spectrum of macrophage activation. Nat Rev Immunol $\underline{8}, 958-969$ 
Mottok A, Steidl C (2018): Biology of classical Hodgkin lymphoma: implications for prognosis and novel therapies. Blood 131, 1654-1665

Murray PJ, Allen JE, Biswas SK, Fisher EA, Gilroy DW, Goerdt S, Gordon S, Hamilton JA, Ivashkiv LB, Lawrence T et al. (2014): Macrophage activation and polarization: nomenclature and experimental guidelines. Immunity $\underline{41}, 14-20$

Nakayama S, Yokote T, Hiraoka N, Nishiwaki U, Hanafusa T, Nishimura Y, Tsuji M (2016): Role of mast cells in fibrosis of classical Hodgkin lymphoma. Int J Immunopathol Pharmacol $\underline{29}, 603-611$

Oishi S, Takano R, Tamura S, Tani S, Iwaizumi M, Hamaya Y, Takagaki K, Nagata T, Seto S, Horii $\mathrm{T}$ et al. (2016): M2 polarization of murine peritoneal macrophages induces regulatory cytokine production and suppresses T-cell proliferation. Immunology 149, 320-328

Pauken KE, Wherry EJ (2015): Overcoming T cell exhaustion in infection and cancer. Trends Immunol $\underline{36}, 265-276$

Pham LV, Pogue E, Ford RJ (2018): The role of macrophage/B-cell interactions in the pathophysiology of B-cell lymphomas. Front Oncol $\underline{8}, 147$

Poppema S (2005): Immunobiology and pathophysiology of Hodgkin lymphomas. Hematology $\underline{2005}, 231-238$

Poppema S, Potters M, Visser L, van den Berg AM (1998): Immune escape mechanisms in Hodgkin's disease. Ann Oncol 9 Suppl 5, S21-24

Pugin J, Heumann ID, Tomasz A, Kravchenko VV, Akamatsu Y, Nishijima M, Glauser MP, Tobias PS, Ulevitch RJ (1994): CD14 is a pattern recognition receptor. Immunity $1,509-516$

Pyonteck SM, Akkari L, Schuhmacher AJ, Bowman RL, Sevenich L, Quail DF, Olson OC, Quick ML, Huse JT, Teijeiro V et al. (2013): CSF-1R inhibition alters macrophage polarization and blocks glioma progression. Nat Med $\underline{19}, 1264-1272$

Re D, Hofmann A, Wolf J, Diehl V, Staratschek-Jox A (2000): Cultivated H-RS cells are resistant to CD95L-mediated apoptosis despite expression of wild-type CD95. Exp Hematol 28, 31-35

Re D, Thomas RK, Behringer K, Diehl V (2005): From Hodgkin disease to Hodgkin lymphoma: biologic insights and therapeutic potential. Blood 105, 4553-4560

Reichel J, Chadburn A, Rubinstein PG, Giulino-Roth L, Tam W, Liu Y, Gaiolla R, Eng K, Brody J, Inghirami $G$ et al. (2015): Flow sorting and exome sequencing reveal the oncogenome of primary Hodgkin and Reed-Sternberg cells. Blood 125, 1061-1072

Ribatti D: The Chick Embryo Chorioallantoic Membrane in the Study of Angiogenesis and Metastasis: The CAM assay in the study of angiogenesis and metastasis. 2010. Auflage; Springer 2010

Ribatti D (2014): The chick embryo chorioallantoic membrane as a model for tumor biology. Exp Cell Res $\underline{328}, 314-324$

Ries CH, Cannarile MA, Hoves S, Benz J, Wartha K, Runza V, Rey-Giraud F, Pradel LP, Feuerhake F, Klaman I et al. (2014): Targeting tumor-associated macrophages with anti-CSF-1R antibody reveals a strategy for cancer therapy. Cancer Cell $\underline{25}$, 846-859

Roemer MGM, Advani RH, Redd RA, Pinkus GS, Natkunam Y, Ligon AH, Connelly CF, Pak CJ, Carey CD, Daadi SE et al. (2016a): Classical Hodgkin lymphoma with reduced $\beta 2 \mathrm{M} / \mathrm{MHC}$ 
class I expression is associated with inferior outcome independent of 9p24.1 status. Cancer Immunol Res 4, 910-916

Roemer MGM, Advani RH, Ligon AH, Natkunam Y, Redd RA, Homer H, Connelly CF, Sun HH, Daadi SE, Freeman GJ et al. (2016b): PD-L1 and PD-L2 genetic alterations define classical Hodgkin lymphoma and predict outcome. J Clin Oncol $\underline{34}$, 2690-2697

Roma-Rodrigues C, Mendes R, Baptista PV, Fernandes AR (2019): Targeting tumor microenvironment for cancer therapy. Int J Mol Sci $\underline{20}$

Ruella M, Klichinsky M, Kenderian SS, Shestova O, Ziober A, Kraft DO, Feldman M, Wasik MA, June CH, Gill S (2017): Overcoming the immunosuppressive tumor microenvironment of Hodgkin lymphoma using chimeric antigen receptor T cells. Cancer Discov $\underline{7}, 1154-1167$

Schaadt M, Fonatsch C, Kirchner H, Diehl V (1979): Establishment of a malignant, Epstein-Barrvirus (EBV)-negative cell-line from the pleura effusion of a patient with Hodgkin's disease. Blut $\underline{38}, 185-190$

Schattner E, Friedman SM (1996): Fas expression and apoptosis in human B cells. Immunol Res $\underline{15}, 246-257$

Scheeren FA, Diehl SA, Smit LA, Beaumont T, Naspetti M, Bende RJ, Blom B, Karube K, Ohshima K, van Noesel CJM, Spits H (2008): IL-21 is expressed in Hodgkin lymphoma and activates STAT5: evidence that activated STAT5 is required for Hodgkin lymphomagenesis. Blood 111, 4706-4715

Schmid C, Pan L, Diss T, Isaacson PG (1991): Expression of B-cell antigens by Hodgkin's and Reed-Sternberg cells. Am J Pathol 139, 701-707

Schmitz N, Pfistner B, Sextro M, Sieber M, Carella AM, Haenel M, Boissevain F, Zschaber R, Müller P, Kirchner H et al. (2002): Aggressive conventional chemotherapy compared with high-dose chemotherapy with autologous haemopoietic stem-cell transplantation for relapsed chemosensitive Hodgkin's disease: a randomised trial. Lancet $\underline{359}$, 2065-2071

Schmitz R, Stanelle J, Hansmann ML, Küppers R (2009): Pathogenesis of classical and lymphocytepredominant Hodgkin lymphoma. Annu Rev Pathol 4, 151-174

Schulz C, Gomez Perdiguero E, Chorro L, Szabo-Rogers H, Cagnard N, Kierdorf K, Prinz M, Wu B, Jacobsen SEW, Pollard JW et al. (2012): A lineage of myeloid cells independent of Myb and hematopoietic stem cells. Science $\underline{336}, 86-90$

Schwering I, Bräuninger A, Klein U, Jungnickel B, Tinguely M, Diehl V, Hansmann ML, Dalla-Favera R, Rajewsky K, Küppers R (2003): Loss of the B-lineage-specific gene expression program in Hodgkin and Reed-Sternberg cells of Hodgkin lymphoma. Blood 101, 1505-1512

Scott DW, Steidl C (2014): The classical Hodgkin lymphoma tumor microenvironment: macrophages and gene expression-based modeling. Hematol Am Soc Hematol Educ Program $\underline{2014}, 144-150$

Sica A, Mantovani A (2012): Macrophage plasticity and polarization: in vivo veritas. J Clin Invest $\underline{122}, 787-795$

Skinnider BF, Mak TW (2002): The role of cytokines in classical Hodgkin lymphoma. Blood $\underline{99}$, 4283-4297 
Skinnider BF, Elia AJ, Gascoyne RD, Trümper LH, von Bonin F, Kapp U, Patterson B, Snow BE, Mak TW (2001): Interleukin 13 and interleukin 13 receptor are frequently expressed by Hodgkin and Reed-Sternberg cells of Hodgkin lymphoma. Blood 97, 250-255

Skinnider BF, Elia AJ, Gascoyne RD, Patterson B, Trumper L, Kapp U, Mak TW (2002a): Signal transducer and activator of transcription 6 is frequently activated in Hodgkin and ReedSternberg cells of Hodgkin lymphoma. Blood 99, 618-626

Skinnider BF, Kapp U, Mak TW (2002b): The role of interleukin 13 in classical Hodgkin lymphoma. Leuk Lymphoma $\underline{43}, 1203-1210$

Sousa S, Mättä J (2016): The role of tumour-associated macrophages in bone metastasis. J Bone Oncol $\underline{5}, 135-138$

Steidl C, Lee T, Shah SP, Farinha P, Han G, Nayar T, Delaney A, Jones SJ, Iqbal J, Weisenburger DD et al. (2010): Tumor-associated macrophages and survival in classic Hodgkin's lymphoma. N Engl J Med $\underline{362}, 875-885$

Steidl C, Connors JM, Gascoyne RD (2011): Molecular pathogenesis of Hodgkin's lymphoma: increasing evidence of the importance of the microenvironment. J Clin Oncol 29, 1812-1826

Stein H, Uchánska-Ziegler B, Gerdes J, Ziegler A, Wernet P (1982): Hodgkin and Sternberg-Reed cells contain antigens specific to late cells of granulopoiesis. Int J Cancer 29, 283-290

Stein H, Marafioti T, Foss HD, Laumen H, Hummel M, Anagnostopoulos I, Wirth T, Demel G, Falini B (2001): Down-regulation of BOB.1/OBF.1 and Oct2 in classical Hodgkin disease but not in lymphocyte predominant Hodgkin disease correlates with immunoglobulin transcription. Blood 97, 496-501

Swerdlow SH, M. D. Campo E, M. D. Harris NL, M. D. Jaffe ES, Pileri SA: WHO classification of tumours of haematopoietic and lymphoid tissues. 4. Auflage; IARC, Lyon 2008

Tataroglu C, Sarioglu S, Kargi A, Ozkal S, Aydin O (2007): Fibrosis in Hodgkin and non-Hodgkin lymphomas. Pathol Res Pract 203, 725-730

Taylor PR, Gordon S, Martinez-Pomares L (2005): The mannose receptor: linking homeostasis and immunity through sugar recognition. Trends Immunol 26, 104-110

Thomas RK, Re D, Zander T, Wolf J, Diehl V (2002): Epidemiology and etiology of Hodgkin's lymphoma. Ann Oncol 13 Suppl 4, 147-152

Thomas RK, Re D, Wolf J, Diehl V (2004): Part I: Hodgkin's lymphoma--molecular biology of Hodgkin and Reed-Sternberg cells. Lancet Oncol $\underline{5}, 11-18$

Trümper LH, Brady G, Bagg A, Gray D, Loke SL, Griesser H, Wagman R, Braziel R, Gascoyne RD, Vicini S (1993): Single-cell analysis of Hodgkin and Reed-Sternberg cells: molecular heterogeneity of gene expression and p53 mutations. Blood $\underline{81}, 3097-3115$

Tsao SW, Tsang CM, Lo KW (2017): Epstein-Barr virus infection and nasopharyngeal carcinoma. Philos Trans R Soc Lond B Biol Sci $\underline{372}, 20160270$

Tudor CS, Bruns H, Daniel C, Distel LV, Hartmann A, Gerbitz A, Buettner MJ (2014): Macrophages and dendritic cells as actors in the immune reaction of classical Hodgkin lymphoma. PLoS One $\underline{9}$, e114345

Twum DYF, Burkard-Mandel L, Abrams SI (2017): The Dr. Jekyll and Mr. Hyde complexity of the macrophage response in disease. J Leukoc Biol 102, 307-315 
Tymoszuk P, Evens H, Marzola V, Wachowicz K, Wasmer MH, Datta S, Müller-Holzner E, Fiegl H, Böck G, van Rooijen N et al. (2014): In situ proliferation contributes to accumulation of tumor-associated macrophages in spontaneous mammary tumors. Eur J Immunol $\underline{44}$, $2247-2262$

Tzankov A, Matter MS, Dirnhofer S (2010): Refined prognostic role of CD68-positive tumor macrophages in the context of the cellular micromilieu of classical Hodgkin lymphoma. Pathobiology $\underline{77}, 301-308$

Vardhana S, Younes A (2016): The immune microenvironment in Hodgkin lymphoma: T cells, B cells, and immune checkpoints. Haematologica 101, 794-802

Vari F, Arpon D, Keane C, Hertzberg MS, Talaulikar D, Jain S, Cui Q, Han E, Tobin J, Bird R et al. (2018): Immune evasion via PD-1/PD-L1 on NK cells and monocyte/macrophages is more prominent in Hodgkin lymphoma than DLBCL. Blood 131, 1809-1819

Varol C, Yona S, Jung S (2009): Origins and tissue-context-dependent fates of blood monocytes. Immunol Cell Biol 구, 30-38

Varol C, Mildner A, Jung S (2015): Macrophages: development and tissue specialization. Annu Rev Immunol $\underline{33}, 643-675$

Vassilakopoulos TP, Chatzidimitriou C, Asimakopoulos JV, Arapaki M, Tzoras E, Angelopoulou MK, Konstantopoulos K (2019): Immunotherapy in Hodgkin lymphoma: present status and future strategies. Cancers $\underline{11}$

Venkataraman G, Mirza MK, Eichenauer DA, Diehl V (2014): Current status of prognostication in classical Hodgkin lymphoma. Br J Haematol 165, 287-299

Verdière L, Mourcin F, Tarte K (2018): Microenvironment signaling driving lymphomagenesis. Curr Opin Hematol 25, 335-345

Vinuesa CG, Linterman MA, Goodnow CC, Randall KL (2010): T cells and follicular dendritic cells in germinal center B-cell formation and selection. Immunol Rev $\underline{237}, 72-89$

Vockerodt M, Soares M, Kanzler H, Küppers R, Kube D, Hansmann ML, Diehl V, Tesch H (1998): Detection of clonal Hodgkin and Reed-Sternberg cells with identical somatically mutated and rearranged VH genes in different biopsies in relapsed Hodgkin's disease. Blood 22, 2899-2907

von Tresckow B, Moskowitz CH (2016): Treatment of relapsed and refractory Hodgkin Lymphoma. Semin Hematol $\underline{53}, 180-185$

Wang M, Zhao J, Zhang L, Wei F, Lian Y, Wu Y, Gong Z, Zhang S, Zhou J, Cao K et al. (2017): Role of tumor microenvironment in tumorigenesis. J Cancer $\underline{8}, 761-773$

Wang Q, Lu Y, Li R, Jiang Y, Zheng Y, Qian J, Bi E, Zheng C, Hou J, Wang S, Yi Q (2018): Therapeutic effects of CSF1R-blocking antibodies in multiple myeloma. Leukemia $\underline{32}, 176-183$

Watanabe K, Yamashita Y, Nakayama A, Hasegawa Y, Kojima H, Nagasawa T, Mori N (2000): Varied B-cell immunophenotypes of Hodgkin/Reed-Sternberg cells in classic Hodgkin's disease. Histopathology $\underline{36}, 353-361$

Weniger MA, Tiacci E, Schneider S, Arnolds J, Rüschenbaum S, Duppach J, Seifert M, Döring C, Hansmann ML, Küppers R (2018): Human CD30+ B cells represent a unique subset related to Hodgkin lymphoma cells. J Clin Invest 128, 2996-3007 
Wilming P: Untersuchungen zur Angiogenese des Burkitt-Lymphoms unter besonderer Berücksichtigung des Lymphocyte Enhancer-binding factor-1. Med. Diss. Göttingen 2017

Wilting J, Becker J, Buttler K, Weich HA (2009): Lymphatics and inflammation. Curr Med Chem $\underline{16}, 4581-4592$

Younes A, Bartlett NL, Leonard JP, Kennedy DA, Lynch CM, Sievers EL, Forero-Torres A (2010): Brentuximab vedotin (SGN-35) for relapsed CD30-positive lymphomas. N Engl J Med $\underline{363}, 1812-1821$

Younes A, Santoro A, Shipp M, Zinzani PL, Timmerman JM, Ansell S, Armand P, Fanale M, Ratanatharathorn V, Kuruvilla J et al. (2016): Nivolumab for classical Hodgkin's lymphoma after failure of both autologous stem-cell transplantation and brentuximab vedotin: a multicentre, multicohort, single-arm phase 2 trial. Lancet Oncol 17, 1283-1294

Yue Y, Huang W, Liang J, Guo J, Ji J, Yao Y, Zheng M, Cai Z, Lu L, Wang J (2015): IL4I1 is a novel regulator of $\mathrm{M} 2$ macrophage polarization that can inhibit $\mathrm{T}$ cell activation via $\mathrm{L}$-tryptophan and arginine depletion and IL-10 production. PLoS One $\underline{10}$, e0142979

Zhang Q, Liu L, Gong C, Shi H, Zeng Y, Wang X, Zhao Y, Wei Y (2012): Prognostic significance of tumor-associated macrophages in solid tumor: a meta-analysis of the literature. PLoS One 7, e50946

Zheng GG, Wu KF, Geng YQ, Kong J, Al-Katib A, Dan M, Chen B (1999): Expression of membrane-associated macrophage colony-stimulating factor (M-CSF) in Hodgkin's disease and other hematologic malignancies. Leuk Lymphoma $\underline{32}$, 339-344

Zhu Y, Knolhoff BL, Meyer MA, Nywening TM, West BL, Luo J, Wang-Gillam A, Goedegebuure SP, Linehan DC, DeNardo DG (2014): CSF1/CSF1R blockade reprograms tumor-infiltrating macrophages and improves response to T-cell checkpoint immunotherapy in pancreatic cancer models. Cancer Res 74, 5057-5069

Zijlstra A, Lewis J, Degryse B, Stuhlmann H, Quigley JP (2008): The inhibition of tumor cell intravasation and subsequent metastasis via regulation of in vivo tumor cell motility by the tetraspanin CD151. Cancer Cell 13, 221-234 


\section{Danksagung}

An allererster Stelle möchte ich mich herzlich bei meinem Doktorvater Herrn Prof. Dr. rer. nat. Dieter Kube für die beständige und ausdauernde Betreuung meines Promotionsvorhabens bedanken. Für die Bereitstellung eines interessanten Themas, die hervorragende Erreichbarkeit und viele konstruktive Gespräche während meiner Laborzeit und im Nachgang bei der Verschriftlichung der Dissertation bin ich sehr dankbar.

Herrn Prof. Dr. med. Lorenz Trümper und Herrn Prof. Dr. med. Gerald Wulf danke ich für die Möglichkeit, in der Klinik für Hämatologie und Medizinische Onkologie promoviert zu werden.

Ein großes Dankeschön gebührt Herrn Prof. Dr. rer. nat. Jörg Wilting für die Zweitbetreuung der Arbeit und wertvolle Kritiken der histologischen Ergebnisse. Ich danke für die Möglichkeit, die Laborräumlichkeiten der Anatomie und die dortige Expertise genutzt haben zu können.

Den Dres. rer. nat. Annekatrin Arlt und Isabel Rausch danke ich für die direkte Betreuung im Labor und die Konzeption der Experimente.

Für ihre technische Unterstützung, die geduldige Einarbeitung und ihre Hilfsbereitschaft danke ich herzlich Frederike von Bonin. Ein großer Dank geht auch an Meike Schaffrinski für das Anlernen der Monozyten-Isolierung.

Darüber hinaus danke ich den Mitarbeiter*innen des Instituts für Anatomie und Zellbiologie. Besonders Berti Manshausen stand mir bei technischen Problemen zur Seite, was ich ihm nicht vergessen werde.

Auch bei der Studienstiftung des deutschen Volkes möchte ich mich für die unkomplizierte Förderverlängerung im Zuge des Forschungssemesters bedanken, und zwar namentlich bei Frau Dr. Dorothea Trebesius und meinem geschätzten Vertrauensdozenten Herrn Prof. Dr. theol. Jan Hermelink.

Abschließend bedanke ich mich bei den anderen Promovend*innen der AG Kube für die spannende gemeinsame Laborzeit. 